\title{
Estabilidad en Variables Nominales y el Ciclo Económico: \\ El Caso de México
}

\author{
Alberto Torres García ${ }^{1}$ \\ Noviembre de 2000 \\ Documento de Investigación No. 2000-03 \\ Dirección General de Investigación Económica \\ BANCO DE MÉXICO
}

\footnotetext{
${ }^{1}$ Se agradecen los comentarios y sugerencias de Armando Baqueiro, Jordi Galí, Laura Greenham, Marie Claude Jean, Kenneth Kuttner, Carlos Medina, Jorge E. Restrepo, Moisés Schwartz, Alejandro Werner y de los participantes en el Seminario de Investigación Económica del Banco de México. También se agradece la asistencia de Sybel Galván, Mercedes Sánchez y especialmente de Francisco Rodríguez en la elaboración de este trabajo. Las opiniones expresadas en este documento corresponden exclusivamente al autor y no necesariamente representan el punto de vista del Banco de México. Correspondencia: atorres@banxico.org.mx
} 


\title{
Estabilidad en Variables Nominales y el Ciclo Económico:
}

\author{
El Caso de México
}

Alberto Torres García

Noviembre de 2000

Documento de Investigación No. 2000-03

\begin{abstract}
RESUMEN
Este artículo documenta las características del ciclo económico en México durante los últimos sesenta años y analiza su relación con la estabilidad de las variables nominales. El análisis se realiza desde una perspectiva empírica y con un énfasis especial en el desempeño de largo plazo de la economía mexicana. De los años cuarenta a los años setenta la economía mexicana experimentó un periodo de crecimiento económico sostenido y de estabilidad en las principales variables nominales. Por el contrario, a partir de los años ochenta se observa una tasa de crecimiento económico menor e inestabilidad en las variables nominales. La inestabilidad nominal no solamente está asociada con un menor crecimiento económico sino que, además, coincide con cambios importantes en las características del ciclo económico. Durante el periodo con estabilidad nominal, el ciclo económico en México es muy similar al de los países industrializados y la relación con el ciclo en Estados Unidos es positiva. Sin embargo, durante el periodo con inestabilidad nominal se encuentran algunas diferencias importantes con respecto a la evidencia de las economías industrializadas y la relación con el ciclo en Estados Unidos es más difícil de identificar. Asimismo, se encuentra que las características del ciclo económico en otros países latinoamericanos, que también han experimentado periodos de inestabilidad nominal, son similares a las observadas en México y, por consiguiente, son diferentes a las observadas en los países industrializados.
\end{abstract}




\section{Indice}

Página

1. Introducción 4

2. Revisión de la Literatura 5

3. Desempeño de Largo Plazo de la Economía Mexicana 7

4. Análisis del Ciclo Económico en México 10

4.1. Características del Ciclo Económico de 1940 a 1979

4.2. Características del Ciclo Económico de 1980 a $1997 \quad 13$

4.3. Resumen de Resultados 17

5. El Ciclo Económico en México y su relación con el Ciclo de Otros Países 17

5.1. México y los Países Industrializados 19

5.1.1. Características de los Ciclos Económicos 19

5.1.2. Relación con el Ciclo Económico de Estados Unidos 21

5.2. México y Otros Países de América Latina 35

5.2.1. Características de los Ciclos Económicos 36

5.2.2. Relación entre los Ciclos Económicos 39

5.3. Resumen de Resultados 45

6. Consideraciones finales 45

Apéndice 1: Fuentes de Datos 48

Bibliografía $\quad 53$ 


\section{Introducción}

El propósito de este artículo es documentar algunas de las características del ciclo económico en México durante los últimos sesenta años y analizar su relación con la estabilidad en las variables nominales. El análisis se realiza desde una perspectiva empírica y con un énfasis especial en el desempeño de largo plazo de la economía mexicana. Asimismo, en este trabajo se describe cómo han evolucionado las características del ciclo económico en México y se intentan identificar las similitudes y diferencias que éstas tienen con respecto a las características del ciclo económico en otros países.

El análisis del ciclo económico en México es particularmente interesante debido a las diferentes etapas de desarrollo por las que la economía ha atravesado. Aproximadamente de los años cuarenta a los años setenta la economía experimentó un proceso de crecimiento económico sostenido y de estabilidad en las principales variables nominales. Por el contrario, durante los años ochenta y parte de los noventa el desempeño de la economía mexicana se caracterizó por altas tasas de inflación, devaluaciones del tipo de cambio y bajo crecimiento económico. La notable diferencia, en términos de crecimiento económico y estabilidad nominal, entre estos dos periodos motiva la siguiente pregunta: ¿es posible asociar la inestabilidad nominal observada en las últimas dos décadas con cambios importantes en las características del ciclo económico en México? En este artículo se intenta documentar si durante las últimas dos décadas las características del ciclo económico en México han cambiado de manera importante.

La economía mexicana presenta una situación muy particular. Por un lado existe una relación importante con la economía de los Estados Unidos (EUA) y por el otro sigue siendo una economía en desarrollo que pertenece al bloque de países latinoamericanos. Esta combinación de factores hace que el estudio del ciclo económico en México pueda ser muy enriquecedor, ya que permite analizar no sólo las similitudes con el ciclo económico de países industrializados sino también su relación con el de países en desarrollo. Por esta razón, en este trabajo además de comparar las características del ciclo económico en México con la evidencia de otros países (industrializados y en desarrollo) se intentan contestar las siguientes dos preguntas: ¿qué relación existe entre los ciclos económicos de México y EUA? y ¿qué relación existe entre el ciclo económico en México y en otros países latinoamericanos?

Para contestar las preguntas antes mencionadas, la discusión está organizada de la siguiente manera. En la sección 2 se presenta una revisión de la literatura en donde se describe la metodología utilizada para el análisis y se identifica la contribución de este trabajo a la literatura de ciclos económicos. En la sección 3 se describe el desempeño de la economía mexicana durante los últimos sesenta años, en términos de crecimiento económico y volatilidad, y se muestra que después de los años setenta la economía experimento bajo crecimiento y mayor volatilidad. En la sección 4 se documentan las características del ciclo económico en México y se analiza si durante las últimas dos décadas han habido cambios importantes en dichas características. Una vez descrito el ciclo económico en México, en la sección 5 se comparan dichos resultados con la evidencia internacional. En la primera parte de esta sección la comparación se hace con la evidencia de los países industrializados y en particular se analiza la relación entre los ciclos 
económicos de México y EUA. En la segunda parte de la sección 5 se documentan las principales características de los ciclos económicos en Argentina, Brasil, Chile, Colombia, Perú y Venezuela y se comparan con la evidencia de México. Asimismo se analiza la relación entre los ciclos económicos de estos países latinoamericanos y México. Finalmente, en la sección 6 se presentan las conclusiones.

\section{$2 \quad$ Revisión de la Literatura}

En esta sección se hace referencia a algunos de los artículos que han documentado la evidencia empírica de los ciclos económicos. El propósito de esta revisión es identificar la contribución de este trabajo a la literatura y describir los aspectos más importantes de la metodología utilizada para el análisis.

En los últimos años el análisis empírico de las características de los ciclos económicos ha seguido la metodología propuesta por Kydland y Prescott [1990]. Dicha metodología consiste en utilizar primero el filtro Hodrick-Prescott (HP) para estimar la tendencia de una variable. ${ }^{2}$ Segundo, siguiendo a Lucas [1977], se calcula el componente cíclico de la variable como la diferencia entre el valor observado y la tendencia. Tercero, se analiza el componente cíclico de cada variable con especial énfasis en dos de sus características:

1. Volatilidad: medida como la desviación estándar.

2. Covariabilidad con el componente cíclico del PIB: medida con coeficientes de correlación cruzada. La covariabilidad de una variable se describe en dos dimensiones: i) dirección de los comovimientos: cuando una variable cambia en la misma dirección que el PIB (coeficiente de correlación positivo) se dice que es procíclica; cuando se mueve en la dirección opuesta (coeficiente de correlación negativo) se dice que es contracíclica; y cuando el coeficiente de correlación es cercano a cero se dice que la variable es no correlacionada; ii) relación de tiempo entre los comovimientos: cuando una variable se mueve antes que el PIB se dice que antecede el ciclo del producto; cuando cambia después que el PIB se dice que sigue al ciclo del producto; y cuando se mueve al mismo tiempo que el PIB se dice que es contemporánea del ciclo del producto.

Después del trabajo de Kydland y Prescott [1990] en el que se documentan algunas de las características del ciclo económico en EUA, Backus y Kehoe [1992] extienden el análisis para diez países industrializados. ${ }^{3}$ El análisis en dicho artículo se realiza con una perspectiva histórica y utiliza datos anuales desde principios de siglo. El periodo de análisis lo dividen en tres partes: antes de la Primera Guerra Mundial, el periodo entre la Primera y la Segunda Guerra Mundial y después de la Segunda Guerra. El trabajo compara los

\footnotetext{
${ }^{2}$ Los detalles técnicos del filtro HP se encuentran en Hodrick-Prescott [1997].

${ }^{3}$ Los países son: Australia, Canadá, Dinamarca, Alemania, Italia, Japón, Noruega, Suecia, Reino Unido y los Estados Unidos.
} 
resultados en cada uno de los periodos y así analiza el cambio en las características del ciclo económico en cada país a lo largo del tiempo. Los resultados sugieren que las características de los ciclos económicos en los diferentes países industrializados son muy similares.

A pesar de que esta área de investigación ha recibido mucha atención en los últimos años, hay pocos estudios para los países latinoamericanos. Posiblemente, las limitaciones impuestas por la calidad de los datos y la inestabilidad económica y política han dificultado la identificación de las características del ciclo económico en estos países. Sin embargo, aún con estas dificultades algunos autores han intentado documentar las características del ciclo económico en países en desarrollo (incluyendo algunos países latinoamericanos). Agenor, McDermott y Prasad [1998] presentan evidencia de doce países en desarrollo. Estos autores encuentran que aunque la volatilidad promedio es mayor en los países en desarrollo, existe una correlación positiva entre los ciclos en los países industrializados y en desarrollo. Por otra parte, Belaisch y Soto [1998] documentan las características del ciclo económico en Chile, Kydland y Zarazaga [1997] lo hacen para el caso de Argentina y Restrepo y Reyes [2000] para el caso de Colombia. ${ }^{6}$

Con respecto a la evidencia para el caso de México, como se mencionó anteriormente, el artículo de Agenor, McDermott y Prasad [1998] incluye a México en la muestra de países analizados. Sin embargo, debido a que el propósito de dicho artículo es documentar las características que son comunes en los países en desarrollo, no analizan de manera comprensiva el ciclo económico en cada país. Por otra parte, la falta de datos homogéneos para los diferentes países los lleva a no incluir en el análisis algunas variables que son importantes en la descripción del ciclo económico, por ejemplo, el consumo y la inversión.

Este trabajo contribuye a la literatura de ciclos económicos con un análisis detallado y comprensivo del ciclo económico en México y de su relación con el ciclo económico en otros países. Este análisis extiende los resultados encontrados en los artículos mencionados anteriormente en seis aspectos: i) la metodología propuesta por Kydland y Prescott [1990] es utilizada para documentar las características del ciclo económico en México ${ }^{7}$; ii) siguiendo a Backus y Kehoe [1992], el análisis se realiza con una perspectiva histórica y se comparan los resultados de dos periodos diferentes; iii) los resultados encontrados para México se comparan con la evidencia documentada por otros autores para países industrializados; iv) se analiza explícitamente la relación entre los ciclos económicos de México y EUA; v) la metodología de Kydland y Prescott [1990] se utiliza para documentar

\footnotetext{
${ }^{4}$ En la sección 5 de este artículo se hace referencia a las características de los ciclos económicos en los países industrializados.

${ }^{5}$ Los países son: Chile, Colombia, India, Corea, Malasia, México, Marruecos, Nigeria, Filipinas, Túnez, Turquía y Uruguay.

${ }^{6}$ En la sección 5 se hace referencia a los resultados reportados en esos artículos.

${ }^{7}$ Es importante mencionar que los resultados presentados en este trabajo no son sensibles al tipo de filtro que se utiliza para calcular la tendencia de las variables. Aunque no se presentan, los ejercicios aquí reportados se realizaron también utilizando el filtro de tasas de crecimiento y los resultados son muy similares a los obtenidos con el filtro HP. La similitud entre los ejercicios con ambos filtros sugiere que los resultados son robustos. Dichos resultados se reportan en Torres [1999].
} 
algunas características de los ciclos económicos en Argentina, Brasil, Chile, Colombia, Perú y Venezuela y los resultados se comparan con la evidencia de México; vi) se analiza la relación entre el ciclo económico en México y en los otros países latinoamericanos.

\section{Desempeño de Largo Plazo de la Economía Mexicana}

En esta sección se describe el desempeño de la economía mexicana durante el último siglo en términos de crecimiento y volatilidad. El propósito es ilustrar que la economía ha atravesado por dos periodos de desarrollo muy diferentes durante los últimos sesenta años. En el primer periodo, que abarca de los años cuarenta a los años setenta, la estabilidad nominal estuvo asociada con un proceso de crecimiento económico sostenido. Por el contrario, en el segundo periodo que incluye los años ochenta y parte de los noventa, la inestabilidad nominal ha estado asociada con bajo crecimiento económico y alta volatilidad.

\section{Gráfica 1}

\section{PIB Real en los EUA y México: 1900-1997}
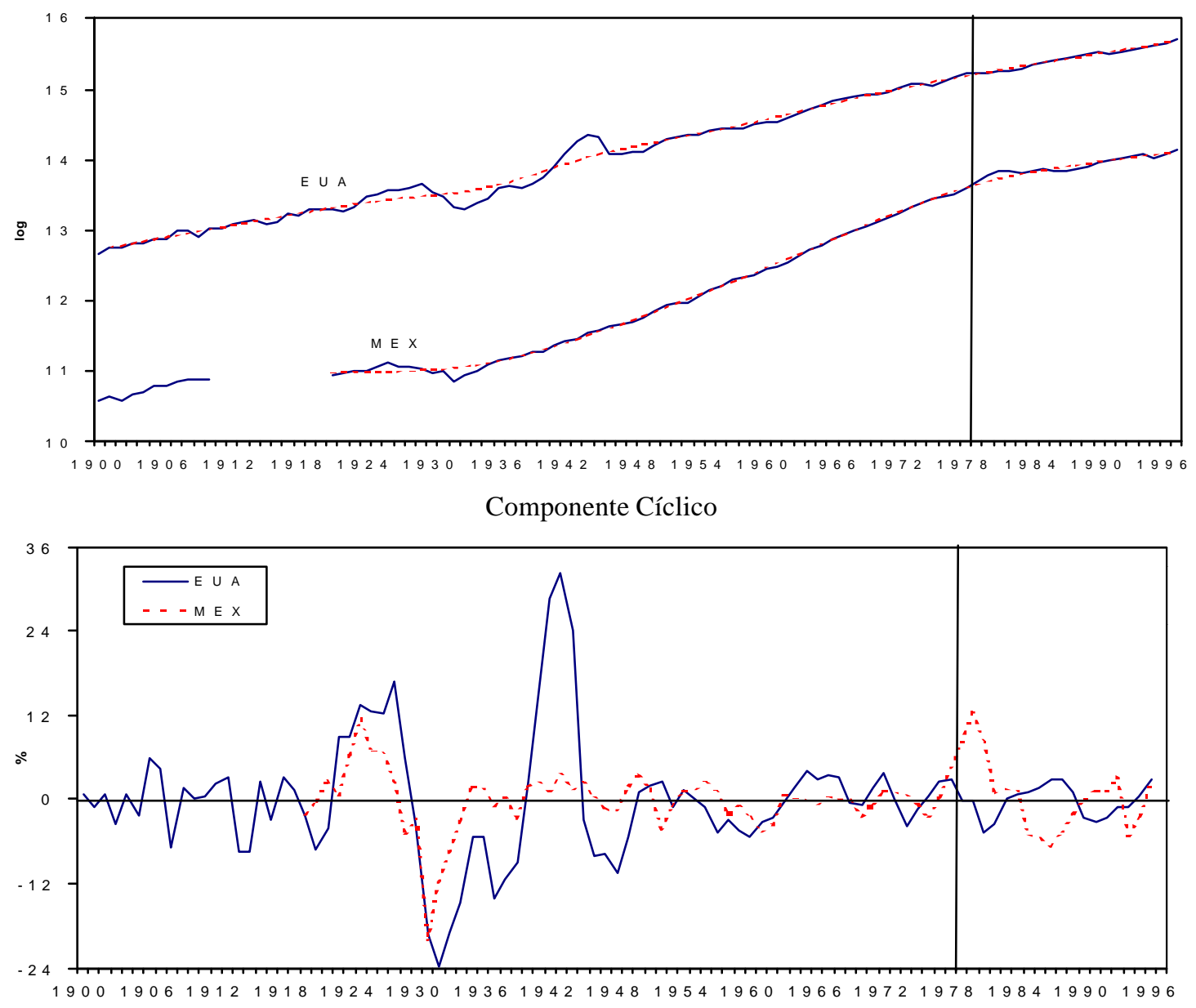
En la Gráfica 1 se presenta la evolución del PIB real en México y EUA desde principios de siglo. Las líneas contínuas representan los datos observados mientras que las líneas punteadas representan la tendencia, que fue calculada con el filtro HP. ${ }^{8}$ Para su estudio, el crecimiento económico en México se puede dividir en tres periodos: de principios de siglo a la gran depresión, de la gran depresión a finales de los años setenta y de principios de la década de los ochenta a finales de los años noventa. Las siguientes estadísticas describen el desempeño de ambas economías en las tres diferentes etapas:

\section{Crecimiento Anual del PIB Real}

\begin{tabular}{c|cc|cc}
\multirow{2}{*}{ Muestra } & \multicolumn{2}{|c|}{ México } & \multicolumn{2}{c}{ EUA } \\
& Media & D. E. & Media & D. E. \\
\hline $1900-1997$ & $4.0 \%$ & $4.5 \%$ & $3.1 \%$ & $6.0 \%$ \\
& & & & \\
$1900-1932$ & $0.9 \%$ & $6.3 \%$ & $2.1 \%$ & $6.8 \%$ \\
$1933-1979$ & $6.0 \%$ & $2.4 \%$ & $4.0 \%$ & $6.3 \%$ \\
$1980-1997$ & $2.5 \%$ & $4.0 \%$ & $2.6 \%$ & $2.0 \%$
\end{tabular}

Durante la primera etapa (1900-1932), el desempeño de la economía mexicana se caracterizó por bajo crecimiento económico y alta volatilidad, medida como la desviación estándar (D.E.). Este resultado probablemente se deba a la inestabilidad política propiciada por la Revolución Mexicana que interrumpió el desarrollo de la economía. El primer cambio importante en la tendencia del crecimiento se da después de la Gran Depresión. A partir de ese momento, de 1933 a 1979, el desempeño de la economía se caracteriza por un mayor crecimiento económico y una menor volatilidad. Asimismo, es interesante observar que mientras la Segunda Guerra Mundial afectó el desempeño de la economía de los EUA, ésta parece no haber tenido un efecto importante en la economía mexicana. El siguiente cambio importante en la tendencia de crecimiento en México ocurre a finales de los años setenta. De 1980 a 1997 ambas economías experimentaron una reducción importante en sus tasas de crecimiento. Aún cuando la disminución en la tasa de crecimiento en México es mayor que en los EUA, la diferencia más importante entre ambas economías es la volatilidad. Mientras que la volatilidad en los EUA disminuyó considerablemente, en México se incrementó casi al doble de lo que había sido en el periodo anterior. Este incremento en la volatilidad del PIB mexicano está asociado con cuatro eventos importantes: la crisis de la deuda en 1982, el plan de estabilización adoptado por el gobierno en 1987, la crisis financiera de 1995 y la estabilización posterior.

Hasta el momento se ha descrito el desempeño de la economía mexicana en términos del crecimiento del PIB real. A continuación se muestra que el bajo crecimiento económico observado después de los años setenta está asociado con mayores tasas de inflación, depreciaciones recurrentes del tipo de cambio y mayor volatilidad. En el cuadro 1 se describen el crecimiento y la volatilidad de algunas variables macroeconómicas de la economía mexicana. El análisis comienza en 1940 ya que no existen datos disponibles antes de dicha fecha para la mayor parte de las variables.

\footnotetext{
${ }^{8}$ Para la estimación el parámetro $\lambda$ del filtro HP se fijó en 400.
} 


\section{Cuadro 1}

\section{Variables Macroeconómicas de México en Tasas de Crecimiento}

\begin{tabular}{|l|c|c|c|c|c|c|}
\hline & \multicolumn{3}{|c|}{ Media (\%) } & \multicolumn{3}{c|}{ Desviación Estándar (\%) } \\
\hline & $1940-1997$ & $1940-1979$ & $1980-1997$ & $1940-1997$ & $1940-1979$ & $1980-1997$ \\
\hline PIB & 4.95 & 6.05 & 2.51 & 3.38 & 2.35 & 4.08 \\
Consumo Privado & 6.64 & 5.66 & 2.37 & 4.21 & 3.37 & 5.05 \\
Consumo del Gobierno & 5.10 & 5.89 & 3.36 & 6.14 & 6.43 & 5.19 \\
Inversión & 6.54 & 8.83 & 1.45 & 13.06 & 10.80 & 16.27 \\
Importaciones & 6.49 & 6.22 & 7.10 & 16.88 & 13.57 & 23.08 \\
Exportaciones & 6.15 & 5.01 & 8.70 & 9.94 & 9.28 & 11.12 \\
Nominal & & & & & & \\
B y M & 20.62 & 13.79 & 35.80 & 17.12 & 10.20 & 19.75 \\
M1 & 21.92 & 15.03 & 37.22 & 17.50 & 9.57 & 21.38 \\
M3 & 24.09 & 16.95 & 39.96 & 18.18 & 11.51 & 20.44 \\
Real & & & & & & \\
B y M & 3.46 & 5.21 & -0.42 & 10.22 & 8.04 & 13.35 \\
M1 & 4.75 & 6.45 & 0.99 & 13.61 & 7.98 & 21.30 \\
M3 & 6.93 & 8.37 & 3.72 & 11.36 & 10.95 & 11.93 \\
Velocidad & & & & & & \\
B y M & 1.47 & 1.14 & 2.21 & 9.41 & 9.51 & 9.41 \\
M1 & 0.17 & -0.09 & 0.79 & 12.30 & 9.62 & 17.15 \\
M3 & -1.99 & -0.02 & -1.94 & 10.98 & 11.52 & 9.97 \\
Tipo de Cambio Nominal & 12.63 & 3.70 & 32.49 & 26.34 & 10.40 & 38.37 \\
Tipo de Cambio Real & 0.62 & 0.74 & 0.39 & 14.36 & 9.03 & 21.29 \\
IPC & & & & & & \\
Deflactor del PIB & 17.16 & 8.58 & 36.23 & 19.80 & 7.59 & 24.99 \\
\hline
\end{tabular}

Del primer (1940-1979) al segundo (1980-1997) periodo, el consumo privado, el consumo del gobierno y especialmente la inversión experimentaron una reducción en su tasa de crecimiento. Por el contrario, tanto las importaciones como las exportaciones experimentaron un incremento en su tasa de crecimiento, que es congruente con la mayor apertura que la economía ha experimentado desde que México ingresó al GATT en 1986. La volatilidad de casi todas las variables es mayor en el segundo periodo. Dicho aumento en volatilidad está asociado con un incremento considerable en la inflación y en la tasa promedio de depreciación del tipo de cambio nominal. Con respecto a los agregados monetarios, el crecimiento en términos nominales es mayor durante el segundo periodo mientras que en términos reales disminuye. Los efectos de mayores tasas de inflación y depreciaciones recurrentes del tipo de cambio también se ven reflejados en mayor volatilidad en los agregados monetarios.

En el Cuadro 2 se describen las variables expresadas como porcentaje del PIB. Del primero al segundo periodo, se observa una reducción importante en la proporción promedio del consumo privado, que se ve acompañada de un incremento en la proporción promedio del consumo del gobierno, la inversión, las importaciones y las exportaciones. La volatilidad relativa del consumo privado y del gobierno, así como de la inversión, no 
cambian de manera significativa. Sin embargo, es interesante observar que la volatilidad relativa de las importaciones y exportaciones es dos veces más grande en el segundo periodo. Este resultado combinado con el incremento en la volatilidad del tipo de cambio (Cuadro 1) sugiere que en el primer periodo el comportamiento de las importaciones y exportaciones fue influenciado principalmente por el nivel de actividad económica (PIB), mientras que en el segundo periodo su mayor volatilidad obedeció a las fluctuaciones en el tipo de cambio y a la inestabilidad generada por las crisis financieras experimentadas durante las últimas dos décadas

\section{Cuadro 2}

Variables Macroeconómicas de México como Porcentaje del PIB

\begin{tabular}{|l|c|c|c|c|c|c|}
\hline & \multicolumn{3}{|c|}{ Media (\%) } & \multicolumn{3}{c|}{ Desviación Estándar (\%) } \\
\hline & $1940-1997$ & $1940-1979$ & $1980-1997$ & $1940-1997$ & $1940-1979$ & $1980-1997$ \\
\hline & & & & & \\
Consumo Privado & 72.92 & 75.59 & 67.00 & 5.80 & 4.35 & 3.94 \\
Consumo del Gob. & 8.77 & 7.75 & 11.02 & 1.72 & 0.91 & 0.52 \\
Inversión & 17.40 & 16.98 & 18.34 & 3.49 & 3.57 & 3.18 \\
Importaciones & 13.35 & 12.90 & 14.33 & 4.35 & 2.98 & 6.45 \\
Exportaciones & 12.74 & 11.00 & 16.61 & 4.13 & 2.11 & 4.90 \\
& & & & & & \\
B y M & 4.75 & 5.29 & 3.55 & 1.49 & 1.47 & 0.46 \\
M1 & 10.66 & 11.52 & 8.75 & 2.35 & 1.95 & 2.03 \\
M3 & 22.44 & 17.45 & 33.54 & 8.37 & 3.79 & 3.63 \\
\hline
\end{tabular}

Con respecto al dinero, expresado como porcentaje del PIB nominal (o sea el inverso de la velocidad del dinero), la reducción en los agregados monetarios líquidos, billetes y monedas (ByM) y M1, es congruente con las mayores tasas de inflación observadas en el segundo periodo. Por el contrario, el incremento en el porcentaje que M3 representa del PIB nominal, además de reflejar la revaloración de los instrumentos denominados en moneda extranjera, sugiere un incremento en la intermediación financiera. Es interesante observar que la volatilidad de ByM, como porcentaje del PIB, es tres veces más grande en el primer periodo. Este resultado sugiere que durante el segundo periodo la relación entre ByM y el producto es más estable.

La evidencia presentada en esta sección describe el desempeño de la economía mexicana en términos de crecimiento y volatilidad. La inestabilidad nominal (mayor inflación y depreciaciones recurrentes del tipo de cambio) observada durante el segundo periodo está asociada con bajo crecimiento económico y mayor volatilidad. En la siguiente sección se intenta identificar si esta inestabilidad nominal también se puede asociar con cambios importantes en las características del ciclo económico en México.

\section{Análisis del Ciclo Económico en México}

En esta sección se documentan las características del ciclo económico en México durante dos periodos: 1940-1979 y 1980-1997. Al comparar los resultados de ambos periodos se pueden identificar aquellos cambios en las características del ciclo económico 
que coinciden con el bajo crecimiento económico y la inestabilidad de las variables nominales.

\subsection{Características del Ciclo Económico de 1940 a 1979}

A continuación se presentan las principales características del ciclo económico mexicano de 1940 a 1979. Los datos utilizados para el análisis son anuales y en el apéndice 1 de este trabajo se incluye una descripción detallada de cada una de las variables utilizadas y de sus respectivas fuentes.

Como se mencionó anteriormente, el componente cíclico de cada una de las variables se estima como la diferencia entre el valor observado de la variable y su tendencia. ${ }^{9}$ Se consideran dos tipos de características. La primera es la volatilidad (desviación estándar) de cada variable, medida en este caso con respecto a la volatilidad del PIB. La segunda característica de interés es la covariabilidad (correlación cruzada) de cada variable con el PIB. Los resultados se reportan en el Cuadro 3.

Variables Reales. En el Cuadro 3 se puede observar que la volatilidad del consumo privado, consumo del gobierno, inversión, importaciones y exportaciones es mayor que la volatilidad del PIB (2\%). ${ }^{10}$ Con respecto a los coeficientes de correlación cruzada, el consumo privado es, de acuerdo a lo esperado, procíclico y contemporáneo (0.73). Asimismo, se observa que el consumo del gobierno también es procíclico y contemporáneo al PIB (0.40). Por su parte, la inversión es procíclica y al parecer sigue al producto con un periodo de rezago (0.39). Con respecto a las importaciones y exportaciones ambas son procíclicas, sin embargo, mientras que las importaciones son contemporáneas (0.43) las exportaciones parecen anteceder el ciclo (0.38).

Agregados Monetarios. El análisis incluye tres agregados monetarios: ByM, M1 y M3. ${ }^{11}$ La relación entre el ciclo del producto y cada una de las definiciones de dinero parece ser muy similar. En términos nominales, su volatilidad relativa a la del producto es 5.8, 6.2 y 6.9 respectivamente. Con respecto a los coeficientes de correlación cruzada, el dinero en términos nominales parece ser procíclico y contemporáneo al PIB $(0.13,0.22$ y 0.22 respectivamente). Por otra parte, los resultados también sugieren que el dinero en términos reales es procíclico (0.42) pero en este caso antecede el ciclo en un periodo. La evidencia con respecto a que la velocidad del dinero es contracíclica (-0.39) y antecede el ciclo en un periodo, confirma el carácter procíclico de la cantidad real de dinero, ya que de acuerdo con la teoría cuantitativa del dinero $(M V=P Y)$, cuando la cantidad real de dinero $(M / P)$ crece más rápido que el producto $(Y)$, la velocidad $(V)$ decrece.

\footnotetext{
${ }^{9}$ Debido a que las variables están expresadas en logaritmos, las fluctuaciones cíclicas representan el porcentaje por arriba o por debajo de la tendencia.

${ }^{10}$ El hecho de que la volatilidad del consumo sea mayor que la volatilidad del producto es contrario a la recomendación teórica acerca del suavizamiento del consumo de bienes no durables. Es posible que la alta volatilidad se deba al consumo de bienes durables; sin embargo, no se cuenta con la información suficiente para probar esta hipótesis.

${ }^{11}$ Adicionalmente se analizaron otros dos agregados monetarios: depósitos en cuentas de cheques (M1-ByM) e instrumentos de ahorro financiero con madurez de menos de un año (M3-M1). Los resultados no se presentan porque las conclusiones no son diferentes a las que se obtienen del análisis de ByM, M1 y M3.
} 


\section{Cuadro 3}

\section{Características de las Fluctuaciones Cíclicas \\ Datos Anuales: 1940-1979}

\begin{tabular}{|c|c|c|c|c|c|c|c|c|c|c|c|}
\hline \multirow[t]{3}{*}{ Variable $\mathrm{X}$} & \multirow{3}{*}{$\begin{array}{c}\text { Desv. } \\
\text { Est. } \\
(\%)\end{array}$} & \multirow{3}{*}{$\begin{array}{c}\text { Desv. Est } \\
\text { relativa } \\
\text { al PIB }\end{array}$} & \multicolumn{9}{|c|}{ Correlación Cruzada del PIB con } \\
\hline & & & \multicolumn{4}{|c|}{ Rezagos } & & \multicolumn{4}{|c|}{ Adelantos } \\
\hline & & & $X_{t-4}$ & $X_{t-3}$ & $X_{t-2}$ & $X_{t-1}$ & $X_{t}$ & $X_{t+1}$ & $X_{t+2}$ & $X_{t+3}$ & $X_{t+4}$ \\
\hline PIB & 2.02 & 1.00 & & & & & & & & & \\
\hline Consumo Privado & 2.84 & 41 & -0.14 & -0.29 & -0.32 & 0.13 & 0.73 & 0.51 & 0.25 & 0.04 & -0.15 \\
\hline Cons. del Gob. & 5.30 & 2.62 & -0.22 & 0.00 & 0.16 & 0.33 & 0.40 & 0.16 & -0.24 & -0.26 & -0.28 \\
\hline Inversión & 11.01 & 5.45 & 0.26 & -0.06 & -0.36 & -0.13 & 0.33 & 0.39 & 0.11 & -0.16 & -0.24 \\
\hline Importa & 13.22 & 6.54 & 0.06 & -0.26 & -0.46 & -0.08 & 0.43 & 0.42 & 0.11 & -0.18 & -0.27 \\
\hline Exportacic & 7.51 & 3.72 & -0.23 & -0.40 & 0.03 & 0.38 & 0.32 & -0.00 & -0.41 & -0.43 & -0.02 \\
\hline \multicolumn{12}{|l|}{ Nominal } \\
\hline B y M & 11.68 & 5.78 & -0.40 & -0.41 & -0.24 & 0.01 & 0.13 & -0.16 & -0.23 & -0.22 & -0.03 \\
\hline M1 & 12.46 & 6.17 & -0.46 & -0.50 & -0.23 & 0.12 & 0.22 & -0.08 & -0.33 & -0.30 & -0.04 \\
\hline M3 & 13.97 & 6.92 & -0.25 & -0.30 & -0.06 & 0.24 & 0.22 & -0.05 & -0.28 & -0.26 & -0.0 \\
\hline \multicolumn{12}{|l|}{ Real } \\
\hline B y & 7.45 & 3.69 & -0.15 & 0.01 & 0.36 & 0.42 & 0.23 & -0.21 & -0.04 & -0.08 & -0.02 \\
\hline M1 & 8.64 & 4.28 & -0.26 & -0.12 & 0.34 & 0.52 & 0.32 & -0.06 & -0.14 & -0.15 & -0.05 \\
\hline M3 & 12.64 & 6.26 & 0.00 & 0.10 & 0.43 & 0.50 & 0.21 & -0.01 & -0.06 & -0.07 & -0.0 \\
\hline \multicolumn{12}{|l|}{ Velocidad } \\
\hline B y $M$ & 9.01 & 4.46 & 0.20 & 0.04 & -0.24 & -0.39 & -0.11 & 0.15 & 0.10 & 0.06 & -0.02 \\
\hline M1 & 9.50 & 4.70 & 0.30 & 0.17 & -0.24 & -0.50 & -0.22 & 0.05 & 0.21 & 0.14 & 0.00 \\
\hline M3 & 12.27 & 6.07 & 0.05 & -0.05 & -0.37 & -0.52 & -0.16 & 0.01 & 0.12 & 0.08 & 0.01 \\
\hline T. de C. N & 13.12 & & -0.27 & -0.15 & 0.09 & 0.13 & -0 . & -0.38 & -0.34 & -0.09 & 0.0 \\
\hline T. de C. Real & 8.88 & 4.40 & -0.45 & -0.17 & 0.30 & 0.25 & -0.08 & -0.29 & 0.00 & 0.26 & 0.22 \\
\hline IPC & 10.24 & 5.07 & -0.33 & -0.48 & -0.58 & -0.35 & -0.00 & -0.03 & -0.20 & -0.18 & -0.02 \\
\hline Deflactor del PIB & 10.22 & 5.06 & -0.20 & -0.37 & -0.52 & -0.51 & -0.17 & -0.14 & -0.14 & 0.12 & 0.00 \\
\hline
\end{tabular}

Tipos de Cambio. La volatilidad relativa de los tipos de cambio nominal y real es 6.5 y 4.4 respectivamente. Es interesante observar que dicha volatilidad es menor que la de los agregados monetarios nominales lo que sugiere un comportamiento más estable del tipo de cambio, que probablemente se debe al régimen de tipo de cambio predeterminado que prevaleció durante este periodo. Dado que el tipo de cambio está definido como pesos por dólar, un incremento representa una depreciación y viceversa. Por consiguiente, una correlación positiva entre el tipo de cambio y el ciclo económico sugiere que las depreciaciones son procíclicas. De esta manera, el patrón observado en los tipos de cambio nominal y real no es claro, ya que primero ambos anteceden el ciclo en forma procíclica (0.13 y 0.30 respectivamente) y luego ambos siguen el ciclo en forma contracíclica (-0.38 y -0.29 respectivamente).

Precios. Se consideran dos indicadores del nivel de precios: el índice de precios al consumidor y el deflactor implícito del PIB. Los resultados son robustos bajo las dos definiciones. La volatilidad relativa de ambos índices es 5.07 y 5.06 respectivamente. Con 
respecto a los coeficientes de correlación cruzada la evidencia indica que los precios en México son contracíclicos y que anteceden el ciclo (-0.58 y -0.52). Este resultado sugiere que las fluctuaciones del PIB en México se deben principalmente a movimientos de oferta y no de demanda.

\subsection{Características del Ciclo Económico de 1980 a 1997}

A continuación se documentan las características del ciclo económico en México de 1980 a 1997 y se comparan con la evidencia del periodo 1940-1979 discutida en la sección anterior. El propósito es identificar si la inestabilidad nominal que se observa después de 1980 coincide con cambios importantes en las características del ciclo económico.

Con la finalidad de utilizar un mayor número de observaciones, en esta sección la frecuencia de los datos es trimestral y éstos también se encuentran descritos en el apéndice 1. ${ }^{12}$ La comparación directa de la desviación estándar y de los coeficientes de correlación de este ejercicio con los de la sección anterior puede ser engañosa debido a que los datos tienen una periodicidad diferente. Por consiguiente, dicha comparación se realiza en términos de la volatilidad de cada variable en relación con la volatilidad del PIB; y en el caso de los coeficientes de correlación, los resultados se comparan desde un punto de vista cualitativo (dirección y relación en el tiempo de los comovimientos) y no en términos del valor absoluto de los coeficientes de correlación. En el Cuadro 4 se presentan dichos resultados.

Variables Reales. La volatilidad del componente cíclico de cada una de estas variables con respecto al PIB es menor en el periodo 1980-1997 (Cuadro 4) que en el periodo 1940-1979 (Cuadro 3). Posiblemente, el desarrollo del mercado financiero haya suavizado el efecto que los choques que ha sufrido la economía mexicana pudieran haber tenido sobre los diferentes componentes del producto. Este resultado sugiere que la alta volatilidad observada en la mayoría de las variables a partir de 1980 (Cuadros 1 y 2) no se debe a una mayor volatilidad en el componente cíclico de las mismas. Por otra parte, los resultados de los coeficientes de correlación cruzada para el periodo 1980-1997 son congruentes con la evidencia del periodo 1940-1979. Sin embargo, a partir de 1980 las exportaciones parecen ser contracíclicas. Este resultado es contrario a lo encontrado en el periodo anterior. El hecho de que las importaciones y exportaciones se muevan en direcciones opuestas sugiere que la actividad económica (PIB) no es la fuerza que predomina sobre estas dos variables. Como se mencionó anteriormente, la inestabilidad nominal y las crisis financieras experimentadas durante el segundo periodo parecen haber influido de manera importante sobre el comportamiento de las exportaciones e importaciones.

\footnotetext{
${ }^{12}$ Los datos fueron desestacionalizados siguiendo el método descrito por Gujarati [1995], p.517.
} 


\section{Cuadro 4}

\section{Características de las Fluctuaciones Cíclicas \\ Datos Trimestrales: 1980:03 - 1997:04}

\begin{tabular}{|c|c|c|c|c|c|c|c|c|c|c|c|}
\hline \multirow[t]{3}{*}{ Variable X } & \multirow{3}{*}{$\begin{array}{l}\text { Desv. } \\
\text { Est. } \\
(\%) \\
\end{array}$} & \multirow{3}{*}{$\begin{array}{c}\text { Desv. Est } \\
\text { relativa } \\
\text { al PIB } \\
\end{array}$} & \multicolumn{9}{|c|}{ Correlación Cruzada del PIB con } \\
\hline & & & \multicolumn{4}{|c|}{ Rezagos } & & \multicolumn{4}{|c|}{ Adelantos } \\
\hline & & & $X_{t-4}$ & $\mathrm{X}_{\mathrm{t}-3}$ & $\mathrm{X}_{\mathrm{t}-2}$ & $\mathrm{X}_{\mathrm{t}-1}$ & $X_{t}$ & $X_{t+1}$ & $X_{t+2}$ & $X_{t+3}$ & $X_{t+4}$ \\
\hline PIB & 2.60 & 1.00 & & & & & & & & & \\
\hline Consumo Privado & 3.24 & 1.25 & -0.02 & 0.15 & 0.38 & 0.59 & 0.90 & 0.71 & 0.50 & 0.16 & 0.16 \\
\hline Cons. del & 4.44 & 1.71 & 0.13 & -0.03 & 0.26 & 0.19 & 0.45 & 0.12 & 0.07 & 0.00 & 0.22 \\
\hline Inversión & 10.92 & 4.20 & -0.02 & 0.17 & 0.48 & 0.72 & 0.89 & 0.65 & 0.43 & 0.11 & -0.05 \\
\hline Importaciones & 14.63 & 5.63 & 0.02 & 0.31 & 0.47 & 0.59 & 0.56 & 0.41 & 0.20 & -0.07 & -0.27 \\
\hline Exportaciones & 6.75 & 2.60 & -0.09 & -0.03 & -0.23 & -0.41 & -0.46 & -0.40 & -0.22 & -0.13 & -0.18 \\
\hline Nomir & & & & & & & & & & & \\
\hline B y & 10.94 & 4.21 & 0.13 & 0.01 & 0.02 & 0.01 & 0.00 & -0.07 & -0.11 & -0.21 & -0.26 \\
\hline M1 & 12.77 & 1 & 0.22 & 0.25 & 0.34 & 0.35 & 0.29 & 0.19 & 0.11 & -0.02 & -0.11 \\
\hline M3 & 10.78 & 4.15 & 0.17 & 0.07 & 0.01 & -0.05 & -0.08 & -0.17 & -0.25 & -0.36 & -0.40 \\
\hline Real & & & & & & & & & & & \\
\hline B y M & 8.20 & 3.15 & -0.21 & -0.08 & -0.22 & 0.50 & 0.69 & 0.68 & 0.60 & 0.42 & 0.29 \\
\hline M1 & 13.83 & 5.32 & -0.02 & 0.17 & 0.42 & 0.60 & 0.67 & 0.63 & 0.54 & 0.38 & 0.27 \\
\hline M3 & 7.38 & 2.84 & -0.17 & -0.00 & 0.23 & 0.46 & 0.65 & 0.62 & 0.46 & 0.25 & 0.11 \\
\hline Velo & & & & & & & & & & & \\
\hline B y & 5.80 & 2.23 & 0.28 & 0.20 & -0.02 & -0.29 & -0.38 & -0.55 & -0.55 & -0.48 & -0.34 \\
\hline M1 & 12.23 & 4.70 & 0.01 & -0.15 & -0.34 & -0.48 & -0.48 & -0.52 & -0.47 & -0.38 & -0.27 \\
\hline M3 & 4.82 & 1.85 & 0.25 & 0.10 & 0.00 & -0.19 & -0.28 & -0.45 & -0.36 & -0.25 & -0.09 \\
\hline T. de C. I & 17.38 & & -0 . & -0.37 & -0.59 & -0.71 & -0.60 & -0.47 & -0.39 & -0.28 & -0.18 \\
\hline T. de C. Real & 12.21 & 4.70 & -0.35 & -0.58 & -0.69 & -0.66 & -0.36 & -0.11 & -0.00 & 0.10 & 0.18 \\
\hline Tasa d & 15.28 & 5.88 & -0.33 & -0.42 & -0.50 & -0.52 & -0.39 & -0.20 & -0.07 & 0.03 & 0.12 \\
\hline Tasa de Int. Real & 12.08 & 4.65 & 0.23 & 0.14 & 0.08 & -0.17 & -0.31 & -0.38 & -0.25 & -0.16 & -0.01 \\
\hline IPC & 13.07 & & 0. & 0.06 & -0.11 & -0.30 & -0.43 & -0.49 & -0.47 & -0.45 & -0.40 \\
\hline Deflac & 12.32 & 4.74 & 0.24 & 0.09 & -0.08 & -0.25 & -0.38 & -0.45 & -0.46 & -0.44 & -0.41 \\
\hline Salario & 12.28 & 4.72 & 0.18 & 0.01 & -0.05 & -0.20 & -0.27 & -0.35 & -0.32 & -0.40 & -0.41 \\
\hline Salario Real & 5.57 & 2.24 & -0.16 & -0.12 & 0.15 & 0.26 & 0.41 & 0.36 & 0.39 & 0.16 & 0.02 \\
\hline
\end{tabular}

Agregados Monetarios. La volatilidad relativa del componente cíclico de los agregados monetarios también es menor durante el periodo 1980-1997 que de 1940 a 1979. Este resultado sugiere que el componente cíclico del dinero no es responsable de la mayor volatilidad observada después de 1980 (comparar con Cuadro 3). Los resultados para las variables expresadas en tasas de crecimiento ${ }^{13}$ son congruentes con esta hipótesis. En tasas de crecimiento (incluyen el componente cíclico y el de tendencia) la cantidad de dinero es más volátil después de 1980. Por consiguiente, el componente de tendencia es el que presenta una mayor volatilidad mientras que el componente cíclico presentó una menor volatilidad. Por otra parte, los coeficientes de correlación cruzada para la cantidad nominal

\footnotetext{
${ }^{13}$ Ver Torres [1999].
} 
de dinero son bajos e indican que no hay correlación con el ciclo del producto (Agenor, McDermott y Prasad [1998] encuentran un resultado similar). Con respecto al tiempo de los comovimientos entre la cantidad real de dinero y el producto, a partir de 1980 se observa una diferencia importante con respecto a la evidencia del periodo 1940-1979. Aún cuando en ambos periodos la cantidad real de dinero es procíclica, ésta pasó de anteceder el ciclo durante el periodo anterior a 1979 a ser contemporánea a partir de 1980. De la misma manera, aún cuando la velocidad del dinero es contracíclica en ambos periodos, en el segundo ya no antecede el ciclo. Estos resultados sugieren que a partir de 1980 los agentes económicos comenzaron a ajustar los precios más rápido.

Tipos de Cambio. Los tipos de cambio nominal y real son las únicas variables durante el periodo 1980-1997 con una volatilidad relativa del componente cíclico que es mayor que la observada durante el periodo 1940-1979. Con respecto a los coeficientes de correlación cruzada, la evidencia indica que a partir de 1980 los tipos de cambio son altamente contracíclicos (-0.71 y -0.69 respectivamente) y que anteceden el ciclo (Agenor, McDermott y Prasad [1998] reportan el mismo resultado). Estos resultados son contrarios a la evidencia del periodo 1940-1979 cuando los tipos de cambio antecedían el ciclo de manera procíclica y luego lo seguían de manera contracíclica. El hecho de que los tipos de cambio sean contracíclicos se puede explicar, como se mencionó anteriormente, por cuatro eventos que influyeron de manera importante en el desempeño de la economía mexicana durante las últimas dos décadas: la crisis de la deuda (1982), el pacto de estabilización (1987), la crisis financiera (1995) y la estabilización posterior (1996 y 1997). En la Gráfica 2 se comparan los tipos de cambio nominal y real con el PIB. De la crisis de la deuda en 1982 al pacto de estabilización adoptado en 1987, el tipo de cambio se depreció continuamente mientras que el producto prácticamente no creció. Se observa también que de 1988 a 1994 la estabilidad en el tipo de cambio nominal está asociada con una apreciación del tipo de cambio real mientras que el PIB presenta un crecimiento sostenido. Finalmente, durante la crisis financiera de 1995 la depreciación del tipo de cambio es acompañada de una fuerte contracción en el producto y a partir de 1996 la recuperación del producto coincide con una apreciación del tipo de cambio real y con un tipo de cambio nominal relativamente estable.

Tasas de Interés. La volatilidad relativa de las tasas de interés (5.8 y 4.6) es similar a la del tipo de cambio y un poco mayor que la de los agregados monetarios. Por otra parte, los resultados de los coeficientes de correlación cruzada sugieren que tanto la tasa de interés nominal (-0.52) como la real (-0.17) son contracíclicas y anteceden el ciclo del producto. Este resultado confirma que uno de los canales a través de los que la política monetaria puede afectar la actividad económica es el canal tradicional de tasas de interés. Sin embargo, debido a que no existen datos disponibles para el periodo 1940-1979, no hay evidencia contra la cual comparar estos resultados. En consecuencia, no se puede analizar si este canal de transmisión de la política monetaria funcionó de forma diferente durante el primer periodo. 


\section{Gráfica 2}

\section{PIB Real y Tipo de Cambio en México: 1980:01-1997:04}
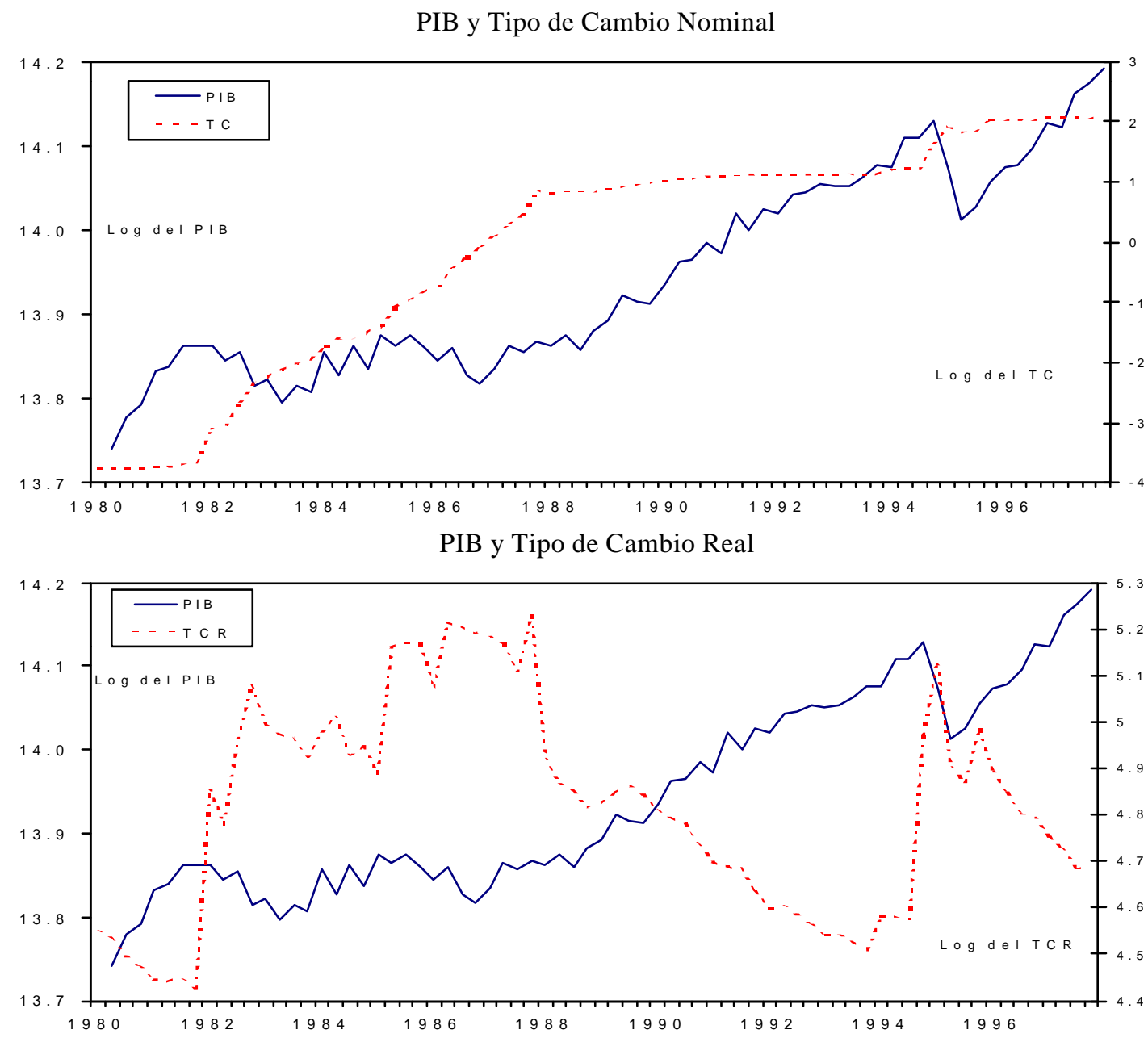

Precios y Salarios. La volatilidad relativa de los precios con respecto al PIB a partir de 1980 es muy similar a la evidencia del periodo 1940-1979. Este resultado sugiere que la relación entre el producto y los precios no parece haber cambiado de manera importante. El hecho de que los precios sean contracíclicos también es congruente con la evidencia del periodo anterior a 1980. La única diferencia es que antes de 1980 los precios antecedían el ciclo y después de 1980 lo siguen con un periodo de rezago (Agenor, McDermott y Prasad [1998] reportan un resultado similar). Estos resultados nuevamente sugieren que las fluctuaciones del PIB son explicadas principalmente por choques de oferta y no por choques de demanda. ${ }^{14}$

\footnotetext{
${ }^{14}$ Un resultado similar es presentado por Rogers y Wang [1995]. Con técnicas de vectores autoregresivos (VAR) encuentran que en México de 1977 a 1990 las fluctuaciones del producto obedecen principalmente a choques reales.
} 


\subsection{Resumen de Resultados}

Al comparar las características del ciclo económico en México durante los dos periodos analizados se encuentra que la inestabilidad en las principales variables nominales coincide con algunos cambios en las características del ciclo económico. Al parecer, después de 1980:

- La volatilidad del componente cíclico de las variables reales y del dinero con respecto a la volatilidad del PIB disminuyó mientras que la volatilidad relativa del componente cíclico de los precios se mantuvo sin cambio. Estos resultados se pueden deber a que la mayor penetración del sistema financiero le ha permitido a los agentes económicos "suavizar" su gasto.

- La volatilidad relativa de las importaciones y exportaciones aumentó y al parecer estas dos variables se han movido en direcciones opuestas. Mientras que las exportaciones son contracíclicas, las importaciones son procíclicas. Este resultado sugiere que las fluctuaciones en el tipo de cambio y las crisis financieras experimentadas durante las últimas dos décadas han influido de manera importante sobre la relación entre la actividad económica y las importaciones y exportaciones.

- La cantidad nominal de dinero parece no ser procíclica como lo era antes ya que la relación con el producto es muy baja. Probablemente las innovaciones financieras han propiciado cambios en la velocidad de circulación del dinero y esto ha modificado la relación entre la cantidad de dinero y la actividad económica.

- Los agentes económicos parecen a ajustar los precios con mayor rapidez ya que, a pesar de que la cantidad real de dinero sigue siendo procíclica, en lugar de anteceder el ciclo ahora es contemporánea.

- Los tipos de cambio nominal y real son contracíclicos. Posiblemente esto se deba a que las devaluaciones han estado asociadas con fuertes contracciones en la actividad económica derivadas de las crisis financieras experimentadas en las últimas dos décadas.

\section{El Ciclo Económico en México y su Relación con Otros Países}

En esta sección se comparan las características del ciclo económico en México con la experiencia de otros países. El análisis se divide en dos partes. En la primera parte se comparan los resultados de México con la evidencia documentada por otros autores para países industrializados y también se analiza la relación entre el ciclo económico de los EUA y el de México. En la segunda parte se documentan las características principales de los ciclos económicos en algunos países latinoamericanos y se comparan con las de México. Al igual que con el caso de los EUA, en esta segunda parte se analiza la relación entre el ciclo económico mexicano y el de algunos otros países latinoamericanos. 
Durante los últimos años la economía mexicana se ha abierto al comercio internacional. A continuación se presenta la evolución a lo largo de los últimos años de las exportaciones e importaciones mexicanas expresadas como porcentaje del PIB:

\section{Exportaciones e Importaciones}

\begin{tabular}{c|c|c} 
Año & $\begin{array}{c}\text { Exportaciones } \\
(\% \text { del PIB })\end{array}$ & $\begin{array}{c}\text { Importaciones } \\
(\% \text { del PIB })\end{array}$ \\
\hline 1970 & $7.7 \%$ & $9.6 \%$ \\
1980 & $10.7 \%$ & $12.9 \%$ \\
1990 & $14.1 \%$ & $15.0 \%$ \\
1998 & $28.3 \%$ & $30.1 \%$
\end{tabular}

Se observa que la participación del sector externo en la economía mexicana ha aumentado considerablemente. Ante esta mayor apertura comercial resulta sumamente importante analizar la relación que el ciclo económico mexicano guarda con el de algunos otros países. Con el fin de identificar a los principales socios comerciales de México, a continuación se presenta el porcentaje de las exportaciones e importaciones que México realiza con diferentes regiones en el mundo:

\section{Destino de las Exportaciones}

\begin{tabular}{c|c|c|c|c} 
Año & EUA & $\begin{array}{c}\text { Unión } \\
\text { Europea }\end{array}$ & Asia & $\begin{array}{c}\text { América } \\
\text { Latina }^{15}\end{array}$ \\
\hline 1990 & $68.6 \%$ & $13.2 \%$ & $6.8 \%$ & $2.5 \%$ \\
1998 & $87.7 \%$ & $3.3 \%$ & $1.6 \%$ & $2.3 \%$
\end{tabular}

\section{Origen de las Importaciones}

\begin{tabular}{c|c|c|c|c} 
Año & EUA & $\begin{array}{c}\text { Unión } \\
\text { Europea }\end{array}$ & Asia & $\begin{array}{c}\text { América } \\
\text { Latina }\end{array}$ \\
\hline 1990 & $65.5 \%$ & $16.6 \%$ & $8.1 \%$ & $2.0 \%$ \\
1998 & $74.3 \%$ & $9.3 \%$ & $10.6 \%$ & $1.9 \%$
\end{tabular}

Los datos muestran que el principal socio comercial de México son los EUA y que en años recientes el comercio se ha concentrado aún más con dicho país. Por consiguiente, es de esperarse que el ciclo económico en México sea fuertemente afectado por el ciclo de los EUA. Por otra parte, aún cuando el comercio con los países latinoamericanos no es muy importante en términos relativos, resulta interesante analizar la relación entre los ciclos económicos de México y los de los países de dicha región por la siguiente razón. México forma parte del bloque latinoamericano de países en desarrollo. Por consiguiente, aunque los vínculos comerciales no sean importantes, es posible que la percepción de los agentes económicos respecto de la economía mexicana pueda verse afectada de manera importante

\footnotetext{
${ }^{15}$ Unicamente incluye Argentina, Brasil, Chile, Colombia, Perú y Venezuela.
} 
por la percepción que ellos mismos tengan respecto de la situación económica de otros países de la región.

A continuación se comparan las características del ciclo económico en México con la evidencia de algunos países industrializados (EUA, Reino Unido y Japón) y con algunos otros países latinoamericanos (Argentina, Brasil, Chile, Colombia, Perú y Venezuela).

\subsection{México y los Países Industrializados}

\subsubsection{Características de los Ciclos Económicos}

Como se mencionó anteriormente, los trabajos de Kydland y Prescott [1990] y Backus y Kehoe [1992] analizan la evidencia de los países industrializados. En el Cuadro 5 se resumen los resultados principales de dichos artículos y se comparan con las características del ciclo económico mexicano que se documentaron en la sección previa. Precisamente, en las dos primeras columnas de dicho Cuadro se reportan los resultados de la sección anterior. En la tercera columna se presentan los resultados documentados por Kydland y Prescott [1990] (KP) para el caso de los EUA. Asimismo, en las columnas cuatro, cinco y seis se incluyen los resultados reportados por Backus y Kehoe [1992] (BK) para los casos de los EUA, el Reino Unido y Japón respectivamente.

Con respecto a las variables reales, se observa que la volatilidad de las fluctuaciones del componente cíclico del PIB en México durante ambos periodos $(2.0 \%$ y $2.6 \%$ respectivamente) no es muy diferente de la evidencia documentada para los EUA (2.2\%), el Reino Unido (1.6\%) y Japón (3.1\%). Asimismo, se observa que la volatilidad relativa de las variables reales en México es un poco más alta aunque no muy diferente a la observada en los otros países. Al observar la relación entre el consumo del gobierno y el PIB se observa que en los países industrializados el consumo del gobierno no esta correlacionado con el producto mientras que en México es procíclico. Otra diferencia importante se encuentra en el comportamiento de las importaciones y exportaciones. En el caso de los EUA se observa que ambas variables son procíclicas mientras que en México durante el primer periodo se observa un resultado similar, pero a partir de 1980 parece que las exportaciones mexicanas han sido contracíclicas.

Por otra parte, al comparar la relación del dinero en términos nominales con el producto, se observa que la volatilidad relativa en México es considerablemente mayor que la observada en los países industrializados. Debido a que en los artículos referidos no existe evidencia con respecto al tipo de cambio y a las tasas de interés no es posible hacer comparaciones con el caso de México. Finalmente, al comparar los resultados para los índices de precios, se observa que la volatilidad relativa de los precios en México es mucho mayor que en los EUA, el Reino Unido y Japón. Sin embargo, es interesante observar que al igual que en dichos países, en México los precios son contracíclicos. 


\section{Cuadro 5}

\section{Características de los Ciclos Económicos en México y en Países Industrializados}

\begin{tabular}{|c|c|c|c|c|c|c|}
\hline $\begin{array}{l}\text { Fuente: } \\
\text { País: } \\
\text { Periodo: } \\
\text { Frecuencia datos: }\end{array}$ & $\begin{array}{c}\text { México } \\
1940-1979 \\
\text { Anual } \\
\end{array}$ & $\begin{array}{c}\text { México } \\
1980-1997 \\
\text { trimestral } \\
\end{array}$ & $\begin{array}{c}\text { KP } \\
\text { EUA } \\
1954-1989 \\
\text { trimestral } \\
\end{array}$ & $\begin{array}{c}\text { BK } \\
\text { EUA } \\
1950-1983 \\
\text { anual } \\
\end{array}$ & $\begin{array}{c}\text { BK } \\
\text { Reino Unido } \\
\text { 1950-1983 } \\
\text { anual } \\
\end{array}$ & $\begin{array}{c}\text { BK } \\
\text { Japón } \\
\text { 1952-1986 } \\
\text { anual } \\
\end{array}$ \\
\hline PIB & $2.0 \%$ & $2.6 \%$ & $1.7 \%$ & $2.2 \%$ & $1.6 \%$ & $3.1 \%$ \\
\hline Consumo Privado & $\begin{array}{l}1.4 \\
+ \\
\mathrm{C}\end{array}$ & $\begin{array}{c}1.2 \\
+ \\
\mathrm{C}\end{array}$ & $\begin{array}{c}0.7 \\
+ \\
\mathrm{C}\end{array}$ & $\begin{array}{c}0.6 \\
+\end{array}$ & $\begin{array}{c}1.2 \\
+\end{array}$ & $\begin{array}{c}1.2 \\
+\end{array}$ \\
\hline Consumo Gobierno & $\begin{array}{l}2.6 \\
+ \\
\mathrm{C}\end{array}$ & $\begin{array}{l}1.7 \\
+ \\
\mathrm{C}\end{array}$ & $\begin{array}{c}1.2 \\
\pm\end{array}$ & $\begin{array}{c}3.4 \\
+\end{array}$ & $\begin{array}{c}2.0 \\
\pm\end{array}$ & $\begin{array}{c}1.1 \\
+\end{array}$ \\
\hline Inversión & $\begin{array}{c}5.4 \\
+ \\
G\end{array}$ & $\begin{array}{l}4.2 \\
+ \\
\mathrm{C}\end{array}$ & $\begin{array}{c}4.8 \\
+ \\
\mathrm{C}\end{array}$ & $\begin{array}{c}2.6 \\
+\end{array}$ & $\begin{array}{c}2.6 \\
+\end{array}$ & $\begin{array}{c}2.0 \\
+\end{array}$ \\
\hline Importaciones & $\begin{array}{c}6.5 \\
+ \\
\mathrm{C}\end{array}$ & $\begin{array}{c}5.6 \\
+ \\
\mathrm{L}\end{array}$ & $\begin{array}{c}2.8 \\
+ \\
\mathrm{C}\end{array}$ & & & \\
\hline Exportaciones & $\begin{array}{c}3.7 \\
+ \\
\mathrm{L}\end{array}$ & $\begin{array}{c}2.6 \\
- \\
\mathrm{C}\end{array}$ & $\begin{array}{c}3.2 \\
+ \\
\mathrm{G}\end{array}$ & & & \\
\hline Dinero nominal & $\begin{array}{l}5.8 \\
+ \\
\mathrm{C}\end{array}$ & $\begin{array}{c}4.2 \\
\pm\end{array}$ & $\begin{array}{c}0.4 \\
+ \\
\mathrm{C}\end{array}$ & $\begin{array}{c}0.7 \\
+\end{array}$ & $\begin{array}{c}3.1 \\
+\end{array}$ & $\begin{array}{c}1.3 \\
+\end{array}$ \\
\hline Dinero real & $\begin{array}{c}6.3 \\
+ \\
\mathrm{L}\end{array}$ & $\begin{array}{l}3.1 \\
+ \\
\mathrm{C}\end{array}$ & & & & \\
\hline Dinero velocidad & $\begin{array}{c}4.4 \\
- \\
\mathrm{L}\end{array}$ & $\begin{array}{c}2.2 \\
- \\
\mathrm{G}\end{array}$ & $\begin{array}{l}0.7 \\
+ \\
\mathrm{C}\end{array}$ & & & \\
\hline $\begin{array}{l}\text { Tipo de cambio } \\
\text { Nominal }\end{array}$ & $\begin{array}{c}6.5 \\
+ \\
\mathrm{L}\end{array}$ & $\begin{array}{c}6.7 \\
- \\
\mathrm{L}\end{array}$ & & & & \\
\hline $\begin{array}{l}\text { Tipo de cambio } \\
\text { Real }\end{array}$ & $\begin{array}{c}4.4 \\
+ \\
\mathrm{L}\end{array}$ & $\begin{array}{c}4.7 \\
- \\
\mathrm{L}\end{array}$ & & & & \\
\hline $\begin{array}{l}\text { Tasa de interés } \\
\text { Nominal }\end{array}$ & & $\begin{array}{c}5.8 \\
- \\
\mathrm{L}\end{array}$ & & & & \\
\hline $\begin{array}{l}\text { Tasa de interés } \\
\text { Real }\end{array}$ & & $\begin{array}{c}4.6 \\
- \\
\mathrm{G}\end{array}$ & & & & \\
\hline IPC & $\begin{array}{c}5.0 \\
- \\
\mathrm{L}\end{array}$ & $\begin{array}{c}5.0 \\
- \\
G\end{array}$ & $\begin{array}{c}0.8 \\
- \\
\mathrm{L}\end{array}$ & $\begin{array}{c}0.3 \\
-\end{array}$ & $\begin{array}{c}3.0 \\
-\end{array}$ & $\begin{array}{c}1.3 \\
-\end{array}$ \\
\hline $\begin{array}{l}\text { Deflactor Implícito } \\
\text { PIB }\end{array}$ & $\begin{array}{c}5.0 \\
- \\
\mathrm{L}\end{array}$ & $\begin{array}{c}4.7 \\
- \\
G\end{array}$ & $\begin{array}{c}0.4 \\
- \\
\mathrm{L}\end{array}$ & & & \\
\hline Salario nominal & & $\begin{array}{c}4.7 \\
- \\
\text { G }\end{array}$ & & & & \\
\hline Salario real & & $\begin{array}{c}4.1 \\
+ \\
\mathrm{G}\end{array}$ & $\begin{array}{l}+ \\
\mathrm{C}\end{array}$ & & & \\
\hline
\end{tabular}

Nota: Para cada variable, los números en el primer renglón se refieren a la volatilidad (desviación estándar) de la variable con respecto a la volatilidad del PIB. Los signos en el segundo renglón indican si la variable es procíclica (+), contracíclica (-) o no correlacionada con el PIB ( \pm ). La letra en el tercer renglón indica si los cambios en la variable anteceden $(\mathrm{L})$, son contemporáneos $(\mathrm{C})$ o siguen con rezago $(\mathrm{G})$ al producto. 


\subsubsection{Relación con el Ciclo Económico de EUA}

Antes de analizar la relación entre los ciclos económicos de México y los EUA es importante tener en cuenta el tamaño relativo de ambas economías. A lo largo del siglo, el PIB de los EUA ha sido aproximadamente 20 veces más grande, en promedio, que el de México (el PIB de México ha representado, en promedio, a lo largo del siglo 5.2\% del PIB de los EUA). ${ }^{16}$ Dado que la economía de los EUA es una economía mucho más grande, se esperaría que las fluctuaciones en ésta podrían tener repercusiones significativas en la economía mexicana. Por el contrario, también es de anticiparse que las fluctuaciones en la economía mexicana tengan un efecto mucho menor en la economía de los EUA.

Como se mencionó anteriormente, la Segunda Guerra Mundial parece no haber tenido efectos importantes sobre el ciclo económico en México. Sin embargo, como se puede observar en la Gráfica 1, el ciclo económico de los EUA presenta grandes fluctuaciones durante los años de la guerra. Para evitar las distorsiones causadas en los EUA por la Segunda Guerra Mundial, la relación entre los ciclos económicos de México y de los EUA se analiza para el periodo: 1948-1997. Al igual que al documentar las características del ciclo económico mexicano, en este caso el análisis se divide en dos periodos: 1948-1979 y 1980-1997. De esta manera, también es posible analizar si la inestabilidad nominal observada en México a partir de 1980 coincide con un cambio importante en la relación con el ciclo económico en los EUA.

Para documentar la relación entre los dos ciclos económicos se aplican dos metodologías: al igual que en las secciones anteriores se utilizan los coeficientes de correlación cruzada entre las fluctuaciones cíclicas de ambos países y se usan también funciones impulso respuesta estimadas mediante vectores autorregresivos (VAR). Los resultados son robustos bajo ambas metodologías.

\section{a) Análisis del Periodo 1948-1979}

\section{Correlación entre los Ciclos Económicos}

En el Cuadro 6 se presentan los coeficientes de correlación cruzada entre el PIB de los EUA y algunas variables macroeconómicas de México. Nuevamente el análisis es robusto bajo dos diferentes especificaciones de los datos: fluctuaciones cíclicas y tasas de crecimiento. El coeficiente de correlación entre ambos productos sugiere que el ciclo económico mexicano sigue al de los EUA con dos periodos de rezago (0.55). Este resultado también se puede apreciar en la Gráfica 3 donde el componente cíclico del PIB de los EUA es comparado con el componente cíclico de algunas variables macroeconómicas de México. A continuación se analiza el mecanismo de transmisión a través de dos canales: vínculos comerciales y mercados financieros.

\footnotetext{
${ }^{16}$ Las fuentes de estos datos se proporcionan en el Apéndice1.
} 


\section{Cuadro 6}

\section{PIB de los EUA y Variables Mexicanas}

Datos Anuales: 1948-1979

\begin{tabular}{|c|c|c|c|c|c|c|c|c|c|}
\hline \multirow{3}{*}{ Variable X } & \multicolumn{9}{|c|}{ Correlación Cruzada del PIB de los EUA con } \\
\hline & \multicolumn{4}{|c|}{ Rezagos } & \multirow[b]{2}{*}{$X_{t}$} & \multicolumn{4}{|c|}{ Adelantos } \\
\hline & $X_{t-4}$ & $X_{t-3}$ & $X_{t-2}$ & $\mathrm{X}_{\mathrm{t}-1}$ & & $X_{t+1}$ & $X_{t+2}$ & $X_{t+3}$ & $X_{t+4}$ \\
\hline PIB de México & -0.10 & -0.07 & 0.10 & 0.27 & 0.28 & 0.39 & 0.55 & 0.35 & 0.13 \\
\hline Exportaciones & 0.02 & 0.08 & -0.02 & 0.25 & 0.55 & 0.20 & -0.07 & -0.06 & -0.21 \\
\hline Importaciones & 0.26 & -0.31 & -0.10 & 0.09 & 0.33 & 0.53 & 0.48 & 0.24 & -0.13 \\
\hline Tipo de Cambio Real & -0.32 & -0.01 & 0.02 & 0.06 & 0.11 & 0.02 & 0.13 & 0.32 & 0.31 \\
\hline Inversión & -0.07 & -0.11 & 0.10 & 0.37 & 0.53 & 0.62 & 0.55 & 0.35 & 0.06 \\
\hline
\end{tabular}

Vínculos Comerciales. Los coeficientes de correlación que se reportan en el Cuadro 6 sugieren que el PIB de los EUA está correlacionado positiva y contemporáneamente con las exportaciones en México (0.55). Este resultado sugiere que un mayor crecimiento económico en los EUA incrementa la demanda por exportaciones mexicanas que a su vez afectan de manera positiva al PIB mexicano. Con respecto a las importaciones, el hecho de que estén positivamente correlacionadas con el PIB de los EUA y que lo sigan con un periodo de rezago (0.53) sugiere que las fluctuaciones en el producto de los EUA afectan los insumos importados por México y a través del componente importado en la producción mexicana esto se ve reflejado en el PIB de México. Estos resultados confirman que las importaciones y exportaciones mexicanas durante el periodo 1948-1979 son: procíclicas respecto del PIB en México; que son influenciadas en gran parte por el ciclo económico internacional y no por movimientos en el tipo de cambio; y que las fluctuaciones de los EUA se transmiten a México a través de vínculos comerciales. 


\section{Gráfica 3}

\section{Fluctuaciones Cíclicas en los EUA y México: 1948-1979}

PIB de México y PIB de los EUA

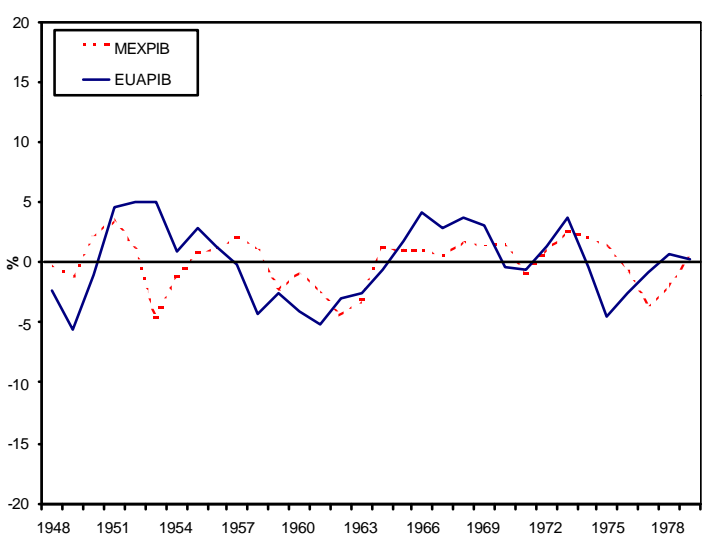

Exportaciones de México y PIB de los EUA

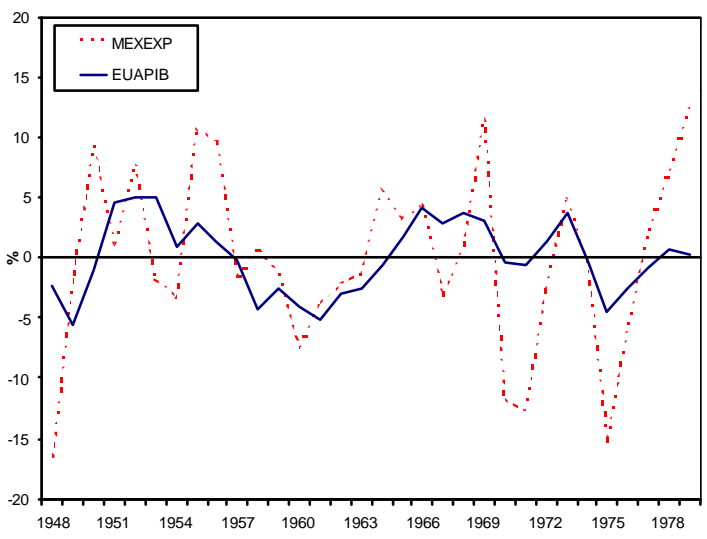

Inversión de México y PIB de los EUA

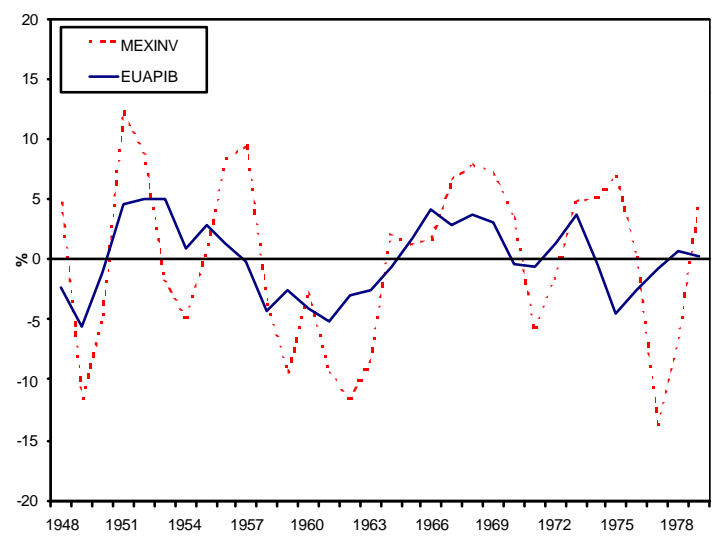

Importaciones de México y PIB de los EUA

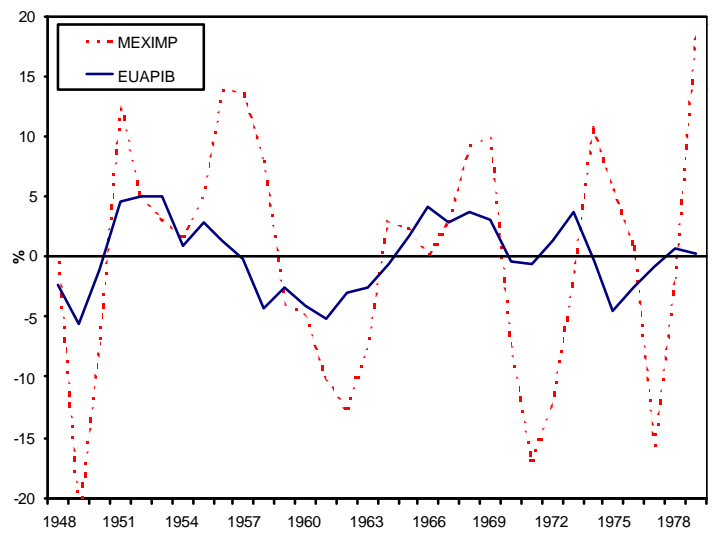

Mercados Financieros: las fluctuaciones en la tasa de interés de los EUA afectan las condiciones de crédito en los mercados financieros internacionales y pueden causar movimientos de capitales de un país a otro y eventualmente afectar el ciclo económico. Contrariamente a lo esperado, los coeficientes de correlación reportados en el Cuadro 7 sugieren que el tipo de cambio real se aprecia (-0.12) después de un incremento en la tasa de interés de los EUA. Esta apreciación puede darse como resultado de un aumento en los precios en México o bien por un incremento en la tasa de interés mexicana. ${ }^{17} \mathrm{La}$ apreciación del tipo de cambio real es acompañada de un incremento en las importaciones (0.52) que es consistente con la correlación positiva entre la tasa de interés de los EUA y la inversión (0.52) y el PIB (0.37) en México. De manera similar, a la apreciación cambiaria le sigue una reducción en las exportaciones (-0.53) que a su vez es seguida de una caída en

\footnotetext{
${ }^{17}$ Para comprender la razón por la cual se da una apreciación del tipo de cambio real en México, sería interesante documentar la relación entre la tasa de interés de los EUA y la de México. Después de un incremento en la tasa de interés de los EUA, podría darse una apreciación si el incremento subsecuente en la tasa de interés en México resulta mayor que el que ocurre en los EUA. Sin embargo, dicho ejercicio no se realiza por falta de información respecto a la tasa de interés en México antes de 1975, pero queda abierto para futuras investigaciones.
} 
la inversión (-0.36) y en el PIB (-0.31) en México. Estos resultados sugieren que después de un incremento en la tasa de interés en los EUA se presenta una apreciación del tipo de cambio que afecta las exportaciones, las importaciones, la inversión y eventualmente al producto. Los resultados sugieren que la transmisión de las fluctuaciones económicas de los EUA hacia la economía mexicana puede haberse dado fundamentalmente a través de los mercados financieros. Sin embargo, es necesario un análisis más detallado para clarificar el papel que ha jugado la tasa de interés en México, para así poder explicar la razón por la que se observa la apreciación cambiaria.

\section{Cuadro 7}

\section{Tasa de Interés de los EUA y Variables Mexicanas Datos Anuales: 1948-1979}

\begin{tabular}{|c|c|c|c|c|c|c|c|c|c|}
\hline \multirow[t]{3}{*}{ Variable X } & \multicolumn{9}{|c|}{ Correlación Cruzada de la Tasa de Interés de EUA con } \\
\hline & \multicolumn{4}{|c|}{ Rezagos } & & \multicolumn{4}{|c|}{ Adelantos } \\
\hline & $X_{t-4}$ & $X_{t-3}$ & $\mathrm{X}_{\mathrm{t}-2}$ & $X_{t-1}$ & $X_{t}$ & $X_{t+1}$ & $X_{t+2}$ & $X_{t+3}$ & $X_{t+4}$ \\
\hline PIB de México & -0.08 & -0.20 & 0.11 & 0.42 & 0.37 & 0.17 & -0.15 & -0.31 & -0.06 \\
\hline Exportaciones & 0.13 & -0.39 & -0.09 & 0.66 & 0.36 & -0.53 & -0.52 & 0.10 & 0.17 \\
\hline Importaciones & -0.07 & -0.31 & -0.03 & 0.38 & 0.52 & 0.17 & -0.29 & -0.50 & -0.26 \\
\hline Tipo de Cambio Real & -0.24 & 0.07 & 0.20 & 0.05 & -0.12 & -0.17 & 0.32 & 0.54 & -0.04 \\
\hline Inversión & 0.01 & -0.16 & 0.02 & 0.38 & 0.52 & 0.24 & -0.17 & -0.36 & -0.17 \\
\hline
\end{tabular}

\section{$\underline{\text { Análisis de Vectores Autorregresivos (VAR) }}$}

La metodología VAR se utiliza para estimar funciones impulso respuesta que describan la reacción de algunas de las variables macroeconómicas de México ante fluctuaciones en la economía de los EUA. En cada VAR se incorporan dos variables y el orden es el siguiente: primero se incluye la variable de EUA que recibe el choque y en segundo lugar la variable mexicana que se desea analizar. El hecho de considerar en el VAR primero la variable de los EUA implica que la variable mexicana puede responder contemporáneamente a los choques en la variable de los EUA. Es decir, bajo esta metodología la respuesta de la variable mexicana no está sujeta a ningún tipo de restricción. Las variables se especifican en tasas de crecimiento (primeras diferencias) ${ }^{18}$ y dos rezagos fueron suficientes para inducir residuales de tipo "ruido blanco".

El primer ejercicio estima la respuesta de las variables mexicanas a una perturbación positiva en el PIB de los EUA. En la Gráfica 4.1 se presentan las funciones impulso respuesta de las variables mexicanas (PIB, exportaciones, importaciones, tipo de cambio real e inversión). ${ }^{19}$ Los resultados son compatibles con la evidencia de la sección anterior: el PIB, las exportaciones, las importaciones y la inversión aumentan después de la

\footnotetext{
${ }^{18}$ Se realizaron pruebas de raíz unitaria para analizar la estacionariedad del nivel de las variables utilizadas. Los resultados indican que al $95 \%$ de confianza no es posible rechazar la existencia de raíces unitarias, por consiguiente, se supone que las variables son integradas de orden 1 .

${ }^{19}$ Los intervalos de confianza representan \pm 1.5 desviaciones estándar y se calcularon con un ejercicio de tipo Montecarlo que incluye 500 simulaciones.
} 
perturbación al PIB de los EUA. Sin embargo, es importante mencionar que aún cuando la estimación puntual de la respuesta del PIB es positiva, ésta no es significativa. Este resultado es congruente con el hecho de que los coeficientes de correlación del Cuadro 6 son menores para el PIB que para las otras variables.

\section{Gráfica 4.1}

Respuesta a una Perturbación Positiva en el PIB de los EUA: 1948-1979

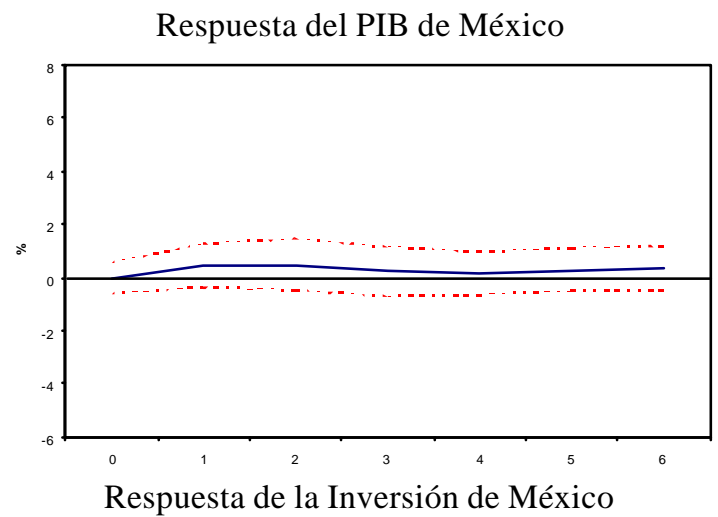

Respuesta de las Exportaciones de México
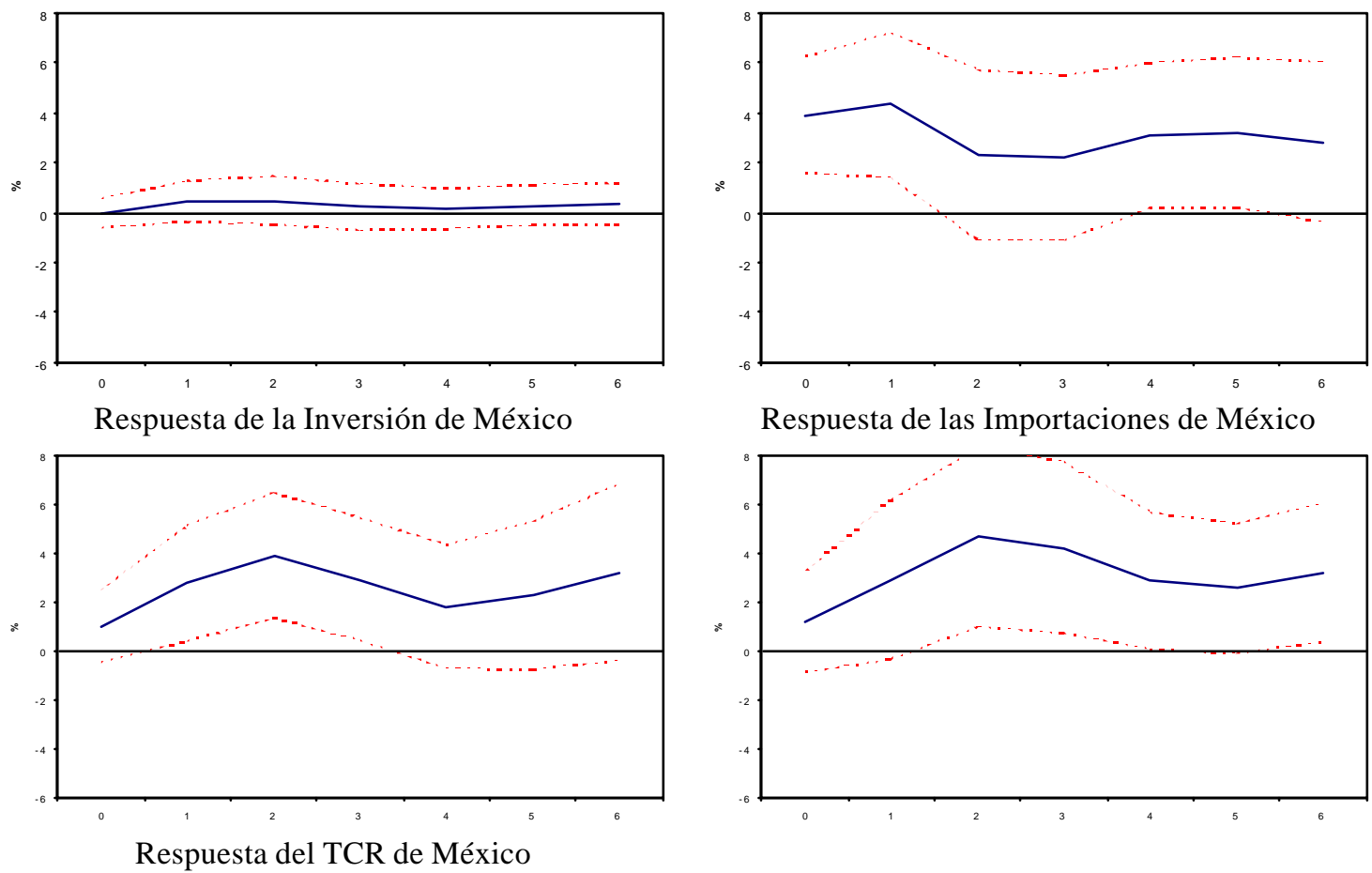

Respuesta de las Importaciones de México
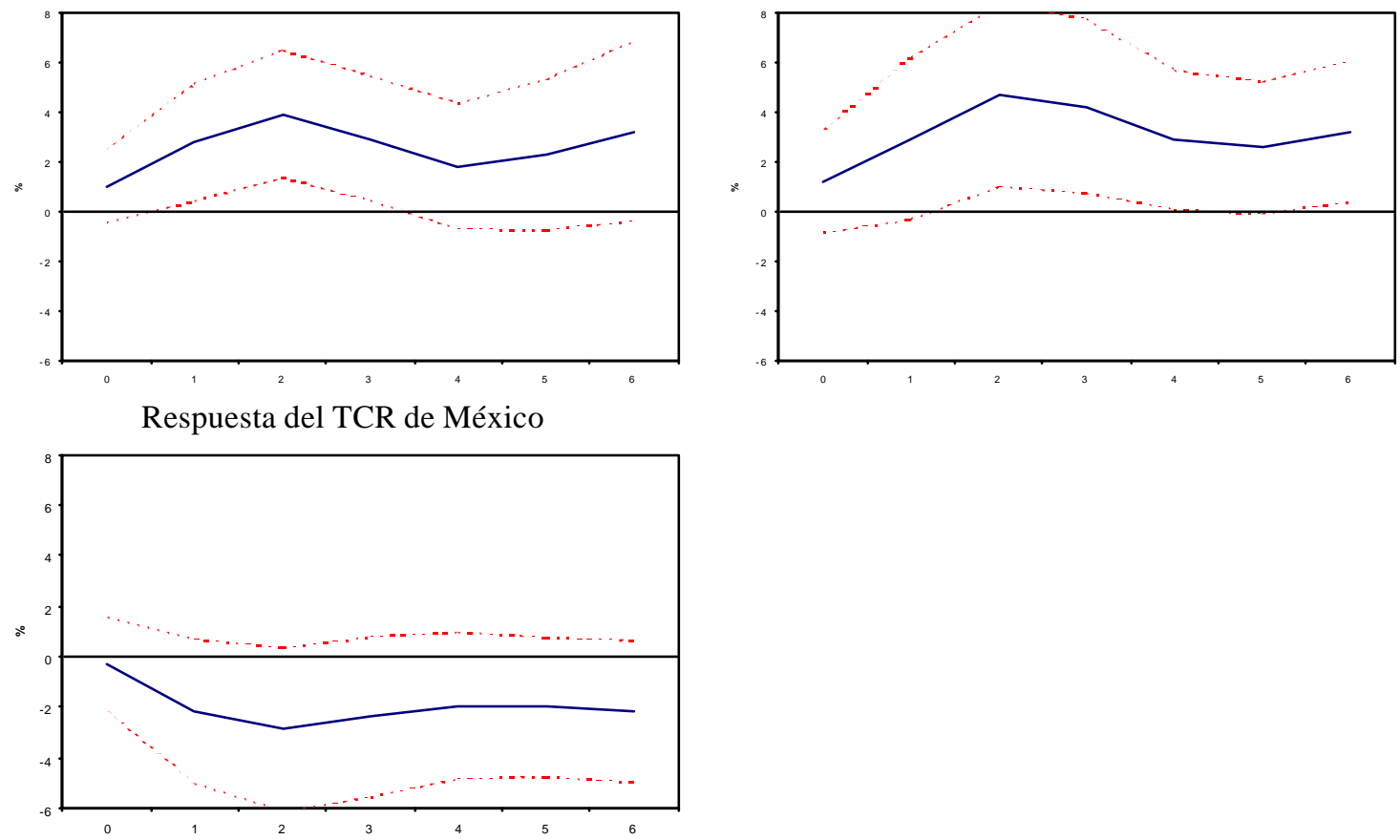

El segundo ejercicio documenta la respuesta a una perturbación positiva (incremento) en la tasa de interés de los EUA. Los resultados se presentan en la Gráfica 4.2. Después de la perturbación hay un efecto positivo sobre el PIB, las exportaciones e inversión. Asimismo, la respuesta del tipo de cambio real parece no ser significativa, aunque la dirección de la estimación puntual sugiere una apreciación. ${ }^{20}$ Después de un tiempo las exportaciones decrecen y el PIB, las importaciones y la inversión aumentan

${ }^{20}$ Como se mencionó anteriormente, entender la razón por la que el tipo de cambio se pudiera apreciar después de un incremento en la tasa de interés de los EUA queda como tema para futuras investigaciones. 
durante otros dos periodos. Eventualmente se observa una reducción en el PIB, la inversión y las importaciones. A pesar de que estos resultados no son concluyentes, dejan abierta la posibilidad de que las fluctuaciones en los EUA puedan transmitirse a la economía mexicana a través de los mercados financieros, sin embargo como se mencionó anteriormente, un análisis más detallado es necesario para comprender el papel de la tasa de interés en México.

\section{Gráfica 4.2}

\section{Respuesta a una Perturbación Positiva en la Tasa de Interés de los EUA: 1948-1979}

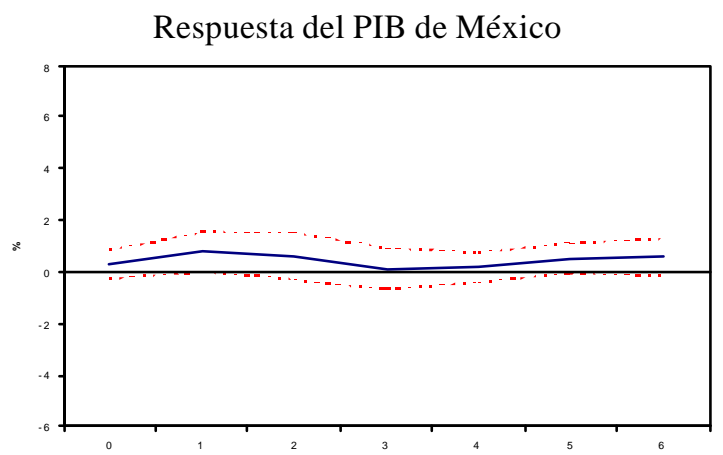

Respuesta de las Exportaciones de México
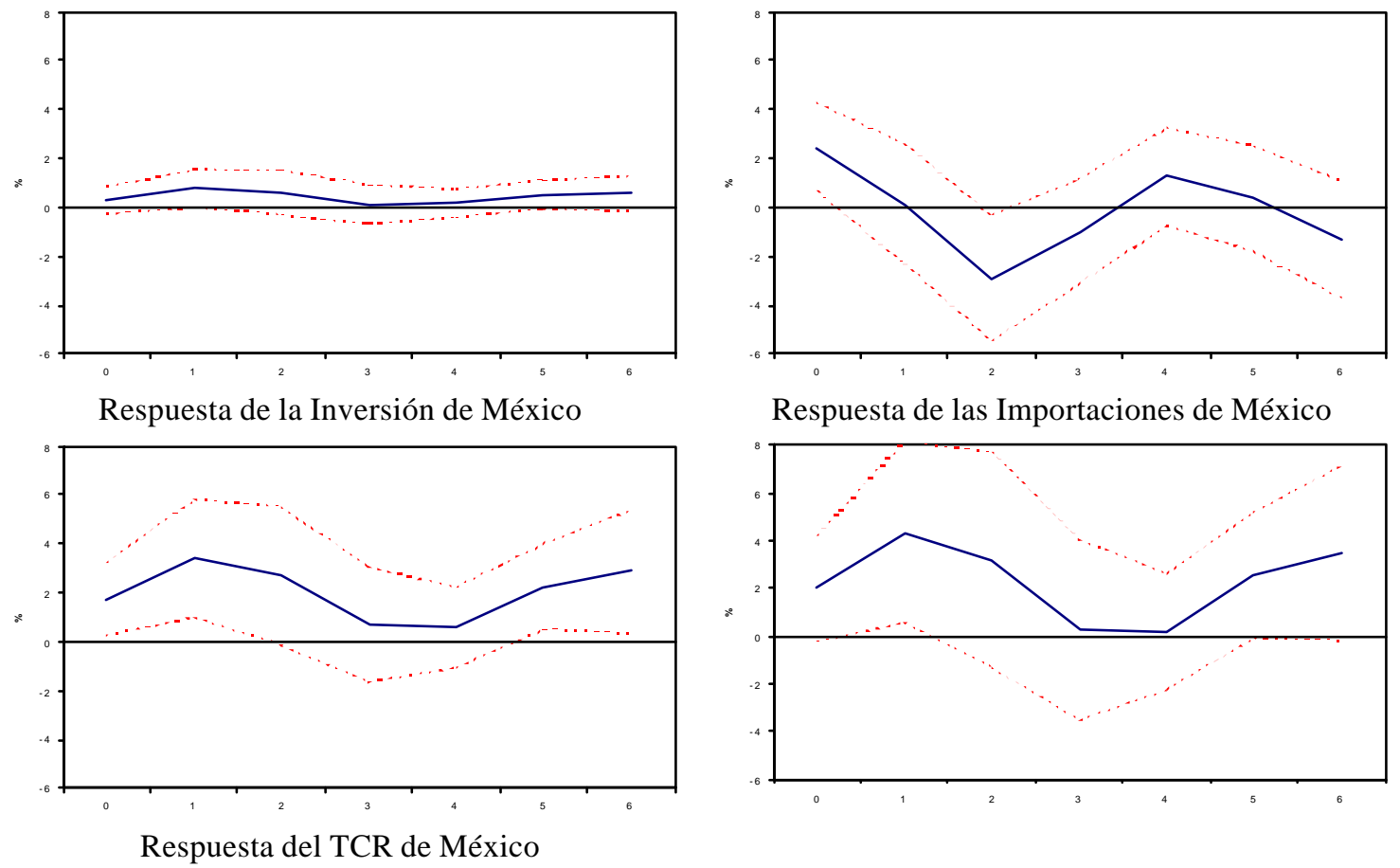

Respuesta de las Importaciones de México
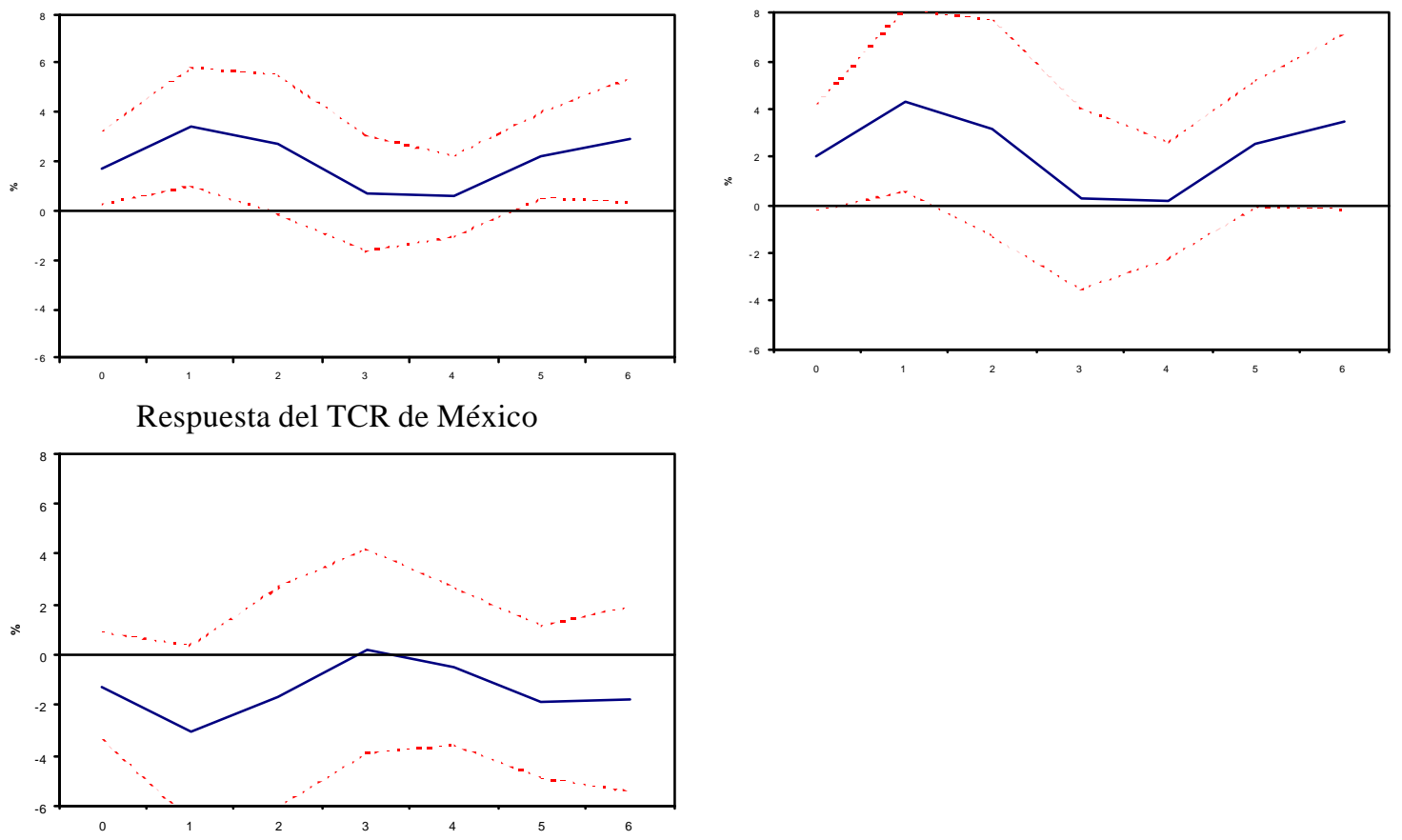

b) Análisis del Periodo 1980-1997

En la Gráfica 5 se presenta el PIB de los EUA y el de México de 1980 a 1997. La relación entre el componente cíclico de ambos productos se puede dividir en dos etapas: de 1980 a 1987 ambos ciclos parecen moverse en la misma dirección y de 1988 a 1997 en 
direcciones opuestas. A continuación, se compara la relación entre ambos ciclos en estas dos etapas.

\section{Gráfica 5 \\ PIB Real en los EUA y México: 1980:02-1997:04}
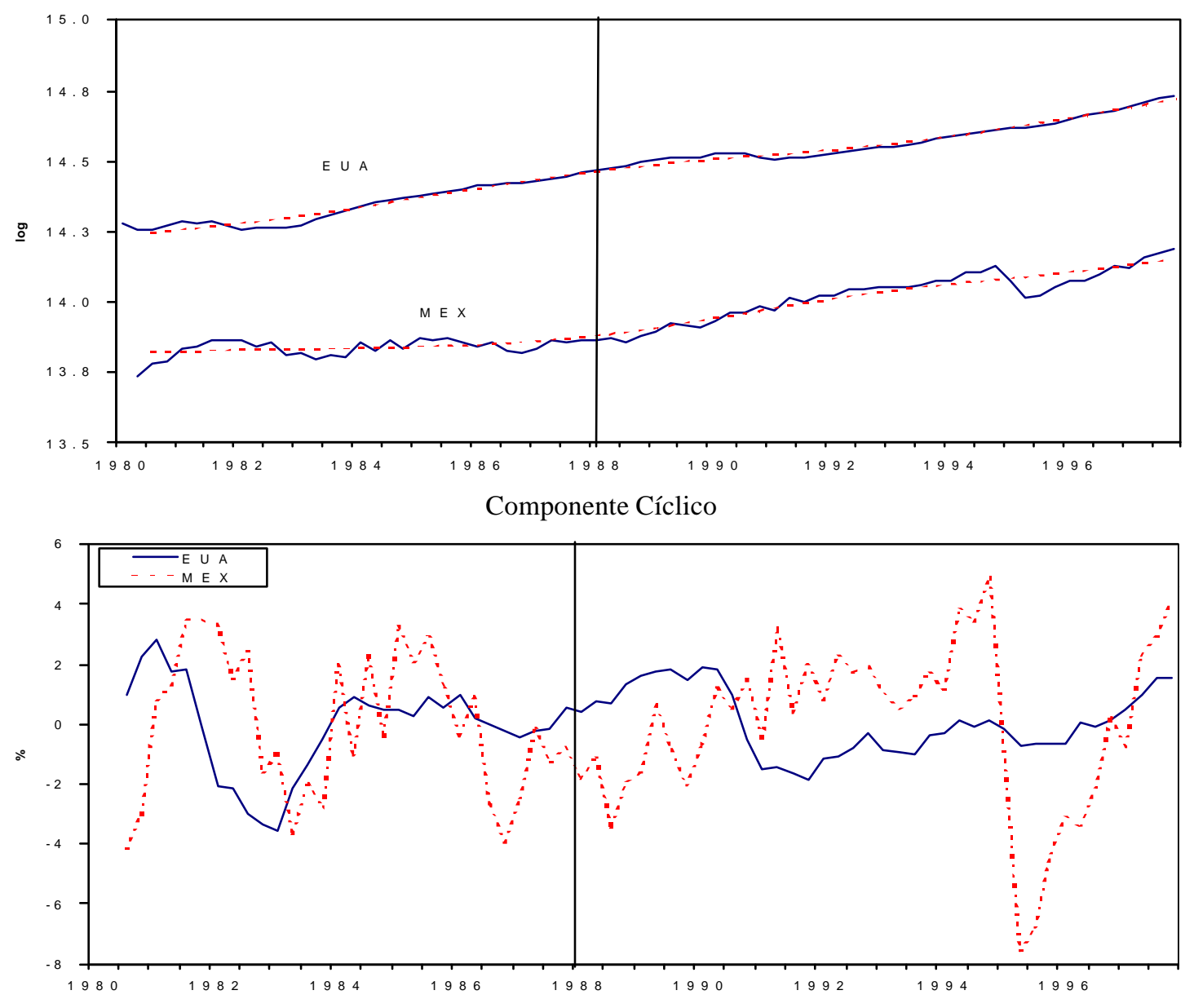

\section{Correlación entre Ciclos Económicos}

En el Cuadro 8 se presentan los coeficientes de correlación cruzada entre el PIB de los EUA y algunas variables macroeconómicas de México para los periodos 1980-1987 y 1988-1997. Durante el primer periodo, el PIB de México sigue al de los EUA con dos periodos de rezago (0.40). La contracción en el PIB de los EUA a principios de los años ochenta corresponde a las recesiones reportadas por el NBER para los periodos de enero de 1980 a julio de 1981 y de julio de 1981 a noviembre de $1982 .^{21}$ Esta contracción en el PIB de los EUA es seguida por la recesión de México en 1982, la "crisis de la deuda". Después de estos eventos ambas economías entraron en un periodo de recuperación. Sin embargo, el

${ }^{21}$ Fuente: National Bureau of Economic Research, Oficina de Información Pública. 
periodo de recuperación en México es muy corto ya que el producto vuelve a contraerse en 1986 y 1987 debido a la caída en el precio del petróleo, a la creciente inflación y a las devaluaciones recurrentes.

\section{Cuadro 8}

\section{PIB de los EUA y Variables Mexicanas Datos Trimestrales: 1980:03 - 1997:04}

\begin{tabular}{|c|c|c|c|c|c|c|c|c|c|}
\hline \multirow[t]{3}{*}{ Variable X } & \multicolumn{9}{|c|}{ Correlación Cruzada del PIB de EUA con } \\
\hline & \multicolumn{4}{|c|}{ Rezagos } & \multirow[b]{2}{*}{$\mathrm{X}_{\mathrm{t}}$} & \multicolumn{4}{|c|}{ Adelantos } \\
\hline & $X_{t-4}$ & $\mathrm{X}_{\mathrm{t}-3}$ & $X_{t-2}$ & $\mathrm{X}_{\mathrm{t}-1}$ & & $X_{t+1}$ & $X_{t+2}$ & $X_{t+3}$ & $X_{t+4}$ \\
\hline \multicolumn{10}{|l|}{ Periodo 1980:03 - 1987:04 } \\
\hline PIB de México & -0.57 & -0.49 & -0.22 & 0.00 & 0.24 & 0.38 & 0.40 & 0.34 & 0.20 \\
\hline Exportaciones & 0.38 & 0.17 & 0.07 & -0.19 & -0.46 & -0.56 & -0.68 & -0.60 & -0.54 \\
\hline Importaciones & -0.59 & -0.35 & -0.02 & 0.26 & 0.55 & 0.73 & 0.78 & 0.64 & 0.37 \\
\hline Tipo de Cambio Real & 0.27 & 0.06 & -0.19 & -0.35 & -0.47 & -0.44 & -0.19 & -0.06 & 0.23 \\
\hline Inversión & -0.71 & -0.54 & -0.20 & 0.08 & 0.34 & 0.59 & 0.74 & 0.75 & 0.56 \\
\hline \multicolumn{10}{|l|}{ Periodo 1988:01 - 1997:04 } \\
\hline PIB de México & -0.40 & -0.36 & -0.31 & -0.21 & -0.12 & -0.14 & -0.15 & -0.16 & -0.13 \\
\hline Exportaciones & 0.04 & 0.17 & 0.19 & 0.10 & 0.09 & 0.11 & 0.22 & 0.27 & 0.32 \\
\hline Importaciones & -0.17 & -0.02 & 0.05 & 0.14 & 0.14 & 0.13 & 0.04 & -0.05 & -0.07 \\
\hline Tipo de Cambio Real & -0.04 & -0.09 & -0.10 & -0.07 & 0.00 & 0.08 & 0.13 & 0.18 & 0.20 \\
\hline Inversión & -0.28 & -0.25 & -0.21 & -0.14 & -0.11 & -0.15 & -0.19 & -0.24 & -0.21 \\
\hline
\end{tabular}

Después de 1988 la relación se invierte y al parecer el ciclo económico en México sigue al de los EUA pero en dirección contraria (-0.16). Después del plan de estabilización adoptado por el gobierno mexicano a finales de 1987, la economía comienza un lento proceso de recuperación que coincide con la recesión experimentada en los EUA de julio de 1990 a marzo de $1991 .^{22}$ Finalmente, la correlación vuelve a ser negativa cuando la recuperación de la economía de los EUA coincide con la fuerte contracción observada en México durante 1995 debido a la crisis financiera. A continuación se analizan los dos canales de transmisión mencionados anteriormente.

Vínculos Comerciales. Para el periodo 1980-1987, las exportaciones siguen al PIB de los EUA en dirección contraria (-0.68) mientras que las importaciones lo siguen en la misma dirección (0.78) (ver Gráfica 6). Estos resultados son congruentes con la correlación negativa entre el tipo de cambio real y el PIB de los EUA (-0.47). Para el periodo 19881997, los signos de los coeficientes de correlación se invierten: la correlación del PIB de los EUA con las exportaciones es positiva (0.32), con las importaciones es negativa (-0.07) y con el tipo de cambio real es positiva ( 0.20 ). La relación entre las exportaciones y el PIB de los EUA se puede deber a que dicho país es un país importador de petróleo y a que una gran proporción de las exportaciones mexicanas durante la primera parte de la década de los ochenta provenían del petróleo. Así, el aumento en los precios del petróleo a principios de la década se reflejó en una menor actividad económica en los Estados Unidos y en

\footnotetext{
${ }^{22}$ Fechas del NBER.
} 
mayores exportaciones mexicanas. Por otra parte, la relación positiva entre estas dos variables a partir de 1988 es congruente con el hecho de que las exportaciones mexicanas cada vez dependen menos del petróleo y más de la demanda de los Estados Unidos. Asimismo, esta evidencia refuerza la hipótesis de que a partir de 1980 las exportaciones e importaciones se han visto afectadas en menor medida por la actividad económica y más por los desequilibrios generados por las crisis financieras.

\section{Gráfica 6 \\ Fluctuaciones Cíclicas en los EUA y México: 1980:03-1997:04}

PIB de México y PIB de los EUA
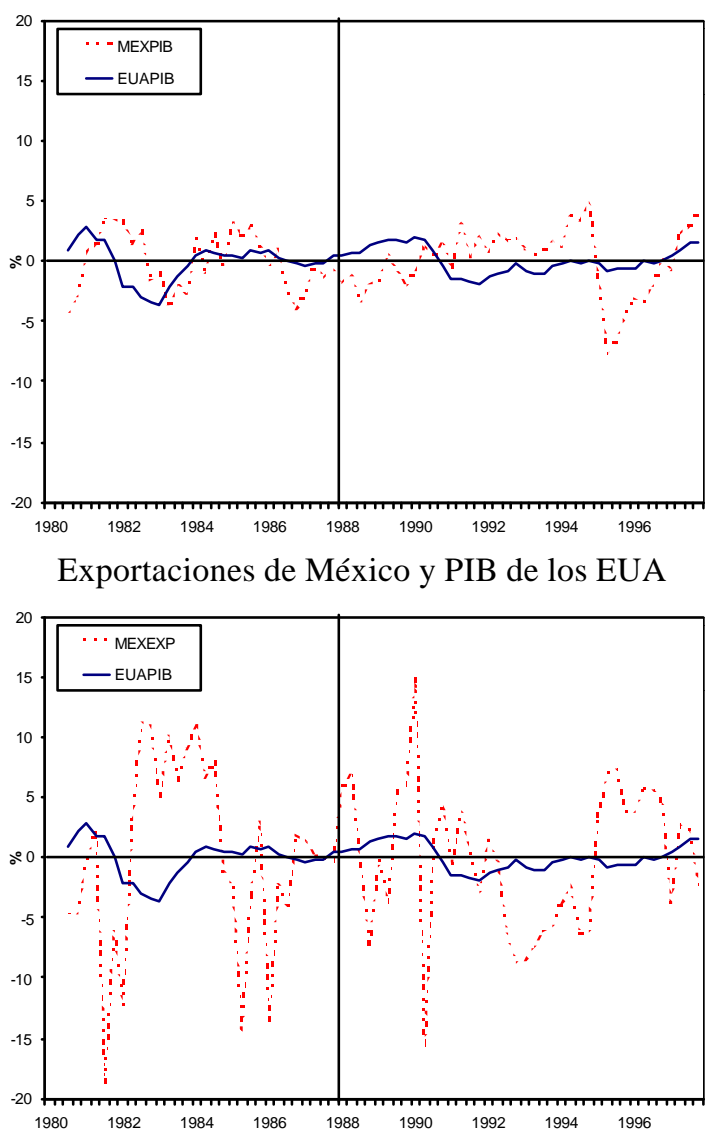

Inversión de México y PIB de los EUA
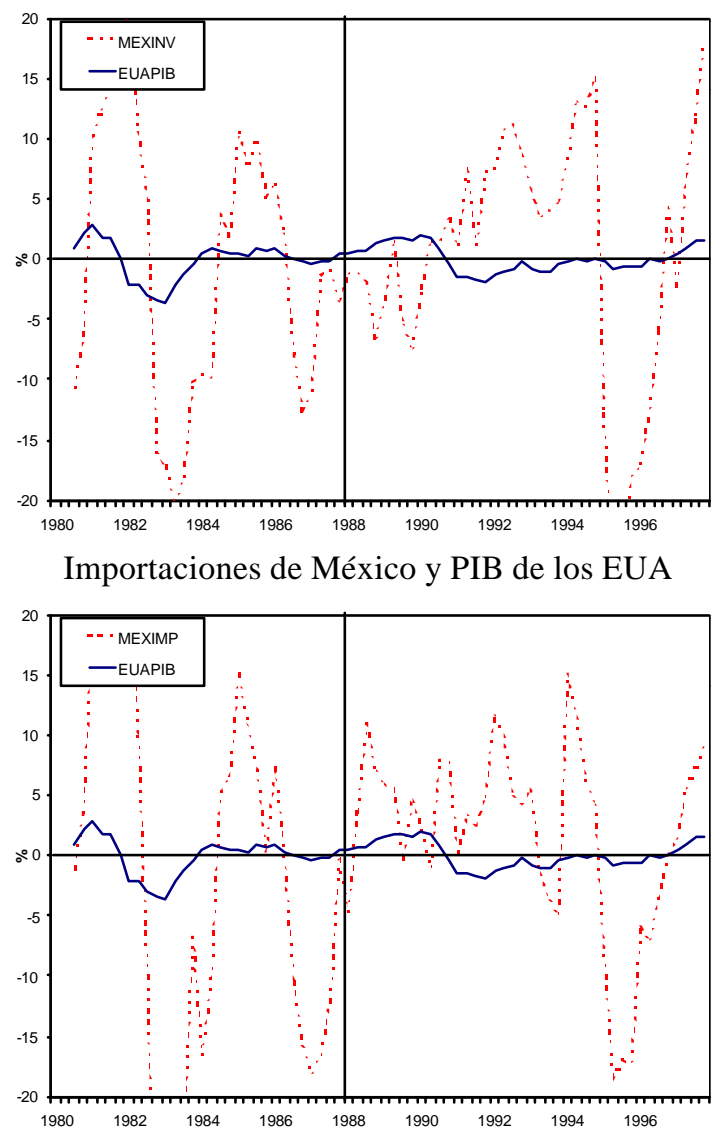

Mercados Financieros. Los coeficientes de correlación cruzada entre la tasa de interés de EUA y las variables mexicanas para los periodos 1980-1987 y 1988-1997 se presentan en el Cuadro 9. Para el periodo 1980-1987, la correlación entre la tasa de interés de los EUA y la de México es negativa (-0.53). Este es un resultado sorpresivo que parece no ser congruente ya que se esperaría que la apreciación observada en los tipos de cambio real y nominal (-0.66 y -0.58 respectivamente) pudiera ser el resultado de un incremento en las tasas de interés en México. Es difícil pensar que la correlación negativa entre las tasas de interés se debe a un efecto de causalidad de la tasa de los EUA sobre la tasa de México. Esta correlación negativa puede deberse a los diferentes caminos que ambas economías siguieron después de sus respectivas recesiones de principios de los años ochenta. Como se 
observa en la Gráfica 7, las tasas de interés en los EUA disminuyeron mientras la inflación caía. Por el contrario, en México éstas aumentaron junto con la tasa de inflación. De cualquier manera, un análisis más detallado sería interesante para comprender la interacción entre la tasa de interés y el tipo de cambio. Finalmente, la apreciación del tipo de cambio es congruente con la reducción en las exportaciones (-0.39) y con el incremento en las importaciones (0.78). Se observa también un efecto positivo sobre la inversión $(0.71)$ y el producto $(0.70)$.

\section{Cuadro 9}

Tasa de Interés de los EUA y Variables Mexicanas Datos Trimestrales: 1980:03 - 1997:04

\begin{tabular}{|c|c|c|c|c|c|c|c|c|c|}
\hline \multirow[t]{3}{*}{ Variable X } & \multicolumn{9}{|c|}{ Correlación Cruzada de la Tasa de Interés de los EUA con } \\
\hline & \multicolumn{4}{|c|}{ Rezagos } & \multirow[b]{2}{*}{$X_{t}$} & \multicolumn{4}{|c|}{ Adelantos } \\
\hline & $X_{t-4}$ & $\mathrm{X}_{\mathrm{t}-3}$ & $\mathrm{X}_{\mathrm{t}-2}$ & $\mathrm{X}_{\mathrm{t}-1}$ & & $X_{t+1}$ & $\mathrm{X}_{\mathrm{t}+2}$ & $X_{t+3}$ & $X_{t+4}$ \\
\hline \multicolumn{10}{|l|}{ Período 1980:03 - 1987:04 } \\
\hline PIB de México & -0.57 & -0.34 & 0.13 & 0.31 & 0.58 & 0.66 & 0.70 & 0.46 & 0.38 \\
\hline Exportaciones & 0.38 & 0.14 & -0.00 & -0.10 & -0.39 & -0.21 & -0.32 & -0.26 & -0.11 \\
\hline Importaciones & -0.34 & -0.10 & 0.23 & 0.51 & 0.68 & 0.78 & 0.53 & 0.14 & -0.09 \\
\hline Tipo de Cambio Real & -0.04 & -0.37 & -0.62 & -0.63 & -0.66 & -0.61 & -0.04 & 0.08 & 0.31 \\
\hline Tipo de Cambio Nominal & 0.59 & 0.17 & -0.21 & -0.44 & -0.58 & -0.66 & -0.41 & -0.38 & -0.27 \\
\hline Precios & 0.83 & 0.76 & 0.48 & 0.08 & -0.21 & -0.35 & -0.40 & -0.44 & -0.45 \\
\hline Tasa de Interés & -0.07 & -0.23 & -0.45 & -0.60 & -0.53 & -0.51 & -0.38 & -0.14 & -0.12 \\
\hline Inversión & -0.54 & -0.34 & 0.03 & 0.33 & 0.60 & 0.71 & 0.68 & 0.43 & 0.26 \\
\hline \multicolumn{10}{|l|}{ Período 1988:01 - 1997:04 } \\
\hline PIB de México & -0.25 & -0.27 & -0.27 & -0.29 & -0.33 & -0.38 & -0.38 & -0.34 & -0.21 \\
\hline Exportaciones & 0.17 & 0.27 & 0.25 & 0.27 & 0.33 & 0.44 & 0.58 & 0.59 & 0.43 \\
\hline Importaciones & 0.04 & 0.09 & 0.04 & -0.04 & -0.15 & -0.26 & -0.27 & -0.19 & -0.07 \\
\hline Tipo de Cambio Real & -0.00 & 0.06 & 0.16 & 0.30 & 0.49 & 0.50 & 0.46 & 0.34 & 0.17 \\
\hline Tipo de Cambio Nominal & 0.36 & 0.34 & 0.34 & 0.37 & 0.51 & 0.59 & 0.62 & 0.58 & 0.47 \\
\hline Precios & 0.45 & 0.37 & 0.28 & 0.20 & 0.19 & 0.27 & 0.39 & 0.52 & 0.63 \\
\hline Tasa de Interés & 0.00 & -0.07 & -0.08 & -0.01 & 0.24 & 0.32 & 0.21 & 0.10 & -0.04 \\
\hline Inversión & -0.21 & -0.26 & -0.30 & -0.36 & -0.44 & -0.49 & -0.48 & -0.38 & -0.02 \\
\hline
\end{tabular}

Para el periodo 1988-1997, los resultados sugieren relaciones en la dirección opuesta. En este caso hay una relación positiva con la tasa de interés en México (0.32). La depreciación del tipo de cambio nominal (0.59) y real (0.50) sugiere que el incremento en la tasa de interés en México es menor que en los EUA. La correlación positiva de la tasa de interés de los EUA con las exportaciones (0.58) y negativa con las importaciones (-0.27) es congruente con la depreciación del tipo de cambio. Finalmente, hay una reducción en la inversión (-0.49) y en el producto (-0.38). 


\section{Gráfica 7}

Tasas de Interés e Inflación en los EUA y México: 1980:03-1997:04

Tasas de Interés e Inflación en los EUA
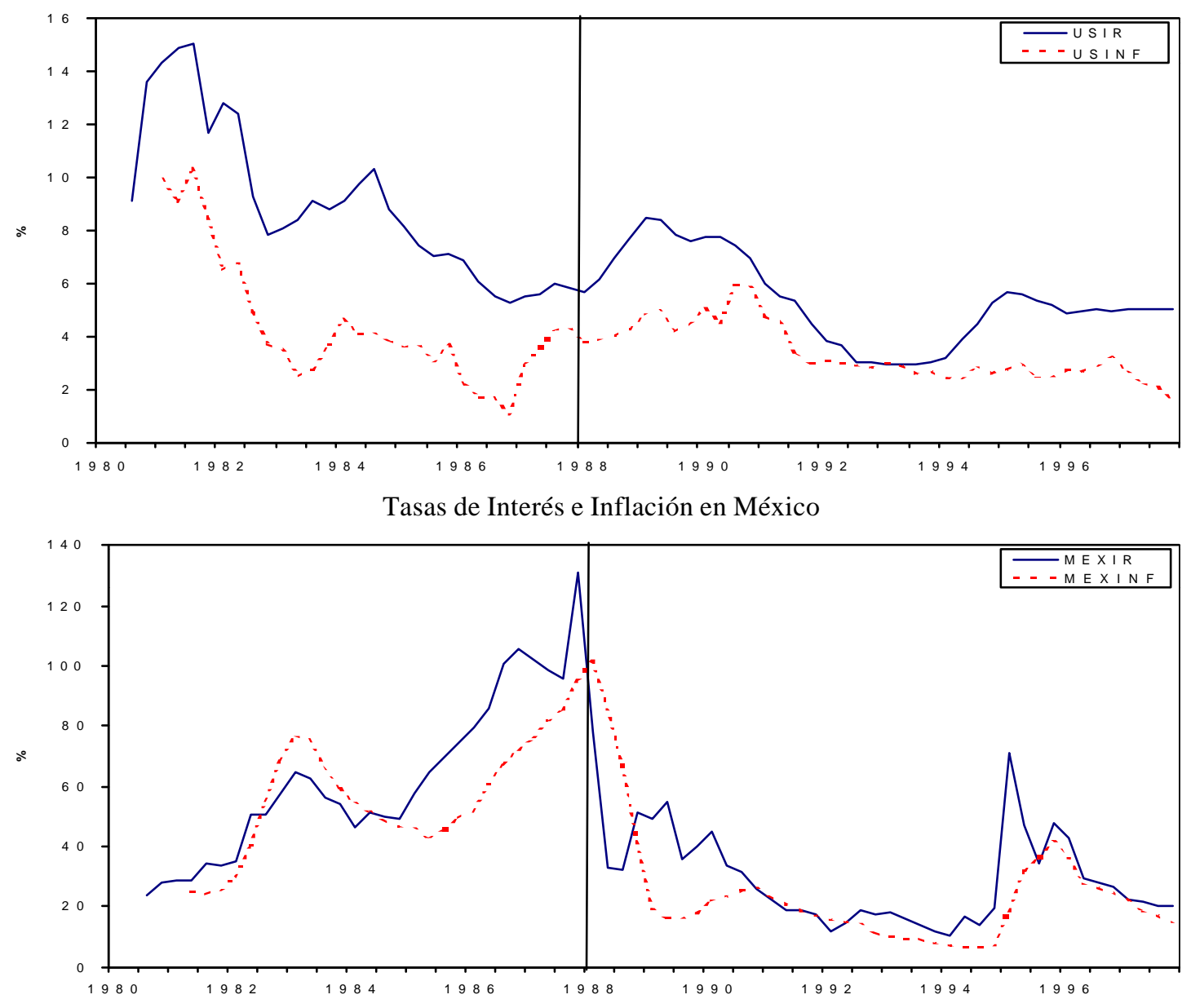

Estos resultados confirman tres de los resultados anteriores. Primero, a partir de 1980 las exportaciones mexicanas son contracíclicas; segundo, las tasas de interés en México son contracíclicas; y tercero, la correlación entre los ciclos económicos de los EUA y de México pasó de positiva antes de 1987 a negativa después de 1988. Estos resultados sugieren que la relación negativa entre ambos ciclos en los últimos años puede deberse a que los efectos del canal financiero dominan a los del canal comercial. Por el lado comercial, el incremento en el PIB de los EUA genera un aumento en la demanda por exportaciones mexicanas que afecta positivamente al PIB de México. Sin embargo por el lado financiero un aumento en el PIB de los EUA propicia que la Reserva Federal incremente las tasas de interés en los EUA. Lo anterior se traduce en un aumento en la tasa de interés en México que eventualmente genera una contracción en el producto mexicano. Por consiguiente, en la medida en que se intensifique el canal comercial y se disminuya la vulnerabilidad financiera de la economía mexicana, se podrá esperar una relación positiva entre el ciclo económico mexicano y el de los EUA. 


\section{$\underline{\text { Análisis con Vectores Autorregresivos (VAR) }}$}

Al igual que en la sección anterior, las variables se especificaron en primeras diferencias y los VARs se estimaron con dos rezagos. Para el periodo 1980-1987, la respuesta de las variables mexicanas ante una perturbación positiva en el PIB de los EUA se presenta en la Gráfica 8.1. Después de la paerturbación, las importaciones, la inversión y el PIB aumentan mientras que las exportaciones disminuyen y el tipo de cambio se aprecia. De la misma manera, la respuesta a una perturbación en la tasa de interés de los EUA se presenta en la Gráfica 8.2. Después del incremento en la tasa de interés de los EUA, la tasa de interés en México y las exportaciones disminuyen, el tipo de cambio se aprecia y las importaciones, la inversión y el PIB aumentan. Nuevamente se observa una incongruencia entre la respuesta negativa de la tasa de interés (aunque ésta no es significativa) y la apreciación del tipo de cambio. Sin embargo, estos resultados nuevamente muestran el comportamiento contracíclico de las exportaciones y la importancia de las fluctuaciones en el tipo de cambio para explicar los movimientos en las importaciones y exportaciones.

\section{Gráfica 8.1}

Respuesta a una Perturbación Positiva en el PIB de los EUA: 1980:03-1987:04

Respuesta del PIB de México

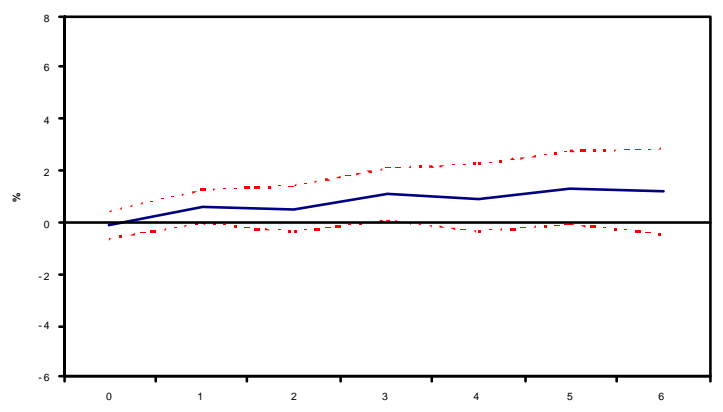

Respuesta de la Inversión de México
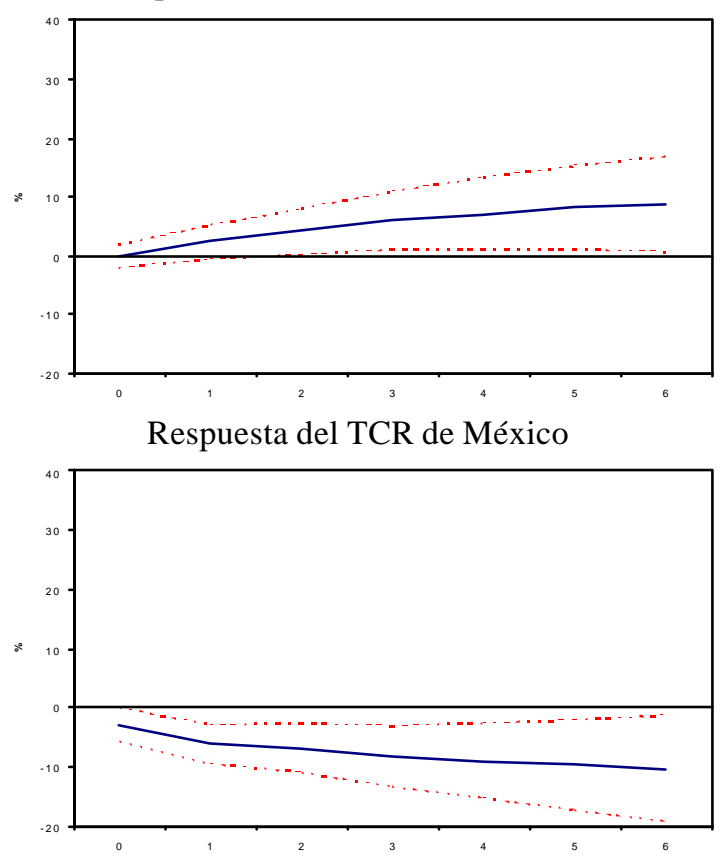

Respuesta de las Exportaciones de México

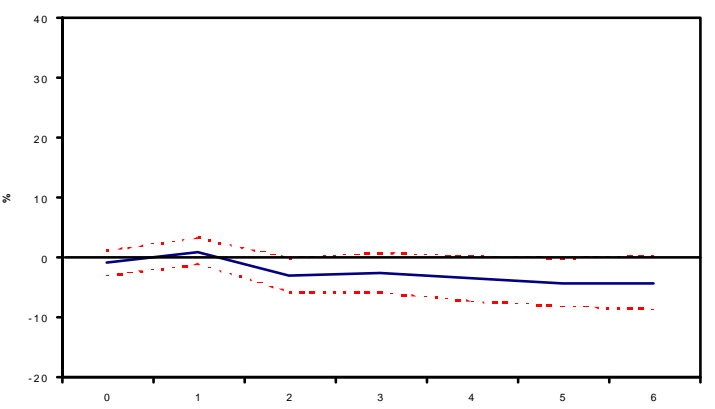

Respuesta de las Importaciones de México

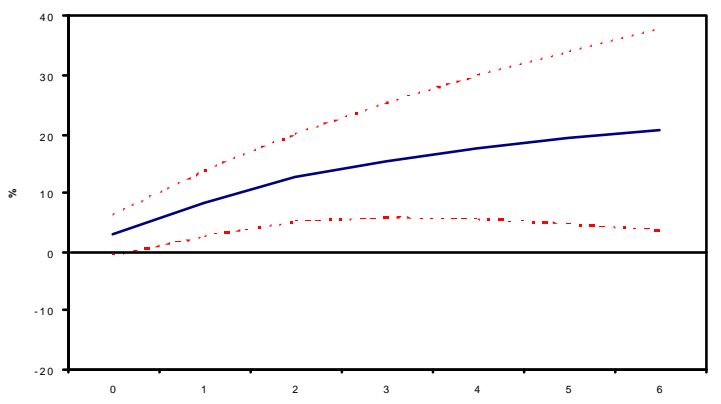


Gráfica 8.2

Respuesta a una Perturbación Positiva en la Tasa de Interés de los EUA: 1980:03-1987:04

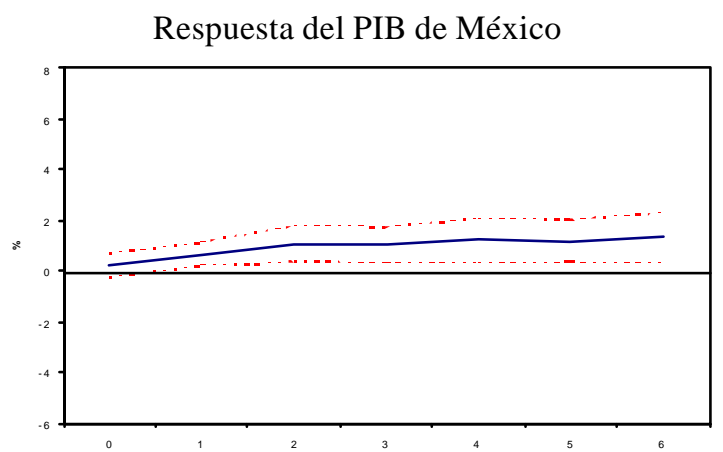

Respuesta de la Inversión de México
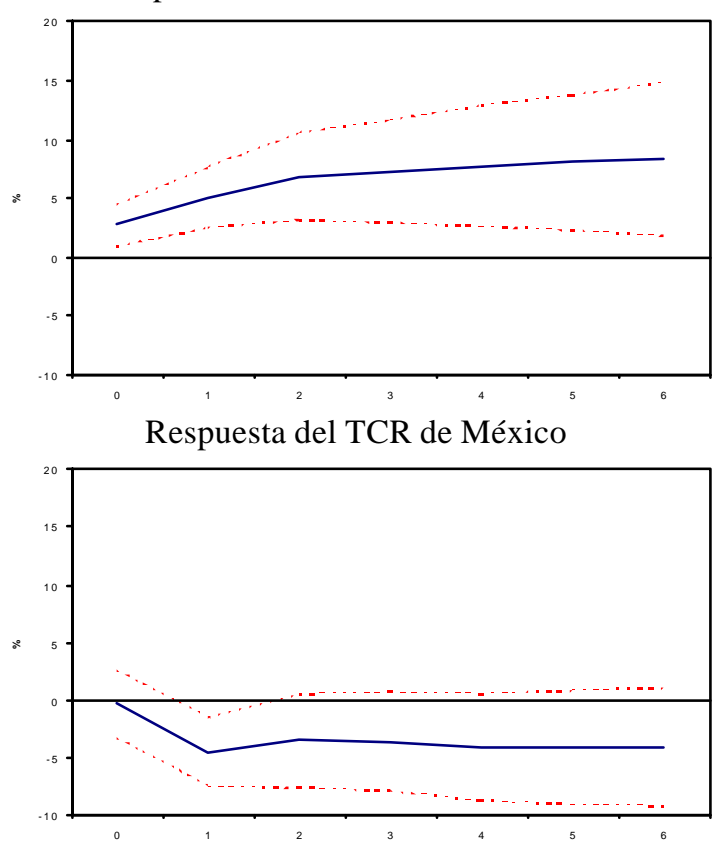

Respuesta de las Exportaciones de México

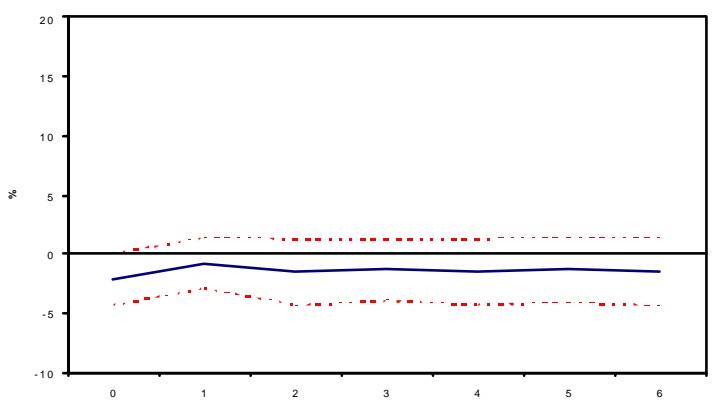

Respuesta de las Importaciones de México

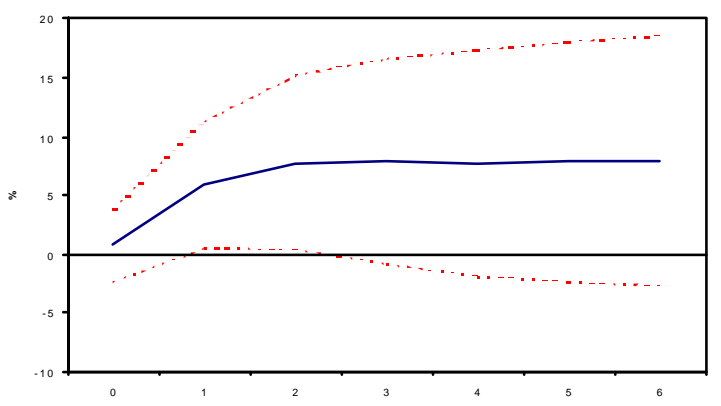

Respuesta de Tasa de Interés de México

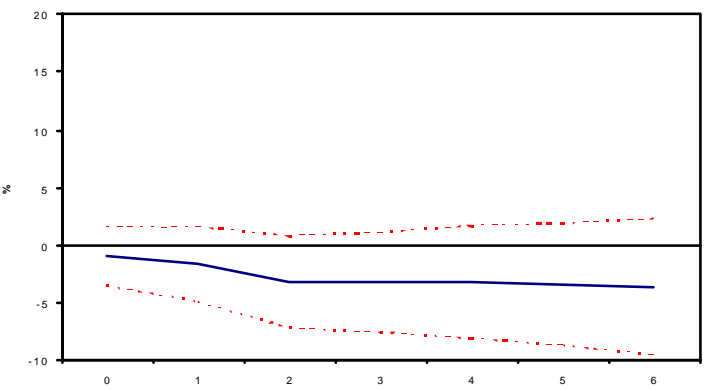

Los resultados para el periodo 1988-1997 se muestran en las Gráficas 8.3 y 8.4. Aún cuando la estimación puntual de las funciones impulso respuesta es consistente con la evidencia de los coeficientes de correlación presentada en los Cuadros 8 y 9 , éstas no son significativas. La dificultad para identificar funciones impulso respuesta que sean significativas es compatible con el hecho de que dichos coeficientes de correlación son cercanos a cero. Estos resultados sugieren que la correlación entre los ciclos económicos de México y los EUA es más débil a partir de 1988. 


\section{Gráfica 8.3}

\section{Respuesta a una Perturbación Positiva en el PIB de los EUA: 1988:01-1997:04}

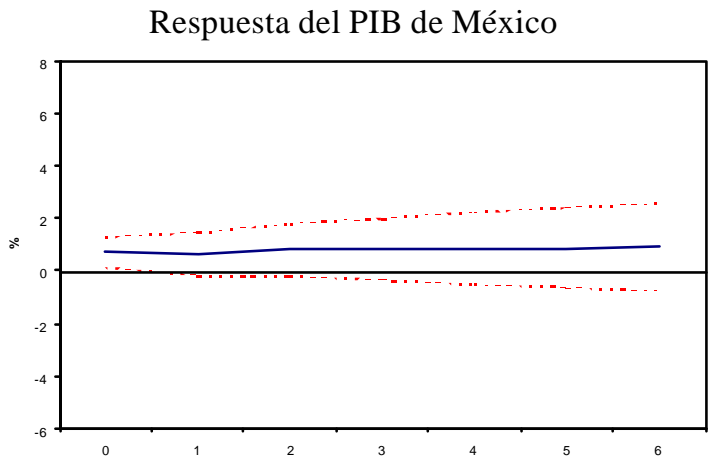

Respuesta de las Exportaciones de México

Respuesta de la Inversión de México
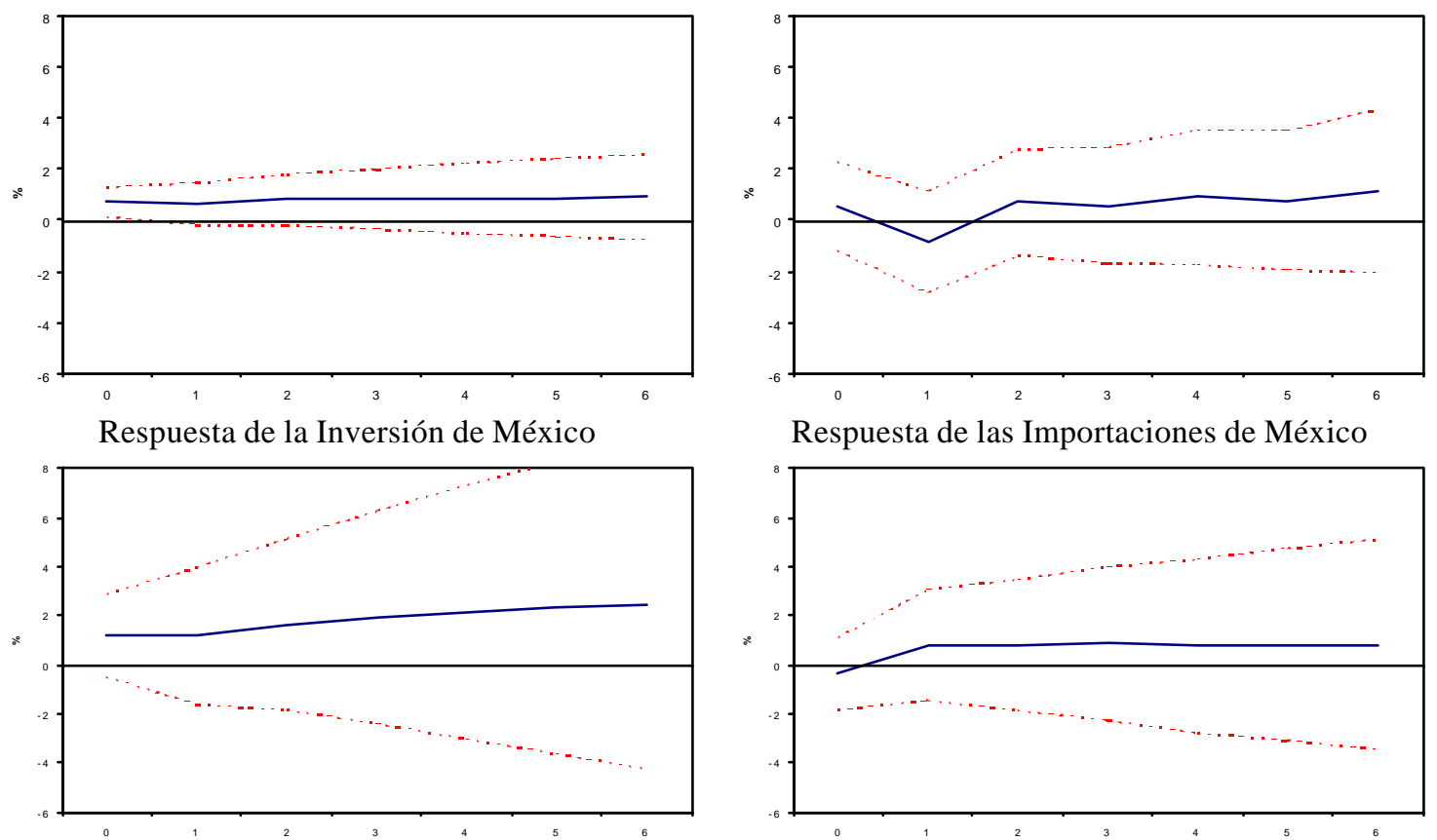

Respuesta de las Importaciones de México

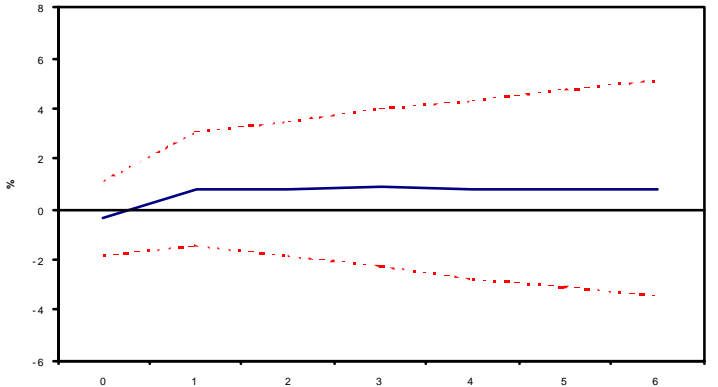

Respuesta del TCR de México

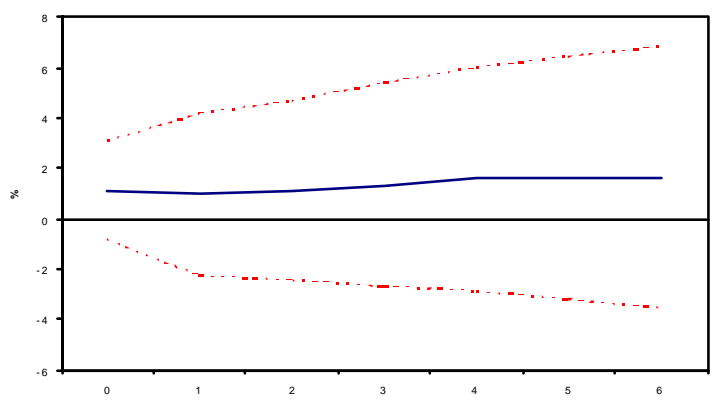


Gráfica 8.4

Respuesta a una Perturbación Positiva en la Tasa de Interés de los EUA: 1988:01-1997:04

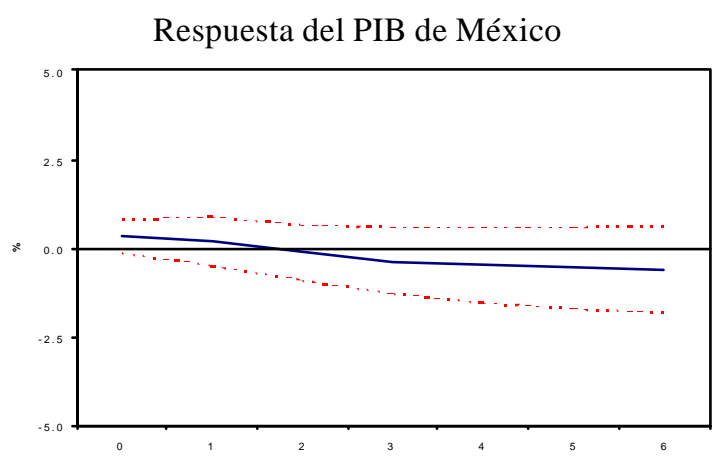

Respuesta de la Inversión de México
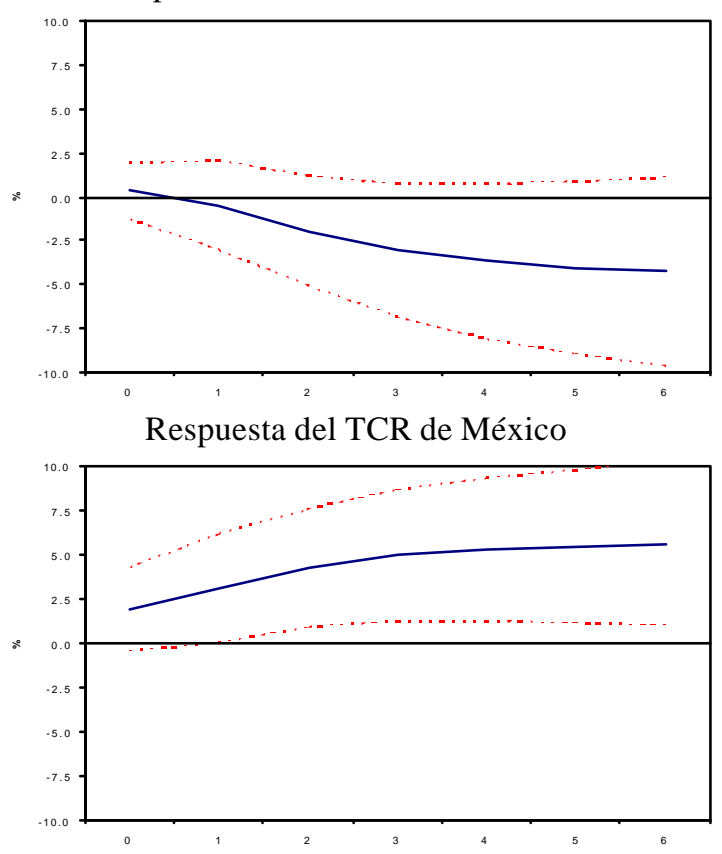

Respuesta de las Exportaciones de México

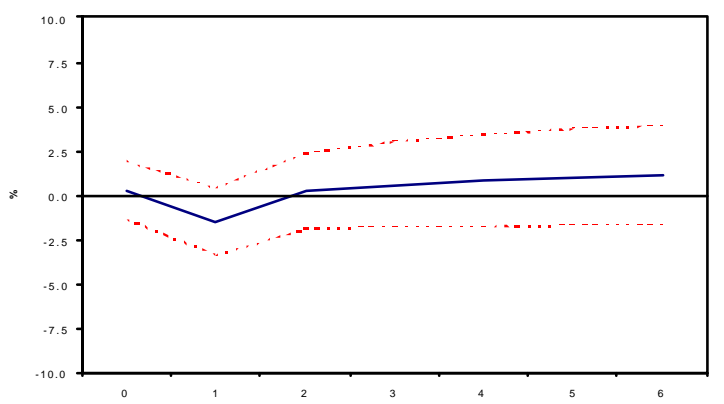

Respuesta de las Importaciones de México

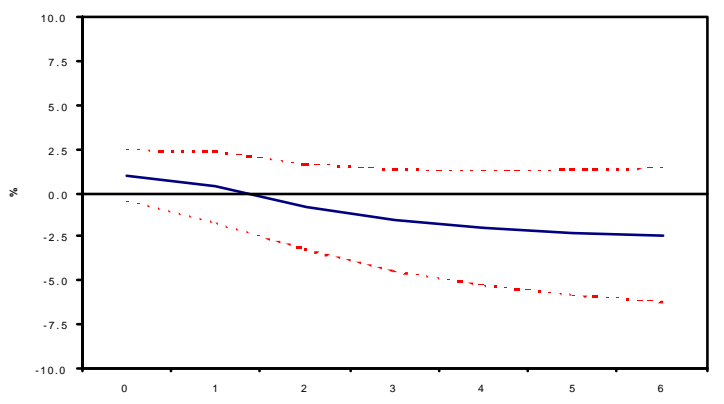

Respuesta de la Tasa de Interés de México

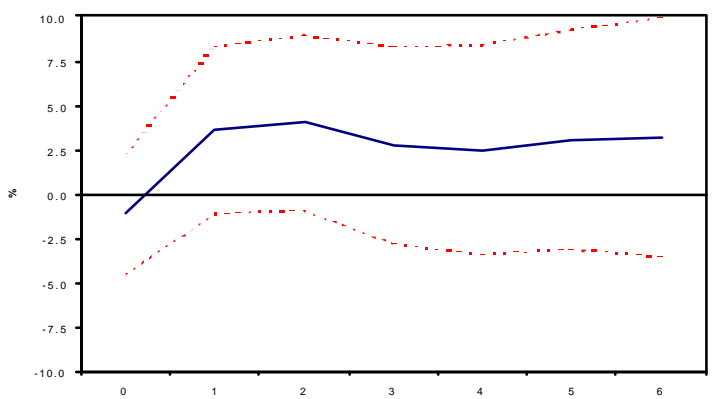

\subsection{México y Otros Países de América Latina}

En esta sección se analiza la relación entre el ciclo económico en México y en otros países de América Latina. A diferencia de la sección anterior, en la que se hizo referencia a los resultados documentados por otros autores para países industrializados, en este caso se documentan directamente las principales características de los ciclos económicos de Argentina, Brasil, Chile, Colombia, Perú y Venezuela y se comparan con el caso de México. También se analiza la relación entre los ciclos económicos de estos países y México. 
Otra diferencia importante con respecto a la sección anterior es el periodo de estudio. De acuerdo con las estadísticas del Fondo Monetario Internacional ${ }^{23}$ se cuenta con datos homogéneos para los países mencionados únicamente a partir de 1970 y con periodicidad anual. ${ }^{24}$ Debido al número de observaciones, tampoco es posible dividir el análisis en dos periodos como en el caso anterior. Por estas razones se examina un sólo periodo: 1970-1997.

\subsubsection{Características de los Ciclos Económicos}

A continuación se describen brevemente las principales características de los ciclos económicos en los países latinoamericanos mencionados previamente. En el Apéndice 1 se presenta la definición de los datos utilizados para cada país y su fuente. Siguiendo la misma metodología que en las secciones anteriores se documentan los casos de Argentina, Brasil, Chile, Colombia, México, ${ }^{25}$ Perú y Venezuela. Para facilitar la exposición únicamente se presenta un resumen de dichos resultados en el Cuadro $10 .^{26}$ En cada una de las columnas de dicho Cuadro se reportan los resultados para cada uno de los países analizados durante el periodo 1970-1997.

Se observa que la volatilidad de las fluctuaciones cíclicas del PIB es similar en todos los países. Colombia tiene la menor con $2.4 \%$ y Perú la mayor con $7.5 \%$. Asimismo, en términos generales la volatilidad relativa de cada una de las variables es similar en todos los países. Sin embargo, llama la atención la alta volatilidad del consumo del gobierno en Argentina y de los precios y variables nominales en los países que han tenido episodios de hiperinflación (Argentina, Brasil y Perú).

Por otra parte, como era de esperarse se observa que en todos los países el consumo es procíclico y contemporáneo con el PIB, excepto en Colombia, donde la relación no es contemporánea sino que el consumo sigue al PIB con un periodo de rezago. Con respecto al consumo del gobierno y a la inversión, se observa que ambos son procíclicos y en general contemporáneos con el PIB. Sin embargo, hay dos aspectos que destacan. En el caso de Colombia, aún cuando las correlaciones contemporáneas del consumo del gobierno y de la inversión con el PIB son positivas (procíclicas), también se observa una relación negativa entre los rezagos de estas variables y el PIB. La metodología que se utiliza en este trabajo sugeriría que tanto el consumo del gobierno como la inversión en Colombia son contracíclicos y anteceden al ciclo económico. Sin embargo, este resultado es contrario a lo reportado por Restrepo y Reyes [2000] para el periodo 1978-1998. Por consiguiente, es preferible sostener la hipótesis de que ambas variables son procíclicas. Por otra parte, el segundo aspecto que llama la atención es que en Brasil se observa que el consumo del gobierno es contracíclico y antecede al ciclo económico.

\footnotetext{
${ }^{23}$ Ver la publicación "International Financial Statistics” del Fondo Monetario Internacional.

${ }^{24}$ Las variables reales con periodicidad trimestral no están disponibles para todos los países.

${ }^{25}$ Las características del ciclo económico en México que fueron reportadas en las secciones anteriores no son estrictamente comparables con los resultados documentados para los otros países latinoamericanos. Ello, debido a que el periodo de estudio es diferente. Por esta razón y para poder hacer una comparación adecuada, en esta sección se vuelven a documentar las características del ciclo en México exactamente de la misma manera como se hace para los otros países.

${ }^{26}$ Los resultados específicos para cada país están disponibles a solicitud de los mismos interesados.
} 


\section{Cuadro 10 \\ Características de los Ciclos Económicos en Latinoamérica Datos Anuales: 1970 - 1997}

\begin{tabular}{|c|c|c|c|c|c|c|c|}
\hline Variable $\mathrm{X}$ & \multicolumn{7}{|c|}{ Correlación Cruzada del PIB de cada país con: } \\
\hline & México & Argentina & Brasil & Chile & Colombia & Perú & Venezuela \\
\hline PIB & $4.6 \%$ & $5.4 \%$ & $5.1 \%$ & $7.1 \%$ & $2.4 \%$ & $7.5 \%$ & $5.7 \%$ \\
\hline Consumo & $\begin{array}{c}1.05 \\
+ \\
\mathrm{C}\end{array}$ & $\begin{array}{c}1.34 \\
+ \\
\mathrm{C}\end{array}$ & $\begin{array}{c}1.56 \\
+ \\
\mathrm{C}\end{array}$ & $\begin{array}{c}1.32 \\
+ \\
\mathrm{C}\end{array}$ & $\begin{array}{c}1.39 \\
+ \\
\mathrm{G}\end{array}$ & $\begin{array}{c}1.01 \\
+ \\
\mathrm{C}\end{array}$ & $\begin{array}{c}1.38 \\
+ \\
\mathrm{C}\end{array}$ \\
\hline Consumo Gobierno & $\begin{array}{c}2.76 \\
+ \\
\mathrm{C} \\
\end{array}$ & $\begin{array}{c}15.13 \\
+ \\
\mathrm{C} \\
\end{array}$ & $\begin{array}{c}7.12 \\
- \\
\mathrm{L} \\
\end{array}$ & $\begin{array}{c}1.35 \\
+ \\
G \\
\end{array}$ & $\begin{array}{ll}3.91 \\
- & + \\
\mathrm{L} & \mathrm{G}\end{array}$ & $\begin{array}{c}2.48 \\
+ \\
\mathrm{C} \\
\end{array}$ & $\begin{array}{c}2.27 \\
+ \\
\mathrm{C} \\
\end{array}$ \\
\hline Inversión & $\begin{array}{c}2.93 \\
+ \\
\mathrm{C}\end{array}$ & $\begin{array}{c}3.11 \\
+ \\
\mathrm{C}\end{array}$ & $\begin{array}{c}2.48 \\
+ \\
\mathrm{C}\end{array}$ & $\begin{array}{c}2.22 \\
+ \\
\mathrm{C}\end{array}$ & $\begin{array}{cc}3.32 \\
- & + \\
\mathrm{L} & \mathrm{G}\end{array}$ & $\begin{array}{c}3.21 \\
+ \\
C\end{array}$ & $\begin{array}{c}4.13 \\
+ \\
\mathrm{C}\end{array}$ \\
\hline Importaciones & $\begin{array}{c}3.12 \\
+ \\
\mathrm{L}\end{array}$ & $\begin{array}{c}5.48 \\
+ \\
\mathrm{C}\end{array}$ & $\begin{array}{c}3.85 \\
+ \\
\mathrm{C}\end{array}$ & $\begin{array}{c}2.65 \\
+ \\
C\end{array}$ & $\begin{array}{c}4.79 \\
+ \\
\mathrm{C}\end{array}$ & $\begin{array}{c}2.86 \\
+ \\
\mathrm{C}\end{array}$ & $\begin{array}{c}4.85 \\
+ \\
\mathrm{C}\end{array}$ \\
\hline Exportaciones & $\begin{array}{ll}5.70 \\
- & + \\
\mathrm{L} & \mathrm{G}\end{array}$ & $\begin{array}{ll}4.83 \\
-\quad+ \\
\mathrm{C} & \mathrm{G}\end{array}$ & $\begin{array}{c}2.66 \\
- \\
G\end{array}$ & $\begin{array}{c}2.72 \\
- \\
G\end{array}$ & $\begin{array}{l}7.65 \\
+\quad- \\
\text { L } \quad \text { G }\end{array}$ & $\begin{array}{c}3.22 \\
+ \\
\mathrm{L}\end{array}$ & $\begin{array}{c}4.01 \\
+ \\
\mathrm{L}\end{array}$ \\
\hline Dinero & $\begin{array}{c}6.88 \\
- \\
G\end{array}$ & $\begin{array}{c}23.62 \\
- \\
G\end{array}$ & $\begin{array}{c}24.64 \\
- \\
G\end{array}$ & $\begin{array}{c}8.94 \\
- \\
G\end{array}$ & $\begin{array}{c}7.32 \\
+ \\
\mathrm{L}\end{array}$ & $\begin{array}{c}18.19 \\
- \\
\mathrm{C}\end{array}$ & $\begin{array}{c}5.02 \\
+ \\
G\end{array}$ \\
\hline Dinero Real & $\begin{array}{c}4.66 \\
+ \\
\mathrm{C}\end{array}$ & $\begin{array}{c}4.11 \\
+ \\
G\end{array}$ & $\begin{array}{c}3.35 \\
+ \\
\mathrm{C}\end{array}$ & $\begin{array}{c}3.34 \\
+ \\
\mathrm{C}\end{array}$ & $\begin{array}{c}7.30 \\
+ \\
\mathrm{L}\end{array}$ & $\begin{array}{c}3.71 \\
+ \\
G\end{array}$ & $\begin{array}{c}3.36 \\
+ \\
G\end{array}$ \\
\hline Tipo de Cambio & $\begin{array}{c}10.72 \\
- \\
\mathrm{C}\end{array}$ & $\begin{array}{c}26.84 \\
- \\
\mathrm{G}\end{array}$ & $\begin{array}{c}25.00 \\
- \\
\mathrm{G}\end{array}$ & $\begin{array}{c}11.13 \\
- \\
\mathrm{G}\end{array}$ & $\begin{array}{c}6.79 \\
- \\
G\end{array}$ & $\begin{array}{c}19.83 \\
- \\
\mathrm{C}\end{array}$ & $\begin{array}{c}4.05 \\
+ \\
\mathrm{L}\end{array}$ \\
\hline Tipo de Cambio Real & $\begin{array}{c}3.99 \\
- \\
C\end{array}$ & $\begin{array}{c}5.68 \\
- \\
C\end{array}$ & $\begin{array}{c}2.75 \\
- \\
G\end{array}$ & $\begin{array}{c}2.75 \\
- \\
C\end{array}$ & $\begin{array}{c}5.96 \\
- \\
G\end{array}$ & $\begin{array}{c}1.90 \\
+ \\
\mathrm{L}\end{array}$ & $\begin{array}{l}2.86 \\
+\quad- \\
L\end{array}$ \\
\hline Precios & $\begin{array}{c}8.59 \\
- \\
C\end{array}$ & $\begin{array}{c}25.44 \\
- \\
G\end{array}$ & $\begin{array}{c}25.02 \\
- \\
\mathrm{G}\end{array}$ & $\begin{array}{c}10.81 \\
- \\
\mathrm{G}\end{array}$ & $\begin{array}{c}2.53 \\
- \\
\mathrm{G}\end{array}$ & $\begin{array}{c}20.21 \\
- \\
\mathrm{C}\end{array}$ & $\begin{array}{c}3.39 \\
+ \\
\mathrm{G}\end{array}$ \\
\hline
\end{tabular}

Nota: Para cada variable, los números en el primer renglón se refieren a la volatilidad (desviación estándar) de la variable con respecto a la volatilidad del PIB. Los signos en el segundo renglón indican si la variable es procíclica (+), contracíclica (-) o no correlacionada con el PIB $( \pm)$. La letra en el tercer renglón señala si los cambios en la variable anteceden (L), son contemporáneos (C) o siguen con rezago $(\mathrm{G})$ al producto.

Las diferencias más importantes entre los países analizados se encuentran en la relación que el PIB de cada país tiene con las importaciones y exportaciones. Por una parte, se observa que en todos los casos las importaciones son procíclicas y contemporáneas excepto en el caso de México donde que anteceden al ciclo. Sin embargo, la relación entre el PIB y las exportaciones presenta algunas diferencias importantes. En los casos de Perú y Venezuela las exportaciones son procíclicas y anteceden al ciclo. Estos resultados son 
congruentes con el carácter procíclico del tipo de cambio real en ambos países. ${ }^{27}$ Por el contrario, en Brasil y Chile se observa que tanto las exportaciones como el tipo de cambio real son contracíclicas. ${ }^{28}$ Finalmente, en México, Argentina y Colombia la evidencia no es muy clara respecto a la relación entre las exportaciones y el PIB. Los resultados sugieren que para México y Argentina las exportaciones primero son contracíclicas y después siguen al PIB de manera procíclica. El resultado opuesto se observa en Colombia, donde las exportaciones anteceden al ciclo contracíclicamente y después lo siguen procíclicamente. El comportamiento del tipo de cambio real, contracíclico en los tres países, sugiere que la opción bajo la cual las exportaciones son contracíclicas en los tres países es la más adecuada. $^{29}$

El hecho de encontrar que en varios países las exportaciones son contracíclicas sugiere que, al igual que en el caso de México, éstas parecen verse influidas por otras variables y no únicamente por el nivel de actividad económica como al parecer sucede en los países industrializados. Esta es una diferencia de los ciclos económicos en Latinoamérica con respecto a los ciclos en economías industrializadas que puede deberse, como en el caso de México, a la inestabilidad nominal que la mayor parte de los países latinoamericanos ha experimentado en las últimas tres décadas.

Con respecto a la cantidad de dinero, en términos nominales ésta parece ser contracíclica y en términos reales procíclica en todos los países excepto en Venezuela y Colombia, donde en términos nominales también es procíclica. Por otra parte, al analizar los tipos de cambio nominal y real se observa que en general ambos son contracíclicos excepto en los casos de Perú y Venezuela. En Perú el tipo de cambio real es procíclico, lo cual es consistente con el carácter procíclico de las exportaciones. Los resultados también muestran que en Venezuela el tipo de cambio real antecede al PIB de manera procíclica y después lo sigue en sentido contrario (contracíclico). Sin embargo, dado que las exportaciones son procíclicas se puede pensar que el tipo de cambio en Venezuela es procíclico.

Finalmente, se observa que los precios son contracíclicos en todos los países excepto en Venezuela. Este resultado es congruente con la relación negativa que se encuentra en casi todos los países entre el PIB y el dinero en términos nominales y el tipo de cambio nominal. Asimismo, el carácter procíclico de estas dos variables en Venezuela también es congruente con el carácter procíclico de los precios.

De los resultados anteriores se pueden identificar cuatro similitudes en los ciclos económicos de los siete países latinoamericanos analizados: i) de acuerdo a lo esperado el consumo y la inversión son procíclicos y contemporáneos con el PIB; ii) el consumo del gobierno (excepto en Brasil) es procíclico a diferencia de los países desarrollados en donde no esta correlacionado con el PIB; iii) el dinero en términos reales es procíclico; y iv) los

\footnotetext{
${ }^{27}$ Un incremento en el tipo de cambio real representa una depreciación.

${ }^{28}$ En el caso de Chile, Belaisch y Soto [1998] reportan que para el periodo 1986-1997 las exportaciones son procíclicas. Fuera de esta excepción, todos sus resultados son congruentes con los encontrados en este trabajo.

${ }^{29}$ Para el caso de Argentina, Kydland y Zarazaga [1997] también encuentran que las exportaciones son contracíclicas. Sin embargo, en el caso de Colombia Restrepo y Reyes [2000] indican que éstas son procíclicas.
} 
precios son contracíclicos (excepto en Venezuela) por lo que las variaciones en el PIB parecen obedecer principalmente a movimientos de oferta y no de demanda.

Por otra parte, también se encontraron algunas diferencias importantes. En los casos de México, Argentina, Brasil, Chile y Colombia las importaciones y exportaciones durante el periodo de estudio se mueven en sentido contrario. En contraste, en Perú y Venezuela tanto las importaciones como las exportaciones son procíclicas. Analizar con mayor detenimiento si esta diferencia se debe a la influencia de las crisis económicas experimentadas en algunos de estos países es un tema que queda abierto para futuras investigaciones.

\subsubsection{Relación entre los Ciclos Económicos}

Como se mencionó, los vínculos comerciales de México con el resto de América Latina no son muy importantes en términos relativos. Sin embargo, México sigue siendo una economía en desarrollo y forma parte del bloque latinoamericano por lo que el desempeño de los otros países de la región puede influir en la percepción que los inversionistas, y en especial los extranjeros, puedan tener sobre la economía mexicana. A continuación se intenta identificar si efectivamente existe una relación clara entre el ciclo económico en México y el de algunos otros países de América Latina.

Antes de examinar la relación entre los ciclos económicos es interesante tener en cuenta el tamaño relativo que cada economía tiene dentro del grupo de países analizados. Las siguientes estadísticas muestran el porcentaje que el PIB de cada país representó en el total de los siete países estudiados.

\begin{tabular}{l|c}
\multicolumn{1}{c|}{ País } & $\begin{array}{c}\text { Participación en el } \\
\text { Total de los } 7 \\
\text { Países de A.L. }\end{array}$ \\
\hline México & $22.3 \%$ \\
Argentina & $18.2 \%$ \\
Brasil & $41.7 \%$ \\
Chile & $4.0 \%$ \\
Colombia & $5.0 \%$ \\
Perú & $3.5 \%$ \\
Venezuela & $5.2 \%$
\end{tabular}

Se observa que la participación de México es importante. Junto con las de Brasil y Argentina representan aproximadamente el $80 \%$ del PIB total de los siete países analizados. Por consiguiente, se esperaría que los cambios en la situación económica de cualquiera de estos tres países pueda tener efectos importantes en algunos otros países de la región.

A continuación se analiza la relación entre el ciclo económico de México y el de los otros seis países. Los primeros resultados se presentan en el Cuadro 11. Los coeficientes de correlación entre el componente cíclico de los PIBs de los países en cuestión, para el periodo 1970-1997, sugieren que la actividad económica en Argentina, Brasil, Colombia y 
Venezuela antecede al ciclo económico en México. Por el contrario, el producto en Perú parece seguir con cierto rezago al PIB de México.

\section{Cuadro 11 \\ PIB de México y PIB de países Latinoamericanos \\ Datos Anuales: 1970 - 1997}

\begin{tabular}{|c|c|c|c|c|c|c|c|c|c|c|c|}
\hline \multirow{3}{*}{ Variable $\mathrm{X}$} & \multirow{3}{*}{$\begin{array}{l}\text { Desv. } \\
\text { Est. } \\
(\%)\end{array}$} & \multirow{3}{*}{$\begin{array}{c}\text { D. E. } \\
\text { Relativa } \\
\text { al PIB }\end{array}$} & \multicolumn{9}{|c|}{ Correlación Cruzada del PIB de México con el PIB de: } \\
\hline & & & \multicolumn{4}{|c|}{ Rezagos } & & \multicolumn{4}{|c|}{ Adelantos } \\
\hline & & & $\mathrm{X}_{\mathrm{t}-4}$ & $X_{t-3}$ & $X_{t-2}$ & $X_{t-1}$ & $X_{t}$ & $X_{t+1}$ & $X_{t+2}$ & $X_{t+3}$ & $\mathrm{X}_{\mathrm{t}+4}$ \\
\hline México & 0.05 & 1.00 & & & & & & & & & \\
\hline Argentina & 0.05 & 1.19 & 0.33 & 0.25 & 0.36 & 0.44 & 0.32 & 0.32 & 0.35 & 0.19 & -0.01 \\
\hline Brasil & 0.05 & 1.13 & 0.52 & 0.53 & 0.49 & 0.32 & 0.10 & -0.14 & -0.32 & -0.30 & -0.03 \\
\hline Chile & 0.07 & 1.55 & -0.03 & 0.24 & 0.54 & 0.76 & 0.59 & 0.17 & -0.20 & -0.49 & -0.58 \\
\hline Colombia & 0.02 & 0.52 & 0.40 & 0.64 & 0.79 & 0.70 & 0.42 & 0.06 & -0.21 & -0.34 & -0.37 \\
\hline Perú & 0.08 & 1.66 & 0.16 & 0.04 & -0.08 & -0.02 & 0.15 & 0.24 & 0.29 & 0.32 & 0.32 \\
\hline Venezuela & 0.06 & 1.25 & 0.78 & 0.85 & 0.72 & 0.46 & 0.23 & 0.01 & -0.27 & -0.47 & -0.65 \\
\hline
\end{tabular}

Para complementar los resultados anteriores, en la Gráfica 9 se presentan las funciones impulso respuesta estimadas mediante el uso de VARs. En la primer columna se presenta la respuesta del PIB de México a una perturbación positiva en el PIB de cada uno de los otros países. ${ }^{30}$ Aunque la respuesta del PIB de México no es significativa al $90 \%$ de confianza, las estimaciones puntuales son congruentes con los resultados del párrafo anterior: el PIB de México se expande después de un incremento en el PIB de Argentina, Brasil, Chile, Colombia y Venezuela. Por otra parte, en la segunda columna se presenta la respuesta del PIB de cada país después de un incremento en el PIB de México. ${ }^{31}$ Se observa que en el caso de Perú el PIB aumenta después del incremento en el producto mexicano.

\footnotetext{
${ }^{30}$ Para cada país se estimó un VAR de dos variables: el PIB del país en cuestión y el de México. De acuerdo con las propiedades de largo plazo de los datos, los VARs se estimaron en primeras diferencias y con 2 rezagos.

${ }^{31}$ En este caso cada VAR incluye primero el PIB de México y después el PIB del país en cuestión.
} 


\section{Gráfica 9}

\section{Respuesta Perturbaciones en el PIB de Países Lationamericanos}

Respuesta PIB México a PIB Argentina

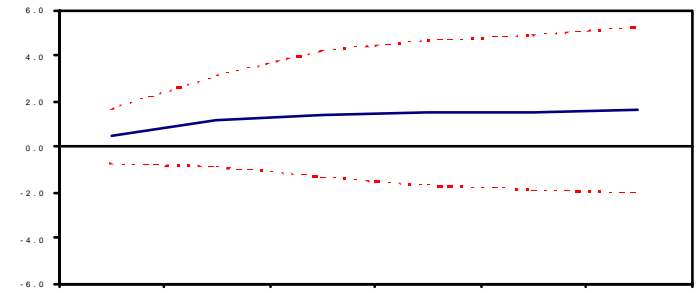

Respuesta PIB México a PIB Brasil

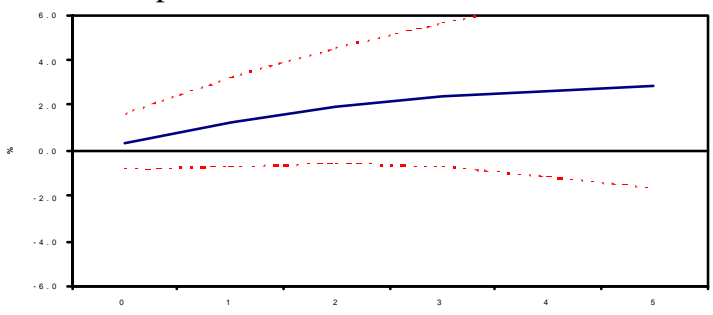

Respuesta PIB México a PIB Chile

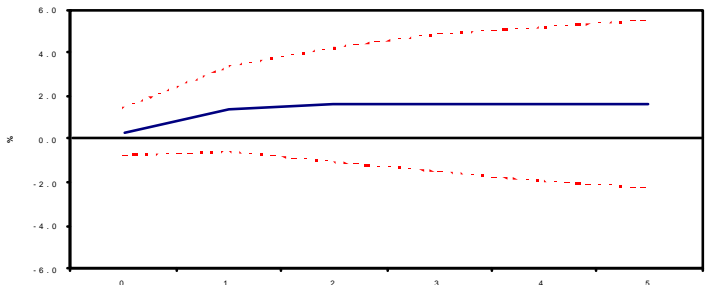

Respuesta PIB México a PIB Colombia

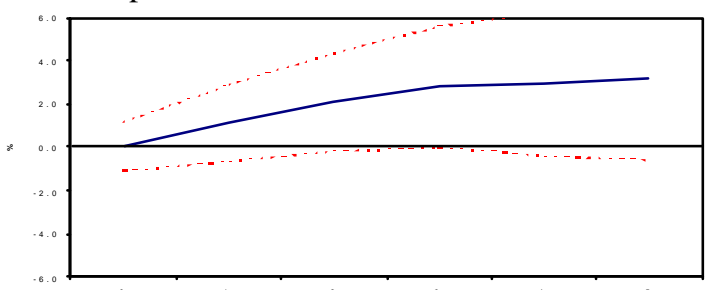

Respuesta PIB México a PIB Perú

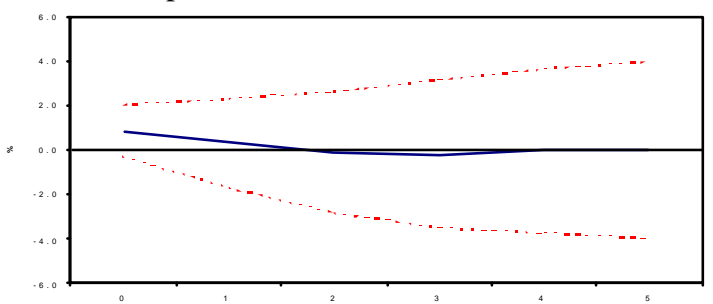

Respuesta PIB México a PIB Venezuela

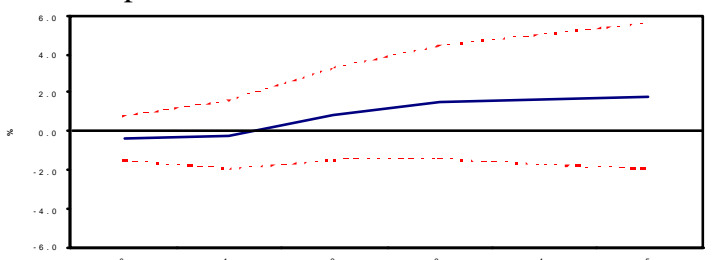

Respuesta PIB Argentina a PIB México

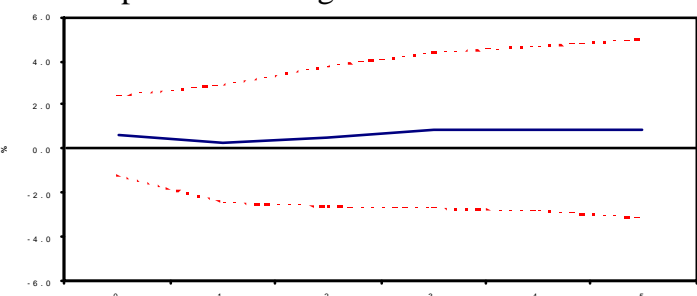

Respuesta PIB Brasil a PIB México

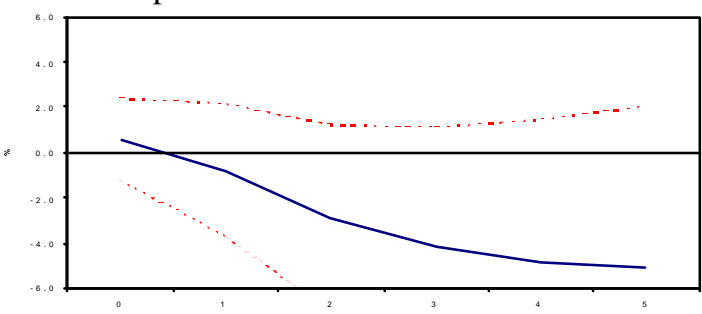

Respuesta PIB Chile a PIB México

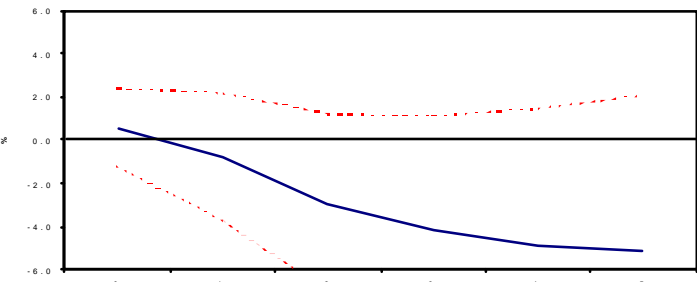

Respuesta PIB Colombia a PIB México

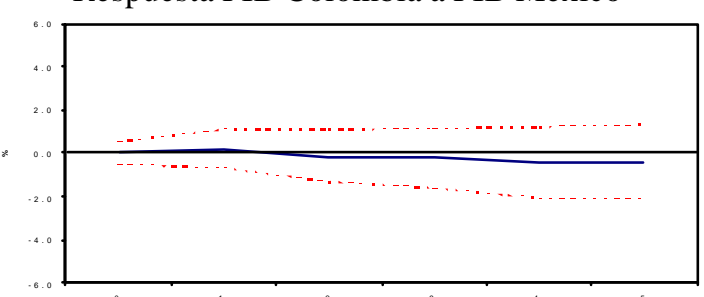

Respuesta PIB Perú a PIB México

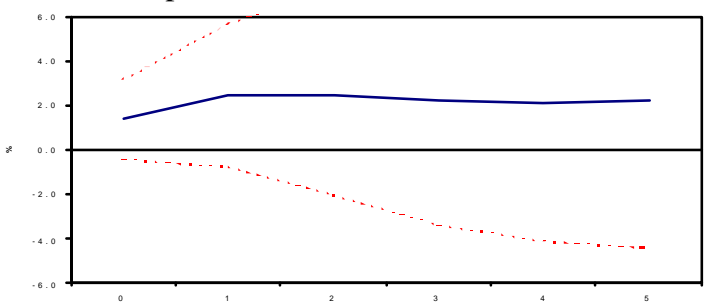

Respuesta PIB Venezuela a PIB México

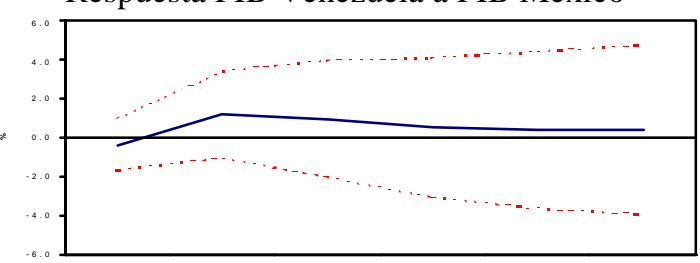


Es importante destacar que en la mayoría de los casos las funciones impulso respuesta no son significativamente diferentes de cero. Este resultado se puede deber a que durante las últimas tres décadas cada país ha experimentado diferentes etapas de desarrollo que no necesariamente han coincidido con las observadas en los otros países de la región y/o porque los problemas internos han dominado. Esto se puede apreciar en la Gráfica 10 donde se presenta el crecimiento del PIB y la inflación en cada uno de los países analizados a partir de 1970. En México se observa que durante la década de los años ochenta el crecimiento fue muy bajo y que la inflación mantuvo una tendencia creciente. En Argentina a partir de 1975 y hasta principios de los años noventa se observó alta volatilidad en el crecimiento y una tendencia creciente en la inflación. Por otra parte, en Brasil la disminución del crecimiento y la alta inflación parecen haber comenzado a principios de los años ochenta. Con respecto a Chile los resultados son diferentes puesto que el fuerte incremento en los precios y las recesiones se dieron durante la primera mitad de los años setenta, aunque nuevamente en 1982 hubo una fuerte contracción económica. Sin embargo, a partir de 1985 el caso de Colombia llama la atención porque a diferencia de los otros países, el crecimiento y la inflación han sido estables durante los últimos quince años. En Perú se observa una fuerte recesión a finales de los años ochenta que fue acompañada de un incremento sustancial en la tasa de inflación. Finalmente, en Venezuela a partir de los años ochenta se observó una tasa de inflación creciente y un comportamiento muy volátil del producto.

\section{Gráfica 10}

\section{Crecimiento e Inflación en América Latina}

Datos Anuales: 1971 - 1997

(15)




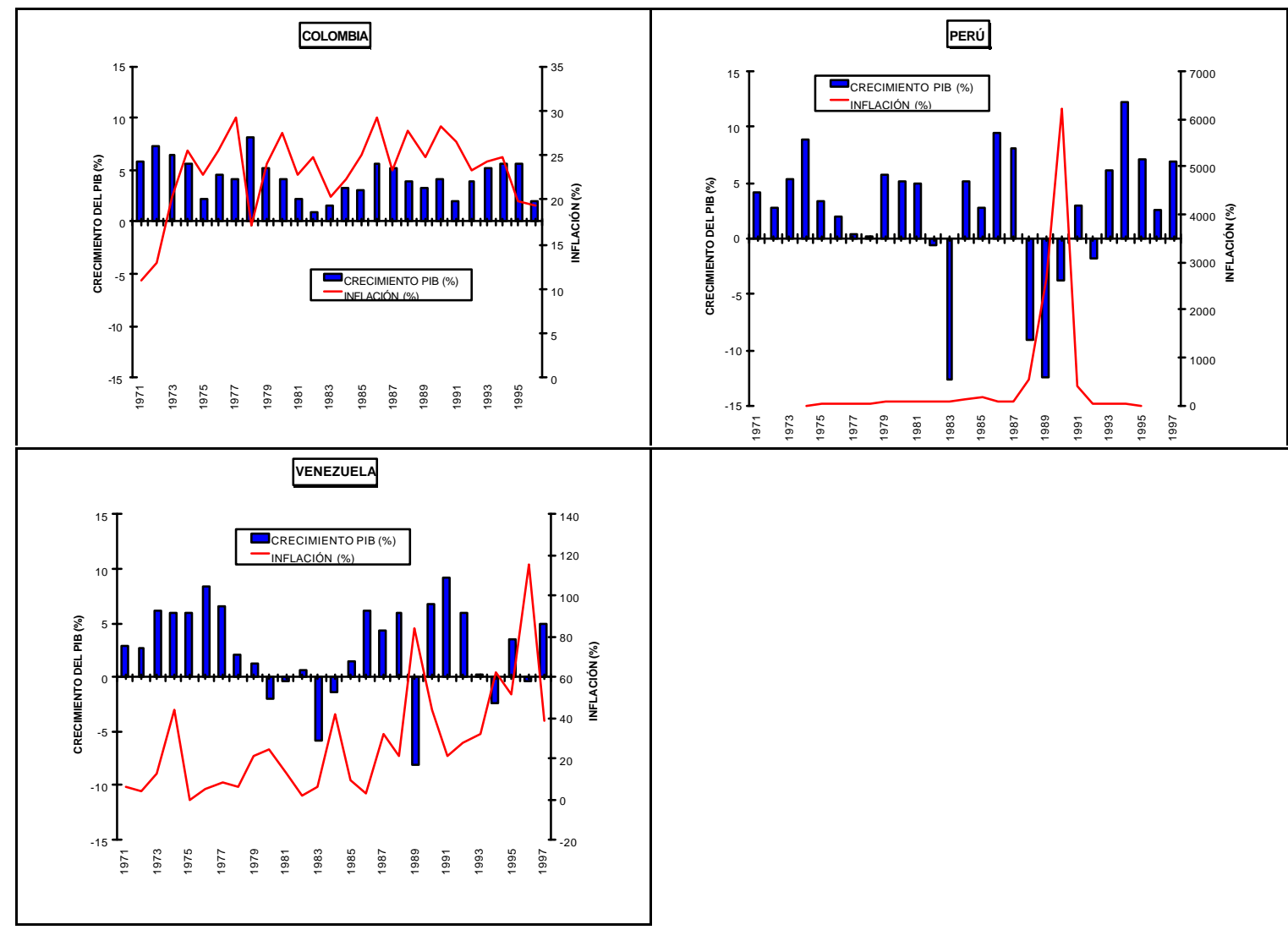

Una característica común de los países analizados es que en todos ellos (excepto Colombia) se han observado periodos de alta volatilidad tanto en variables nominales como en variables reales. Estos antecedentes pudieran propiciar que ante la falta de información, los problemas de un país sean interpretados por los inversionistas internacionales como problemas asociados a toda la región en general. En este caso la relación entre los ciclos económicos pudiera deberse a los mercados financieros, ya que un evento aislado en un país podría dar lugar a una salida de capitales generalizada en toda la región. Esto a su vez podría traducirse en un efecto similar, o al menos en el mismo sentido, en la actividad económica de cada país.

Aún cuando la falta de información financiera para los diferentes países latinoamericanos dificulta el análisis, a continuación se presentan algunos ejercicios que sugieren que la relación entre los ciclos económicos en América Latina se da a través de los mercados financieros.

Para validar la hipótesis anterior se utilizaron cuatro variables financieras. Los resultados se presentan en la Gráfica 11. En primer lugar, se analiza si las tasas de interés se mueven en la misma dirección en los diferentes países. Como se puede observar en la Gráfica 11 no existe una relación clara entre el componente cíclico de las tasas de interés de los diferentes países latinoamericanos. ${ }^{32}$ Este resultado sugiere que las tasas de interés en cada país posiblemente responden a las condiciones del mercado de dinero local y no a la

${ }^{32}$ El componente cíclico de la series se estimó utilizando el filtro HP con el parámetro $\lambda=1600$. 
percepción que los inversionistas puedan tener sobre la región en general. Por otra parte, al analizar el componente cíclico del tipo de cambio real también se observa que la relación no es clara. Sin embargo, al estudiar las fluctuaciones cíclicas de los índices de las bolsas de valores y el riesgo país (EMBI) se observa que la relación es muy estrecha. Estos resultados sugieren que la percepción de riesgo que los inversionistas tienen respecto a cada país obedece en gran parte a consideraciones relacionadas con toda la región y no a condiciones particulares del país en cuestión. Al parecer existe una relación positiva entre la economía mexicana y las demás economías latinoamericanas que se da a través de los mercados financieros. Sin embargo, dicha relación no parece ser lo suficientemente fuerte como para verse reflejada en las tasas de interés o en el tipo de cambio real. Por consiguiente, la relación entre los ciclos económicos no es muy estrecha.

\section{Gráfica 11 \\ Variables Financieras en América Latina Fluctuaciones Cíclicas \\ Datos Trimestrales: 1990:01 - 1999:03}

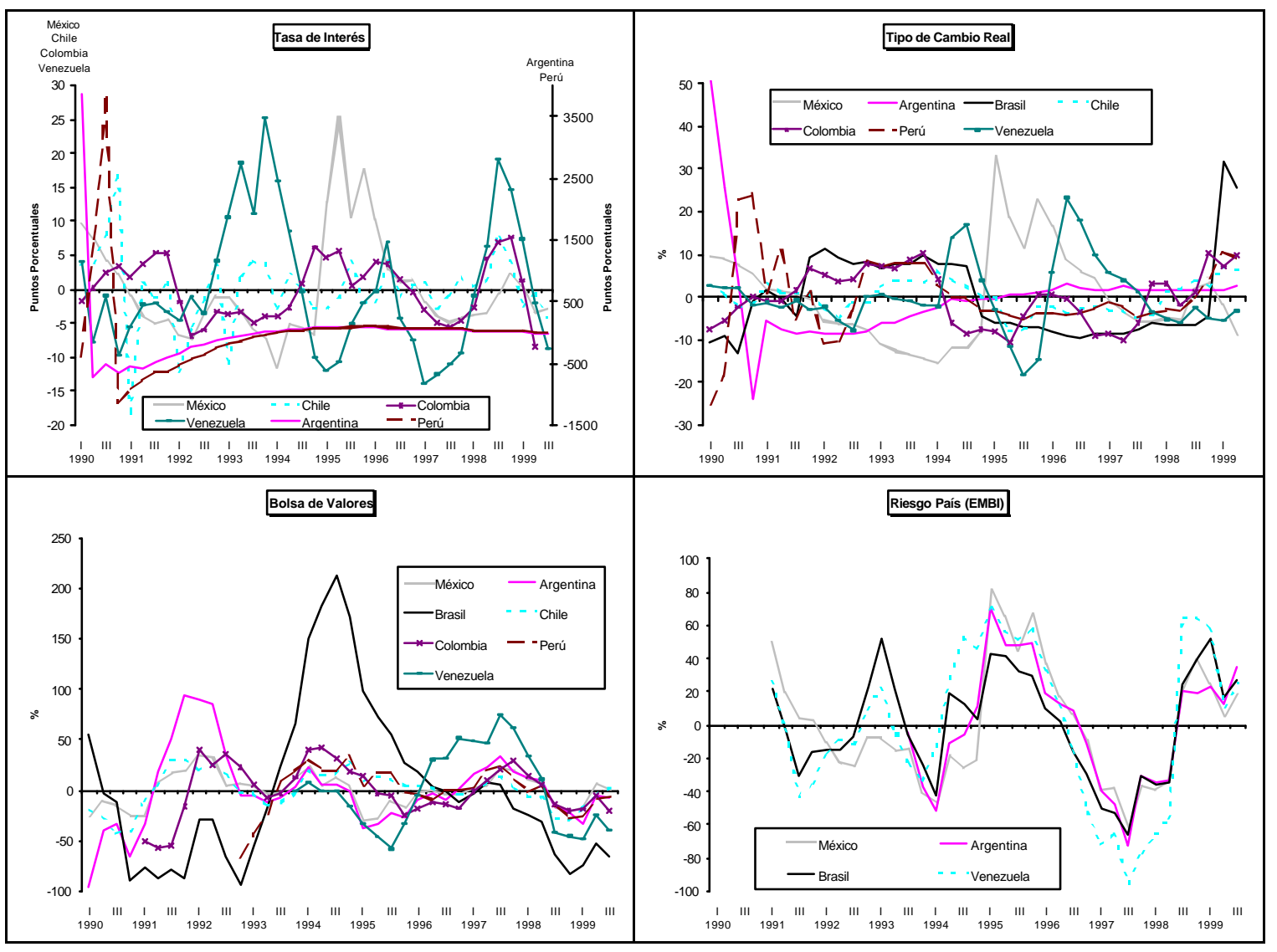

En términos generales se ha observado una correlación positiva entre los ciclos económicos de los siete países analizados. Sin embargo, debido a que en cada país se han experimentado periodos de inestabilidad que no necesariamente han coincidido con los de los otros países, es difícil identificar relaciones estrechas y precisas en lo referente al tiempo que tardan en transmitirse los eventos de un país hacia los demás. Los datos 
presentados sugieren que dicha relación pudiera explicarse a través de los mercados financieros. Sin embargo, para poder sostener esta afirmación con mayor seguridad sería necesario analizar con mayor detenimiento la evolución de las variables financieras en los diferentes países.

\subsection{Resumen de Resultados}

Al comparar las características del ciclo económico en México con el de otros países se encuentra que:

- La volatilidad relativa de las variables reales en México es un poco más alta que en los países industrializados.

- El consumo del gobierno en México y en otros países de Latinoamérica es procíclico mientras que en los países industrializados no está correlacionado con el PIB.

- Durante las últimas dos décadas las exportaciones en México han sido contracíclicas mientras que en los países industrializados son procíclicas.

- Al igual que en los países industrializados los precios en México y en otros países latinoamericanos son contracíclicos.

- La relación entre los ciclos económicos de México y los EUA es positiva y la transmisión de los EUA a México parece darse a través de vínculos comerciales y de los mercados financieros. Sin embargo, esta relación es menos clara a partir de 1987.

- La diferencia más importante entre los ciclos económicos de México y los de otros países latinoamericanos se observa en la relación entre el PIB y las exportaciones. En México, Argentina, Brasil, Chile y Colombia las exportaciones son contracíclicas. Por el contrario, en Perú y Venezuela éstas son procíclicas.

- En México, Argentina, Brasil, Chile y Colombia las exportaciones se mueven en dirección contraria a las importaciones. Este resultado sugiere que ambas responden en mayor medida al tipo de cambio y a algunas otras variables y no únicamente al nivel de actividad económica.

- El consumo del gobierno y el dinero en términos reales son procíclicos en casi todos los países latinoamericanos.

- Los precios en todos los países, excepto en Venezuela, son contracíclicos.

- La relación entre los ciclos económicos de los países latinoamericanos analizados es positiva y posiblemente dicha relación se de a través de los mercados financieros.

\section{Consideraciones finales}

En este artículo se documentaron algunas de las características del ciclo económico en México durante los últimos sesenta años y se compararon con la evidencia de otros países. El desempeño de la economía mexicana de 1940 a 1979 se caracteriza por crecimiento económico sostenido y estabilidad en las variables nominales. Sin embargo, un escenario muy diferente describe el desempeño de 1980 a 1997. La alta inflación y las devaluaciones recurrentes están asociadas con un bajo crecimiento económico y una mayor volatilidad durante este periodo. Al comparar las características del ciclo económico en México del primero al segundo periodo se identifican tres cambios importantes: i) las 
exportaciones son contracíclicas mientras que las importaciones siguen siendo procíclicas y ambas responden principalmente a fluctuaciones en el tipo de cambio y a otras variables y no únicamente al nivel de actividad económica como en el primer periodo; ii) la cantidad real de dinero sigue siendo procíclica pero en lugar de anteceder al ciclo es contemporánea; y iii) las depreciaciones del tipo de cambio son contracíclicas y anteceden al ciclo económico.

En este trabajo se muestra que la inestabilidad en variables nominales experimentada en México durante las últimas dos décadas no sólo está asociada con bajo crecimiento económico, sino que ésta se da a la vez que se observan cambios importantes en las características del ciclo económico. ¿Es posible afirmar que dichos cambios se deben a la inestabilidad en variables nominales? El análisis presentado en este artículo describe la evidencia. Sin embargo, no aborda el aspecto de la causalidad por lo que esta pregunta sigue abierta para futuras investigaciones.

Al comparar las características del ciclo económico en México con la evidencia de países industrializados se encuentra que durante el periodo 1948-1979, en el que México experimentó estabilidad en las variables nominales, las características son muy similares y la relación con el ciclo de los EUA es positiva. Sin embargo, durante el periodo 1980-1997, en el que se observó inestabilidad en las variables nominales, hay algunas diferencias en las características de los ciclos económicos y la relación con el ciclo de los EUA es más difícil de identificar. Sin embargo, en la medida en que se sigan intensificando los vínculos comerciales y continúa reduciéndose la vulnerabilidad financiera de la economía mexicana, como ha ocurrido de 1995 a la fecha, es de esperarse que la relación entre ambos ciclos económicos sea más estrecha y por consiguiente más fácil de identificar. El análisis de dicha relación será cada vez más importante para comprender el desempeño de la economía mexicana.

Por otra parte, al comparar la evidencia de México con la de algunos otros países latinoamericanos durante el periodo 1970-1997 se encuentra que las características de los ciclos económicos son similares. Al igual que en el caso de México, en la mayor parte de los países latinoamericanos analizados se experimentaron periodos de inestabilidad nominal durante el periodo de estudio. Sin embargo, la relación entre el ciclo económico mexicano y el del resto de los países latinoamericanos no es muy estrecha. Los vínculos comerciales entre México y el resto de la región no parecen ser significativos. No obstante, la evidencia sugiere que existe cierta relación a través de los mercados financieros. Al parecer, la percepción que los inversionistas internacionales tienen respecto a un país se ve afectada de manera importante por los acontecimientos que ocurren en cualquiera de los demás países de la región. El estudio de esta relación es otro de los temas que por su importancia y complejidad queda abierto para futuras investigaciones.

El análisis presentado en este trabajo es una primera aproximación al análisis de dos temas: la relación entre la estabilidad en variables nominales y el ciclo económico; y la relación entre el ciclo económico mexicano y el de otros países. Para futuras investigaciones sería interesante, en la medida en que los datos lo permitan, analizar con mayor detenimiento dichas relaciones y en especial durante los últimos diez años en los que 
tanto en México como en la mayor parte de las economías latinoamericanas la tasa de inflación ha disminuido considerablemente y se ha intensificado la apertura comercial. 


\section{Apéndice 1:}

\section{Fuentes de Datos}

\section{Para el análisis de México y los Estados Unidos (secciones 4 y 5.1)}

$\underline{\text { Datos Anuales }}$

- Variables Reales.

PIB real (1900-1997), expresado en millones de pesos de 1993. Fuente para 1900-1938: Sistema de Cuentas Nacionales (SCN) del Instituto Nacional de Estadística, Geografía e Informática (1995). Fuente para 1939-1997: SCN del Banco de México (1997).

PIB nominal (1939-1997), expresado en millones de pesos corrientes utilizando la estructura de 1993. Fuente: SCN del Banco de México (1997).

Consumo privado, consumo del gobierno, inversión, importaciones y exportaciones (1939-1997), expresados en millones de pesos de 1993. Fuente: SCN del Banco de México (1997).

- Agregados Monetarios

Billetes y Monedas, M1 y M3 (1933-1997), expresado en millones de pesos corrientes. Fuente: Banco de México (1997).

Los agregados monetarios reales fueron calculados deflactando cada variable con el índice de precios al consumidor.

La velocidad de los agregados monetarios fue calculada dividiendo el PIB nominal entre el agregado monetario correspondiente.

- Tipos de cambio

Tipo de cambio nominal (1900-1997), expresado en pesos por dólar. Fuente: Banco de México (1997).

Tipo de cambio real (1946-1997), índice base 1994=100. Calculado al multiplicar el tipo de cambio nominal por el índice de precios al consumidor de EUA y dividiendo el producto entre el índice de precios al consumidor de México.

\section{- Precios}

Indice de precios al consumidor (1930-1997), índice base 1994=100. Fuente para 19301972: Índice de Precios al Mayoreo en la Ciudad de México del Banco de México (1997). Fuente para 1973-1997: Índice Nacional de Precios al Consumidor del Banco de México (1997). 
Deflactor del PIB (1939-1997), índice base 1993=100; Fuente: SCN del Banco de México (1997).

\section{- Variables Externas}

PIB real de EUA (1900-1997), expresado en millones de dólares de 1990. Fuente para 1900-1994: Maddison (1995); fuente para 1995-1997: Federal Reserve Bank of St. Louis (1998).

Tasa de interés de EUA (1934-1997), promedio mensual de los Bonos del Tesoro a tres meses tomados del mercado secundario. Fuente: Federal Reserve Bank of St. Louis (1998).

Indice de precios al consumidor de EUA (1946-1997), base 1994=100. Fuente: Federal Reserve Bank of St. Louis (1998).

\section{$\underline{\text { Datos Trimestrales }}$}

- Variables Reales.

PIB real, consumo privado, consumo del gobierno, inversión, importaciones y exportaciones (1980:01-1997:04), expresado en millones de pesos de 1993. Fuente: SCN del Banco de México, "Indicadores Económicos", varias ediciones.

PIB nominal (1980:01-1997:04), expresado en millones de pesos corrientes utilizando la estructura de 1993. Fuente: SCN del Banco de México, "Indicadores Económicos", varias ediciones.

\section{- Agregados Monetarios}

Billetes y Monedas, M1 y M3 (1980:01-1997:04), expresado en millones de pesos corrientes. Fuente: Banco de México, "Indicadores Económicos”, varias ediciones.

Los agregados monetarios reales fueron calculados deflactando cada variable con el índice de precios al consumidor.

La velocidad de los agregados monetarios fue calculada dividiendo el PIB nominal entre el agregado monetario correspondiente.

- Tipos de cambio

Tipo de cambio nominal (1980:01-1997:04), expresado en pesos por dólar. Fuente: Banco de México, “Indicadores Económicos”, varias ediciones. 
Tipo de cambio real (1980:01-1997:04), índice base 1994=100. Calculado al multiplicar el tipo de cambio nominal por el índice de precios al consumidor de EUA y dividiendo el producto entre el índice de precios al consumidor de México.

- Tasas de Interés

Tasa de interés nominal (1980:01-1997:04), promedio mensual de los bonos del tesoro a tres meses de México (CETES) tomados de las subastas primarias. Fuente: Banco de México, "Indicadores Económicos", varias ediciones.

Tasa de interés real (1980:01-1997:04). Calculada como la tasa de interés nominal menos la tasa de inflación de un período adelantado.

- Precios y Salarios

Índice de Precios del Consumidor (1980:01-1997:04), índice base 1994=100. Fuente: Índice Nacional de Precios al Consumidor del Banco de México, "Indicadores Económicos", varias ediciones.

Deflactor del PIB (1980:01-1997:04), índice base 1993=100. Fuente: SCN del Banco de México, "Indicadores Económicos", varias ediciones.

Salario nominal (1980:01-1997:04), índice base 1994=100. Fuente: Índice de Salario Mínimo del Banco de México, "Indicadores Económicos", varias ediciones

Salario real (1980:01-1997:04), índice base 1994=100. Calculado al dividir el índice del salario nominal entre el índice de precios al consumidor.

- Variables Externas

PIB real de EUA (1980:01-1997:04), expresado en millones de dólares de 1990. Fuente: Federal Reserve Bank of St. Louis (1998).

Tasa de interés de EUA (1980:01-1997:04), promedio mensual de los Bonos del Tesoro a tres meses tomados del mercado secundario. Fuente: Federal Reserve Bank of St. Louis (1998).

Indice de precios al consumidor de EUA (1980:01-1997:04), base 1994=100. Fuente: Federal Reserve Bank of St. Louis (1998).

\section{Para el estudio de América Latina (Sección 5.2)}

\section{$\underline{\text { Datos Anuales }}$}

- Variables Reales. 
Para cada país, el PIB real (1970-1997) es expresado en millones de moneda nacional de 1990. Fuente: Estadísticas Financieras Internacionales, (Anuario 1990 y 1998).

Para cada país, el consumo privado, consumo del gobierno, inversión, importaciones y exportaciones (1970-1997) son expresados en millones de moneda nacional de 1990. Fuente: Estadísticas Financieras Internacionales, (Anuario 1990 y 1998).

- Agregados Monetarios

Para cada país, el dinero en términos nominales (1970-1997) es expresado en millones de moneda nacional. Fuente: Estadísticas Financieras Internacionales, (Anuario 1990 y 1998).

Para cada país, el dinero en términos reales se calculó deflactando cada serie con el deflactor implícito del PIB base 1990=100.

- Tipos de cambio

Para cada país, el tipo de cambio nominal promedio anual (1970-1997) es expresado en moneda nacional por dólar. Fuente: Estadísticas Financieras Internacionales, (Anuario 1990 y 1998).

Para cada país, el tipo de cambio real fue calculado al dividir el tipo de cambio nominal entre el deflactor del PIB de cada país base 1990=100.

- Precios

Para cada país, el deflactor del PIB (1970-1997) es un índice con base 1990=100. Fuente: Estadísticas Financieras Internacionales, (Anuario 1990 y 1998).

\section{$\underline{\text { Datos Trimestrales }}$}

\section{- Tasas de interés}

Para cada país, se utiliza la tasa de interés a un mes (1990-1999). Fuente: Estadísticas Financieras Internacionales (Anuario 1990 y 1998).

- Tipo de cambio real

Para cada país, se utiliza el promedio anual del tipo de cambio nominal y del índice de precios al consumidor (1990-1999). Fuente: Estadísticas Financieras Internacionales (Anuario 1990 y 1998).

- Indice de la Bolsa de Valores 
Para cada país, se utiliza el promedio trimestral del índice de la bolsa de valores (19901990). Fuente: Bloomberg.

- Riesgo País (EMBI)

Para cada país, se utiliza el "Emerging Markets Bond Index" (EMBI) calculado por JP Morgan. Fuente: Bloomberg. 


\section{Bibliografía}

[1] Agenor, P. Richard, C. John McDermott y Eswar Prasad, "Macroeconomic Fluctuations in Developing Countries. Some Stylized Facts", Working Papers, Economic Development Institute, The World Bank, 1998.

[2] Backus, David K y Patrick J. Kehoe, "International Evidence on the Historical Properties of Business Cycles”, American Economic Review 82, 4, 1992.

[3] Banco de México “Indicadores Económicos”, México D.F., varias ediciones.

[4] Banco de México “Indicadores Económicos Históricos”, México D.F., 1997.

[5] Belaisch, Agnes y Claudio Soto, 'Empirical Regularities of the Chilean Business Cycle", Working Paper, Central Bank of Chile, 1998.

[6] Federal Reserve Bank of St. Louis, "Federal Reserve Economic Data Base”, 1998.

[7] Fondo Monetario Internacional, "Estadísticas Financieras Internacionales", Anuario 1990 y 1998.

[8] Gujarati, Damodar, "Basic Econometrics", McGraw-Hill, $3^{\text {rd }}$ Edition, 1995.

[9] Instituto Nacional de Estadística, Geografía e Informática, "Sistema de Cuentas Nacionales”, México D.F., 1995.

[10]Hodrick, Robert J. y Edward C. Prescott, 'Postwar US Business Cycles: An Empirical Investigation”, Journal of Money, Credit and Banking, Vol. 29, No.1, 1997.

[11]Kydland, Finn E. y Edward C. Prescott, "Business Cycles: Real Facts and a Monetary Myth”, Quarterly Review, Federal Reserve Bank of Mineapolis Spring 1990.

[12]Kydland, Finn E. y Carlos Zarazaga, "Is the Business Cycles of Argentina "Different"?", Economic Review, Federal Reserve Bank of Dallas, 1994:4

[13]Lucas, Robert E., Jr, "Understanding Business Cycles", en Stabilization of the Domestic and International Economy, ed K Brunner and A. Meltzer, Carnegie Rochester Conference Series on Public Policy 5, 1977.

[14]Maddison, Angus, "Monitoring the World Economy 1820-1992”, OECD, 1995. 
[15]Restrepo Jorge E. y José Reyes "Los ciclos económicos en Colombia. Evidencia empírica 1977-1998”, Coyuntura Económica, Fedesarrollo, Vol. XXX No.1, 2000.

[16]Rogers, John H. y Ping Wang, 'Output, inflation, and stabilization in a small open economy: Evidence from Mexico", Journal of Development Economics, Vol. 46, 1995.

[17]Torres, Alberto, "Essays on Macroeconomics: Evidence from the Mexican Economy", Ph.D. Dissertation, New York University, 1999. 